\title{
THE JOURNEY TO WORK
}

\section{A SINGULAR BASIS FOR TRAVEL \\ PATTERN SURVEYS}

NOVEMBER 1967
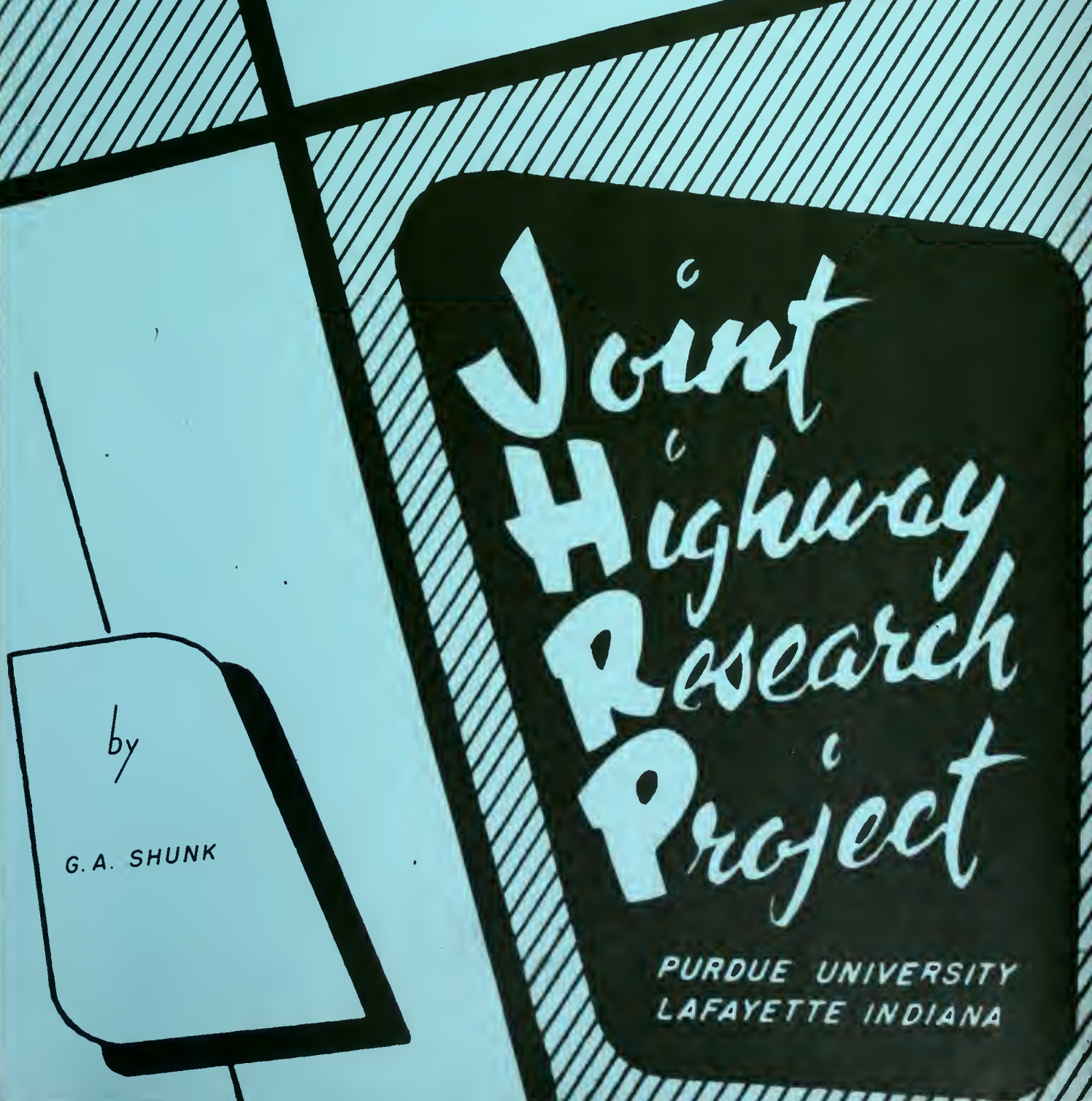

- ola

cahowe

esearch

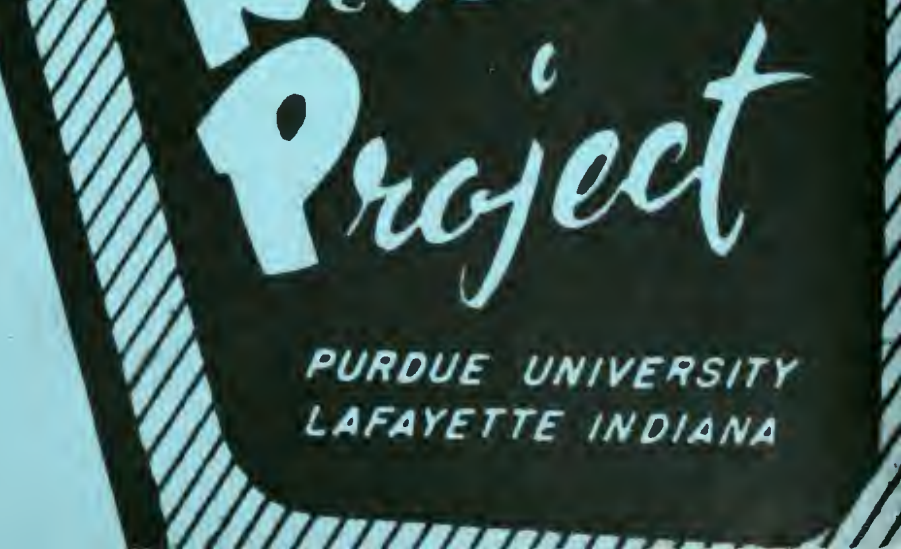



Progress Pagcou

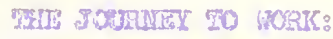

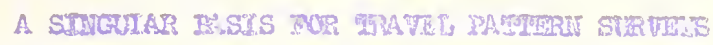

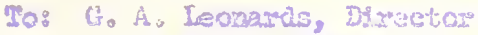

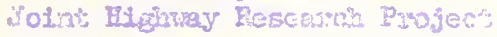

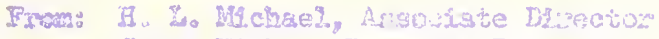

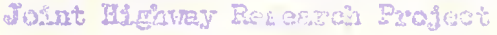

Hroverber $28,196 \%$

Fis.. 15: $30-7-2$

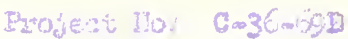

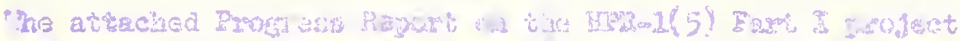

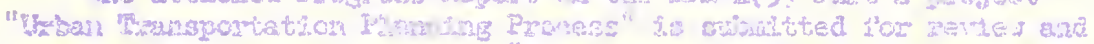

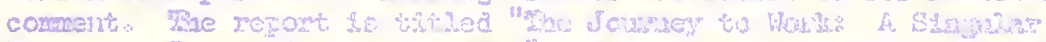

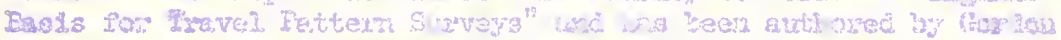

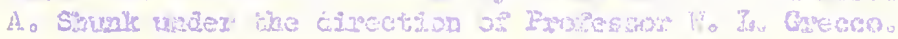

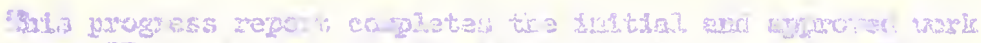

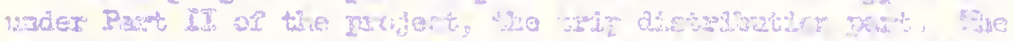

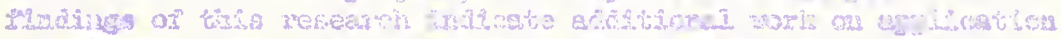

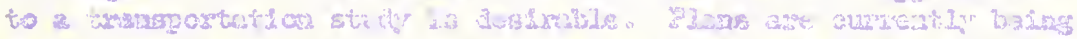

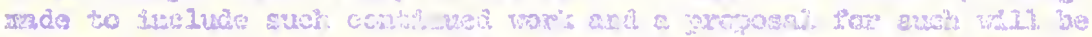

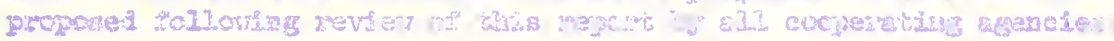

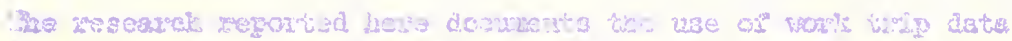

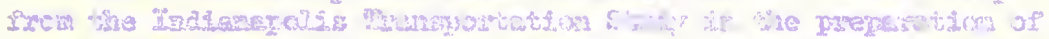

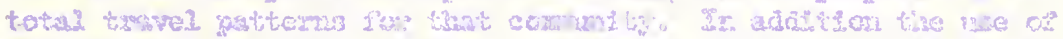

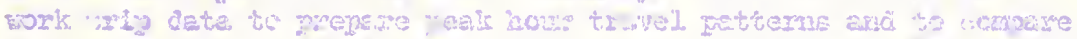

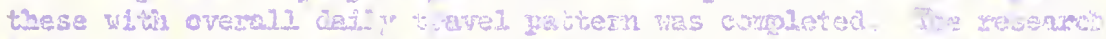

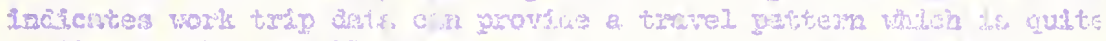

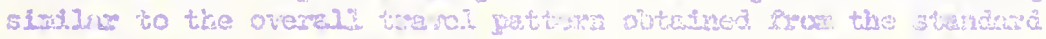

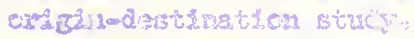

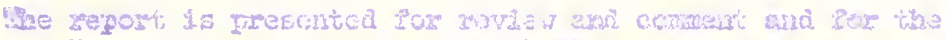

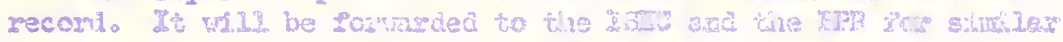
purgoseg 。

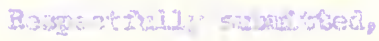

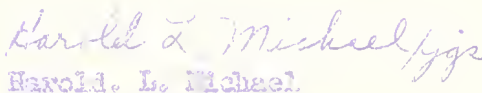

Asscedate Darestor

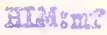

Atrecinus at

\begin{tabular}{|c|c|c|c|}
\hline Cory: & 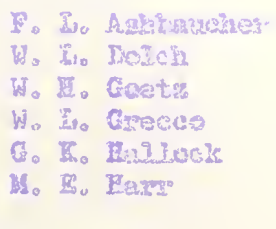 & 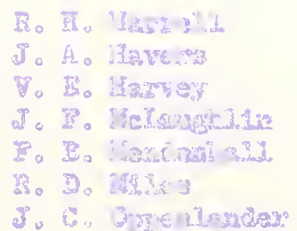 & 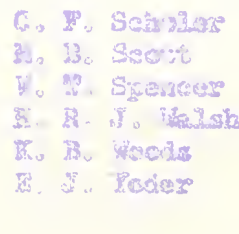 \\
\hline
\end{tabular}




\title{
Progrese Report
}

WHE JOURWEY 10 TORK:

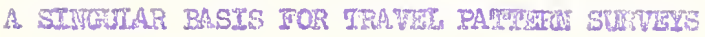

\author{
by \\ Gorgan A. Sarmak \\ Greduste Instractor in Pevared

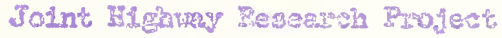 \\ Project Io. Co 36009

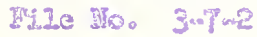

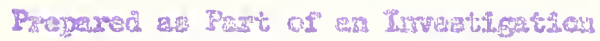 \\ Cocsacter iny

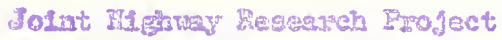

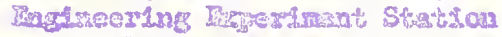

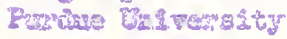

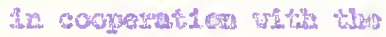

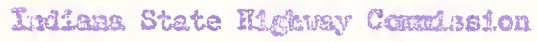 \\ axt the

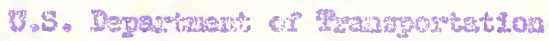

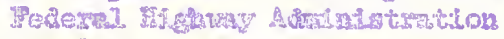

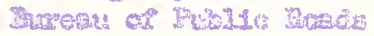

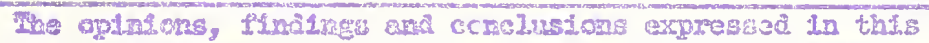

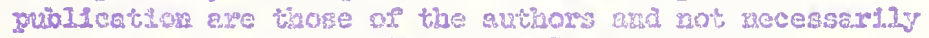
those of the Errreat of Fublic Roads.

\section{Not Relensed for Rublication}

Subject to Chang?

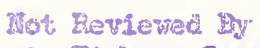

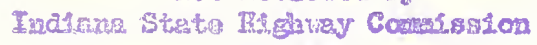

cre the

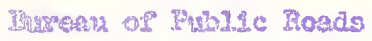

Puredus Fristusity

Latayette, Indituras

Toversar. 20, 1967 


\section{ACKNOWLEDGMENTS}

The author wishes to express his most sincere appreciation to Professor William L. Grecco for his encouragement and guidance in the conception and execution of this research. Professor Grecco's assistance in review of the manuscript was also most valuable.

The assistance of Professor Virgil L. Anderson in development of the statistical analysis and review of the manuscript was very much appreciated. Thanks is also due to Professor Harold I. Michael for the opportunity to undertake this work and for his review of the manuscript.

The author wishes to thank the Joint H1ghway Research Project of Purdue University and the Indiana State Highway Comission for the financial assistance which, together with the support of the Bureau of Public Roads of the U. S. Department of Transportation, made this research possible.

Thanks is also given to personnel of the Bureau of Public Roads, Barton-Aschmann and Associates, and Vogt-Ivers and Associates for their assistance in the preparation of data for analysis.

Greatest appreciation is extended to the author's wife for her patient encouragement and assistance, and to his son, Stephen, for his inspiration. 
Digitized by the Internet Archive in 2011 with funding from

LYRASIS members and Sloan Foundation; Indiana Department of Transportation 
TABLE OF CONTENTS

Page

LIST OF TABLES........................... iv

LIST OF EIGURES.......................... vii

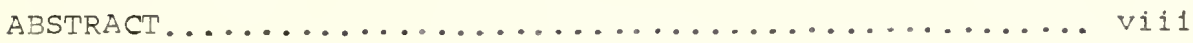

CHAPTER I. URBAN TRANSPORTATION PLANNING............ I

CHAPTER II. DEVELOPMENT OF THE THESIS............ 13

CHAPTER III. PROPOSAL OF THE HYPOTHESES............ 29

CHAPTER IV. DATA PREPARATION PROCEDURES........... 42

CHAPTER $V$. ANALYTICAL PROCEDURES................ 56

CHAPTER VI. ANALYTICAL RESULIS................ 7 I

CHAPTER VII. APPLICATION OF THE METHOD............ 90

CHAPTER VIII. CONCLUSIONS..................... 96

CHAPTER IX. RECOMMENDED EXIEISIONS AND RESEARCH....... 98

LIST OF REFERENCES....................... 100

APPENDIX A.....................................

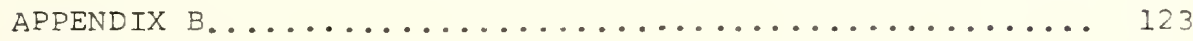

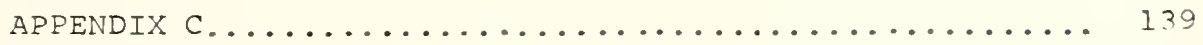

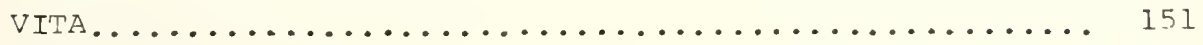


Table

1. Data from Home-Interview Trip Record (No. 2

Card) Used in Various Stages of the Analysis.....

2. Analysis of Variance for Freeway L.R.I..........

3. Analysis of Variance for Arterial L.R.I.........

4. Simple Regression Analysis...................

5. Parameters and Coefficients Multiple Linear

Regression Selected Predictors Normal Dependent

Conditions Entire Street System (FAC)............

6. Parameters and Coefficients Multiple Linear

Regression Selected Predictors Special

Dependent Conditions Entire Street System (FAC)...

7. Parameters and Coefficients Multiple Linear

Regression Selected Predictors Normal Predicted

Situations Freeway and Arterial Classes (EA).....

8. Parameters and Coefficients Multiple Linear Regression Selected Predictors Special Predicted Situations Freeway and Arterial Classes (FA).....

9. Relative Cost in Hours of Three Alternative

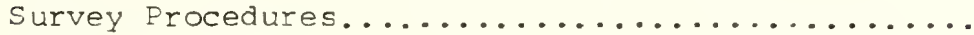

Appendix

Table

Al. Analysis of Variance for Travel Volume.......... 107

A2. Analysis of Variance for Average Trip Length..... 108

A3. Kolmogorov-Smirnov Test for Normality

Maximum Differences for MOD-2 L.R.I............. 109

A4. Bartlett's Test for Variance Homogeneity

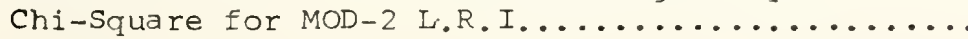




\section{LIST OF TABLES (continued)}

Appendix

Table

A5. Significance Order and Related Parameters Multiple Linear Regression Prediction of Total Day Vehicle Trips (DV) All Street Classes and

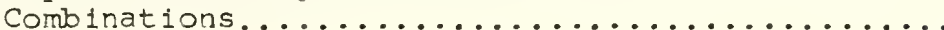

A6. Significance Order and Related Parameters Multiple Linear Regression Prediction of Total Day Person Trips (DP) All Street Classes

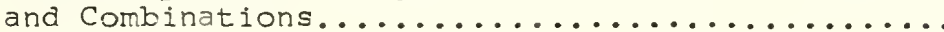

A7. Significance Order and Related Parameters Multiple Linear Regression Prediction of Peak Hour Vehicle Trips (HV) All Street Classes

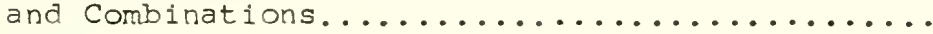

A9. Significance Order and Related Parameters Multiple Linear Regression Prediction of Peak Hour Person Trips (HP) All Street

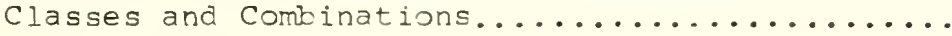

A9. Proportion of Explained Variation $\left(R^{2}\right)$ Multiple Linear Regression Selected Predictors Normal Prediction Situations All Street

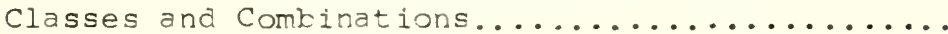

A10. Standard Error of Estimate (S.E.) Multiple Linear Regression Selected Predictors Normal Prediction Situations All Street Classes and

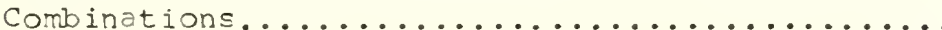

All. Coefficient of Variation (C.V.) Multiple Linear Regression Selected Predictors Normal Prediction Situations All Street Classes and

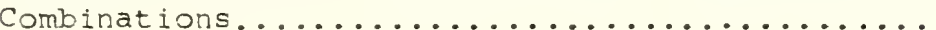

A12. Proportion of Variation Explained $\left(R^{2}\right)$ Multiple Linear Regression Prediction of Total Day Vehicle Trips (DV) Peak Hour Person Trips (HP) Based on Total Day Person Trips (DP) All Street Classes and Combinations...

A13. Standard Error of Estimate (S.E.) Multiple Linear Regression Prediction of Total Day Vehicle Trips (DV) Peak Hour Person Trips (HP) Based on Total Day Person Trips (DP) All Street Classes and Combinations............. 


\section{LIST OF TABLES (continued)}

Appendix

Table

A14. Coefficient of Variation (C.V.) Multiple

Linear Regression Prediction of Total

Day Vehicle Trips (DV) Peak Hour Person

Trips (HP) Based on Total Day Person

Trips (DP) All Street Classes and

Combinations..

A15. Proportion of Variation Explained $\left(R^{2}\right)$

Multiple Linear Regression Prediction of

Peak Hour Vehicle Trips (HV) Three Special

Prediction Situations AII Street Classes

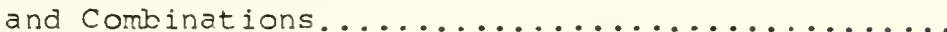

A16. Standard Error of Estimate (S.E.) Coefficient of Variation (C.V.) Multiple Linear Regression Prediction of Peak Hour Vehicle Trips (HV)

Three Special Prediction Situations AII Street

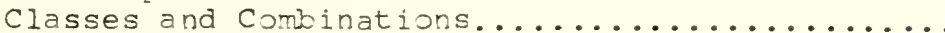




\section{LIST OF FIGURES}

Figure

Page

1. The Urban Transportation Planning Process........ 8

2. Developing the Street Network Data............ 49

3. Developing Travel Data..................... 5 I 


\section{ABSTRACT}

Shunk, Gordon Arthur. Ph.D., Purdue University, January 1968. THE JOURNEY TO WORK: A SINGULAR BASIS FOR TRAVEL PATTERN SURVEYS. Ma jor Professor: William I. Grecco.

This research involved a study of the feasibility of using the patterns of work trips alone to represent the patterns of travel for all purposes in an urban area. Further, the feasibility of using peak hour travel patterns to represent those of the entire day was investigated. The objective was to develop an approach to travel surveys which would satisfactorily reproduce the results of a conventional home interview survey.

Using data from a 1964 comprehensive transportation survey in Indianapolis, Indiana, an analysis of variance was run to determine the effect of the commonly defined factors, mode, purpose, and time, on trip volume and average trip length. Based on the extremely high significance of all main effects and interactions, a second variance analysis was run to determine the effect of more specific purpose, time, and mode factors on the traffic assigned to the freeway and arterlal links of the highway system. The significance of all main effects and a mode-purpose interaction was the basis for regression models accounting for mode, the peak hour, and the work purpose. A high degree of the variation in total 
trips on all major street system links was explained by multiple linear regression equations based on link volumes for the work purpose. Using the same regression approach, high degrees of explanation were achieved for total day, all purpose trips using all peak hour trips, and for all peak hour trips using total day work trips.

The results of this research recommend that travel patterns could be represented by surveys at the destination of trips. One of these would involve tabulation of the residence address from employer records. A second would obtain trip information by employee interviews. The third would, in addition, tabulate arrivals at major shopping areas. Decision on the form of the revised procedure would be on the basis of cost and feasibility. This research has provided for the study director alternate procedures for replacing the costly home-interview survey. 


\section{CHAPTER I. URBAN TRANSPORTATION PLANNING}

The current condition of intracity transportation systems poses one of the gravest problems faced by urban areas today. The very life of the city depends on the ease with which people and goods can move. The analogy to the human internal circulation system is quite valid. Urban transportation or circulation is highly complex in its own right. Eut considered in its proper perspective as an integral part of the total function of the urban body, the ramifications of intracity movement are nearly beyond conceivable complexity. Without effective means of moving the necessary nourishment between its organs, the urban complex will stagnate, wither or die. The solution of existing problems and prevention of their recurrence are the objectives of the activity known as urban transportation planning. Properly executed as a concordant phase of a comprehensive urban dev- . elopment program, the implementation of planned transportation improvements can be a major catalyst in the realization of broader social and economic objectives. In a time when the problems of urbanity are of such concern, the possibilities presented by transportation planning are of even more interest than usual (Turner, 1967).

In seeking a solution to any problem, it is well to reflect on just what led to development of the undesirable 
situation. The first half of the twentieth century saw marked advances in the technology of nearly every field of endeavor. The advent of improved products and procedures was multiplicative, yielding more than singular results in advancement of the economy. The effects of the advancing economy were passed on to consumers through higher wages and more purchasing power. One of the products of the improved technology was very attractive to the newly affluent. The automobile would permit one to expand his choice of environment by traveling from his place of residence with ease and at relatively low cost. The automobile became a symbol of the affluence of the new economy and the society it fostered. With higher productivity came more leisure time in which to enjoy the benefits of affluence. Time became a more significant factor in everyday life, and means of saving time were important. The automobile permitted one to come and go when he wished and to travel the routes he desired.

There was Iittle problem due to the automobile before World War II. As the economy and technology had advanced to where people could afford the large number of cars being produced, the depression retarded the trend in both phases. Automobile manufacturing during the war was curtailed because of the demand on resources for the defense effort. Following the war, the high level of the economy and increased production capacity combined to produce an explosion in auto sales. The romance with the automobile occurred so rapidly, in fact, that it would veritably defy prediction. The concomitant 
increase in traffic volume came much too fast for street improvements to keep pace. By its very nature government is slow to adjust to dynamic situations. But the magnitude of the postwar auto boom left war oriented administrations nearly helpless. The possible problem had been suggested prior to the war (U. S. Congress, 1939) and had even been accounted for In policy as early as 1944 (U. S. Congress, 1944). These documents were primarily concerned with intercity movement. These st11I reflected an unawareness of the magnitude of the intracity transportation problem. When the auto boom occurrea, there were not enough streets to handle the cars, and the traffic problem, as we know it today, had begun.

The traffic problem is not merely one of numbers. Considerably less trouble would occur if existing travel were spread uniformly over time. But the economies of scale that improved productivity also taught the logic of centralized activity which is feasible on a large scale only if adequate transportation is available. Centralized mass production requires simultaneous servicing, thereby demanding that all workers participate in their respective activities at the same time. This fosters the periodic high volumes of traffic which cause the greatest problems for transportation systems. The magnitude of traffic volumes required new street designs to handle them. The most obvious remedy was to provide additional traffic handing capacity. From this was born the multilane facility and eventually divided expressways. But it was even difficult to design adequate expressways, 
since the volume of traffic on them could not be predicted reliably. There were so many deficient streets and the deficiencies were so great that the normal lag time between design and construction increased. This effect was compounded by the greater than expected traffic increase over time. An additional factor causing trouble was the large volume of traffic using new facilities that had not traveled by car before, as well as that diverted from other facilities. All these situations contributed to the immediate overloading so often observed on new urban street facilities.

In 1952 congress launched the first overt attempt to accelerate construction of highways adequate to handle the huge traffic volumes (U. S. Congress, 1952). Following the Korean involvement, in 1956, Congress emphasized the importance of the Interstate system by increasing the rate of government participation in financing to 90 percent of the total cost (U. S. Congress, 1956). It had taken over ten years for Congress to gain sufficient realization of the gravity of the highway traffic problem to make a concerted effort toward its alleviation. The problems in this situation soon became apparent; perhaps it was the very magnitude of the Interstate program which brought out its shortcomings. The amount of money available for construction of the Interstate system permitted such programs as a 10 million dollar per mile freeway through the heart of an urban area. Situations such as this awoke the public to the magnitude of their monster. 
Although principally an intercity network, the Interstate system also contained substantial mileage within urban areas. These segments would be used extensively for intracity travel and would have to depend on urban traffic projections for design volume estimates. High quality facilities require much space and would displace considerable amounts of urban activity at commensurately high costs. It was an economic necessity to base design on future traffic volumes considerably more reliable than had previously been available.

Work had begun in the late 1940's to develop a more valid basis for highway design than mere factoring of existing traffic volumes. This work recognized the already apparent inability of projections to cope with the problem of forecasting urban traffic volumes. The new approach considered travel rather than traffic. It looked at traffic volume as merely a minor part of a much more complex universe of entire trips between an origin and a destination for a specific purpose. Travel, it was theorized, could be much more reliably predicted for a future time than could traffic, because there was an inherent basis for growth projection. It was the development of this approach and the realization of the need to plan for highways as an integral part of the community that led to the Federal Aid Highway Act of 1962 (U. S. Congress, 1962). This legislation requires that all urban highways must be designed as part of a comprehensive planning program. Such a program must account for land using activity 
and its capability for generating trips. It must predict land use and thereby develop travel patterns for location of facilities and traffic volumes on which size is based. This new approach to traffic volume prediction is commonly termed Urban Transportation Planning (UTP).

The UTP approach to traffic volume prediction examines highways in their proper perspective as an integral part of urban activity. It provides not only volume or dimensional design data but locational information as well. It also considers non-highway modes of transport in order to attain balanced transportation systems. UTP provides more than a mere projection of current travel patterns; it permits modification of historic trends due to variations in development policies. The results of UTP are a much more valid and a firm basis for design of transportation facilities.

UTP is based on surveys of current and historic patterns of travel, development and the economy of the area. The elements of urban activity are isolated by thorough analysis of these survey data. The growth and development characteristics of those elements which influence travel are then established. The character of such elements is readily understood and predictable because of the traditional background of the elements as urban activity parameters. These elements then are projected or predicted to some future target date. Prediction here denotes variation from the results due to simple projection of trends. Based on the future levels of the chosen elements, future travel patterns 
are developed for use in design. This procedure takes advantage of the reliable prediction of basic elements for which the growth patterns are known and stable. The relation between these basic elements and travel patterns in the survey year is used, in perhaps a modified form, to determine travel patterns in the target year. The results are based on underlying causal factors and are assumed to be more valid than simple volume projection.

The execution of the UTP process is quite intricate. Figure I shows a general diagram of the UTP procedure. It requires detailed study of the urban area and careful design of the respective surveys to account for all important local conditions. The surveys conducted are of varying depth and character. The economic base study surveys the current and historic condition of the local economy, its elements and interactions, strength and potential. The land use survey examines the qualitative and quantitative aspects of activity on every parcel of land in the urban area. It also includes analysis of the reasons for observed development patterns. Population studies determine the several important compositions of the local community. Other surveys may be of interest depending on the tackground and conditions of the local area.

The most detailed surveys are concerned with travel and the transportation system. The transportation system is inventoried in depth to establish the characteristics of the network of each available mode. The network is defined by 


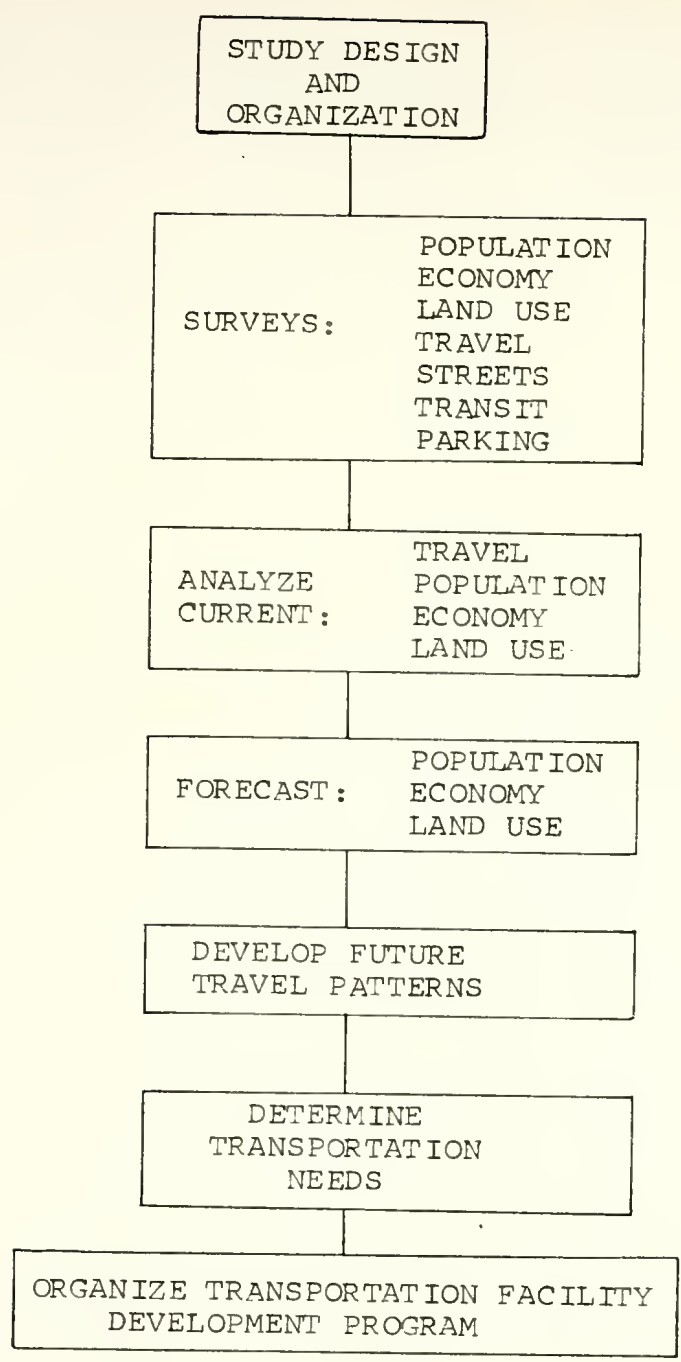

Figure 1. The Urban Transportation Planning Process. 
a series of links describing each constituent of the system. Links are paths connecting nodes or junction points of the network. By using a series of links and nodes, any given route, i.e., transit route or street, may be represented in numeric form suitable for analysis. The entire network, be it highway or transit, is a compendium of interlinking and overlapping routes. Access to the network is via centroids located at activity centers termed origins or destinations. The network inventory not only establishes a link and node configuration, it also places on each link (or node) certain restrictions which define the character of that segment of the system (e.g., travel time, fare, capacity). Also obtained are existing volumes on each network link. The result is a mathematical description of the various components of the transportation system suitable for further analytical examination.

The survey of travel patterns involves considerable effort. Travel is surveyed in three phases, each of which examines only a sample of the universe of trips it represents. The trips made by trucks and taxis during an entire day are surveyed by examining the drivers' delivery records at the places where the vehicles are garaged. Truck surveys may also determine the type of goods carried. Trips into and out of the study area are examined by a "cordon" interview technique. Drivers of vehicles entering or leaving the area are queried as they cross a boundary which circumscribes the study area. Each interview concerns only the immediate trip 
of the vehicle. The cordon survey is done in coordination with a volume counting program; expansion of the trip sample to total day travel is based on the volume count at the point of interview. The major phase of the travel pattern survey involves a personal interview at the dwelling unit to examine all trips made by all members of the respective household during an entire day. The home interview survey is probably the most expensive single activity in the entire UTP process. All travel pattern surveys obtain in some form information on the geographic origin and destination of trips and the purposes for which the trips were made.

The information obtained in the home-interview survey, and to a certain extent the other surveys, is organized by analysis zones. These zones are geographic entities developed in a manner to facilitate execution and expansion of the sample surveys. Trips are coded according to the zone numbers at their origins and destinations. Land use is grouped to indicate the activity in each zone; population studies are broken down to the zone level. It is the same zone that is represented by the centroid in the link-node description of the transportation system.

The data obtained from the several surveys are summarized for each of the analysis zones. The networks are processed to obtain the effective separation (time or distance) between all zone pairs. These data are used to calibrate a mathematical representation or model describing propensity to travel between zones for various trip purposes. Such a model 
may take any of several forms and relates the reluctance to travel to the separation between the zones. The model is termed a distribution model for it describes the manner in which trips are arrayed over the area according to the attractions observed in various zones. Calibration of a distribution model involves defining the function of certain parameters in the equation for the current pattern of travel. These parameters describe the manner in which zonal separation affects the propensity to travel in the given urban area at the current time. Other parameters may also be evaluated. It is assumed that the observed relation will continue to exist or will change in a predictable manner to the target year. Thus the observed (or modified) parameters are used with predicted attraction values to determine travel patterns in the target year.

The elements affecting travel are then predicted for the target year. Population is projected in the standard manner; the activity of the local economy is projected in a manner which accounts for stimulative or restraining factors which are expected to occur. The population and economic activity increases are then allocated to available land in such a manner as to account for the land development policies in existence or desired. Based on the density and location of the various urban activities, zonal aggregate trip origins and destinations are developed. The origins are distributed among the predicted destinations by use of the previously calibrated travel distribution model. The distributed trips 
are then assigned to the respective transportation networks. This process places trips between zones on links of the route connecting the zones, thereby yielding traffic volumes. Where the currently available facilities are inadequate to handle the future volumes, new design must be undertaken to accormodate the target year traffic. A program is then developed to facilitate implementation of necessary improvements according to deficiency, continuity and developmental considerations. 
CHAPTER II. DEVELOPMENT OF THE THES IS

In examining urban travel, it is appropriate to analyze the individual trips which make up the overall travel patterns. Several dimensional parameters of each trip, alone or in combination, describe the overall effect or importance of the trip to the transportation system. Consideration of importance requires definition of those factors which best represent demand on the system. Since the function of the transportation system is to move travelers (and goods), it follows that any trip that is in the system represents a demand. It further follows that the greater demands are due to movements that are in the system longer. The immediate deduction is that those trips which go the farthest distance in the system are the most important. This may seem to contradict notions of the importance of travel time; but importance to the system is the object of the current examination. Since the transportation system is basically a spatial rather than a temporal entity, length is a better demand indicator than time. Trip length alone may not be a sufficient indication of importance. A few long trips would constitute fewer tripmiles than a large number of shorter trips. Since importance implies utilization, it is necessary to consider the number of trip occurrences as well as trip length. The most important components of travel to the transportation system are 
those with the greatest lengths and occurring most often, for they provide the greatest trip-mile utilization.

The third dimension in travel patterns is concerned with time of occurrence. The time when a trip is undertaken, relative to the timing of other demands on the system, is a significant factor in trip importance. Since the system is dynamically loaded, i.e., trips continually move, stress occurs when the arrival rate on a system component exceeds the ability of that segment to adequately process the trips. The time rate of occurrence, or volume, relative to the processing capability, or capacity, indicates the importance that travel of a specific class assumes in patterns of travel on a transportation system. If the occurrence rates vary significantly throughout the day, the system will be less than ideally efficient, unless the distributions are complementary rather than cumulative.

A fourth dimension of travel is utilization of facilities. The importance of a particular trip is a function of which portion of the total system it uses. Trips made on system segments commonly traveled by many other trips contribute to high stress loadings. The same trip, made on less heavily traveled facilities, would contribute less to system stress and to more efficient system use. Whether or not a trip occurs on the major street system contributes to the importance it assumes in regard to the entire transportation system. 
The foregoing importance dimensions are descriptive parameters common to every trip. Their conditions determine the level of significance each particular trip assumes in total urban travel. Certain other descriptive factors are merely elements of trip character rather than importance. They are used as a means of classification to facilitate analytical examination. These factors have traditionally been treated as dimensions, despite their true character as descriptors. The principal descriptive factor is trip purpose, the reason travel is undertaken. Each of the many possible reasons for travel can usually be classified in one of five general groups:

1. Work

2. Shooping

3. School

4. Personal Business

5. Social-Recreational

Classification by purpose implies that a difference in the motivation of travel affects the character of trips that result. The importance parameters assume typical conditions for each of these purpose groups. The fact of this effect is apparent from examination of travel survey data in any urban area. For this reason, trip purpose is usually a means of stratifying trip groups in order to better examine, evaluate, and predict their parameters.

Mode or means of travel is also used for analytical classification. The most basic modal breakdown is between 
highway and transit; under each of these may be subgroups. Highway travel may be broken into truck, taxi, and automobile trips. The latter may be further split into driver and passenger groups. The breakdown of transit travel depends on the diversity of the transit system. The mode groups define different, and usually exclusive, parts of the entire transportation system. The mode chosen for study reflects the orientation of the particular transportation analysis undertaken.

In examining which components of total urban travel are most important to transportation, it is first necessary to define the system of interest. The present research is concerned with private vehicles and non-transit passengers on the highway system. The next step involves comparing the parameters which measure the effect that trip groups have on the transportation system. It is well known that in most urban areas the single most frequent trip is to the place of employment. The journey to work characteristically exhibits the greatest average trip length (Smith, 1961). Work trips also occur in a much more clustered manner than other travel. It follows that the single most important trip group for the highway-person transportation system is that concerned with the journey to work.

Examination of the total importance of transportation should give proper consideration to effects other than those on the transport system itself. Transportation has extensive ramifications for the larger aspect of community activity. 
The community as a social entity is totally dependent on economic activity for its existence. The factors most representative of economic activity are goods movements, communications, and person movements represented by the work trip. Except in a few very extraordinary cases, the number of persons engaged in productive or service activity at a given location presents an excellent demonstration of the level of economic involvement. Work travel then is important to the community as a whole because it represents the lifeblood circulation.

The journey to work is also important to the individual elements of urban existence: the individual persons and their households. It represents the means of livelihood of the household and takes precedence over other travel. The place of residence depends to a large extent on location of the work place. The work trip usually occurs at least twice daily, on weekdays, for each wage earner. At least one person in every household is engaged in some form of income producing activity. Work travel occurs at the same time every day. It usually uses the same routes since the travel orientation in most cases doe not vary. Work travel determines the need for purchase of an automobile. Trips other than work are fitted around the availability of the family car and the time of travel to and involvement in work.

The fourney to work is then as important to the individual and the community as to the transportation system. It is obvious that this important portion of the total travel 
pattern should be pre-eminent in the planning for total transportation. Because of the level of significance, it could even be rationalized that system planning should center on work travel, leaving complementary system usage to the travel which supplements personal and community activity.

The importance of the fourney to work had been recognized by many persons at least as early as the beginning of the current century. The concern first occurred in older, more established countries where development had reached such a density that travel problems were occurring. Several European countries and Japan examined work travel patterns, primarily in connection with census studies. Britain also realized the significance of work travel, as evidenced by a 1921 census study. When it came time to plan for rebuilding the destruction effected in World War II, several more British studies were undertaken. Parkes (1941) examined the location of homes and workplaces in relation to the journey to work as a part of postwar planning for Birmingham. Liepmann (1944) considered certain economic aspects of the work trip relative to the mobility of workers and their choice among alternate places of employment. Further work was done by the London Transit System (1949) and by Glass (1956) and Westergaard (1957).

The problems due to work travel in the United States were not severe enough to cause concern until World War II. The allocations implicit in rationing and the traffic volumes to defense plants motivated investigations of war worker 
travel. The problems due to prospertty following the war generated more interest in the patterns of work travel, but concern was not yet sufficient to motivate government action. Using information from traffic origin-destination (O-D) studies, several people began to examine the problem. Carroll (1950) suggested that "forces" tending to minimize the length of the journey to work have a concentrative effect on urban residential arrangement. Work by Adams and Mackesey (1955) and by Beyer (1951) considered the commutation to work in small urban and rural areas. The continuing prosperity and concomitant increase in travel motivated many studies of the patterns of all urban travel, each of which placed increasing emphasis on work travel. The obvious significance of work travel in the pattern of all travel was behind inclusion of questions regarding the journey to work in the 1960 census. Further concern is evinced by the consideration of amplifying the previous queries for use in the 1970 census (Bureau of Public Roads, 1966b).

Recent works by Loewenstein (1965) and Lapin (1964) have indicated further recognition of the important role of work in total urban travel. Loewenstein presents an analysis of locational aspects of urban residences and workplaces. His interest in location implies a recognition of the properties of the work trip. He implies that his concept of distribution may present a feasible approach for eliminating conventional travel survey procedures (Loewenstein, 1965). He has retained nearly the same concept of trip distribution accepted by 
transportation planners, but his ideas of the requirements and use of travel pattern information for expressway or transit planning appear quite deficient. This is emphasized by his allusion to "trip distribution" procedures when he actually discussed O-D studies. The approach he proposes would estimate the interzonal distribution of work trips as a percent of total trips originating in a zone, based on proportions derived from O-D data of several cities. The procedure would designate as few as five zones (or rings) in even large cities and utilize a single set of distribution factors for all cities. In comparison with patterns derived from an O-D study the approach badly overestimated intrazone trips in four of the five zones, and in only one case approached an acceptable tolerance in estimating total zonal destinations (Loewenstein, 1965). Loewenstein (1965) admits his procedure is crude and merely an attemot to develop a new approach to travel survey. As such, it is consistent with the philosophy of the study reported here.

Lapin's study emphasized the work journey itself, but included analysis of the place of work and residence. He investigated the relations between the several characteristics of work trips and their termini. He also defined the character of several parameters of work travel and related these to changes over time. His objective was apparently to increase the knowledge of this important fraction of total urban travel. Although no direct allusions were made, interpretation of his presentation in the context of the current 
research detected inferences that the journey to work might indeed present sufficient basis for total travel representation. Lapin's work had excellent basis and was very thorough. His implications regarding work trip character a nd prediction could well be the basis for application of the technique proposed in this report. He also suggested that the vast compilation of data on the work trip and all travel could well lead to future synthetic predictions.

The importance of the work component in the total daily pattern of urban travel has been recognized by many others. The Bureau of Public Roads underscored the place that the work trip holds in this respect. "Major emphasis should be placed on that segment of travel which has the most influence on the design of transport systems." The "work trip is the most ritualistic," the "most free from deviations," and "work trips logically end at jobsites" (Bureau of Public Roads, 1956a). Work travel is the most stakle component of a community's daily travel (Smith, 196I). The consistency in work travel character and patterns between cities as pointed out by Lapin has also keen emphasized by Voorhees (1958). It is this common knowledge which permits omission of countless articles which re-emphasize these facts. Bouchard and Pyers (1965) found less discrepancy in travel patterns for work than for any other purpose.

Lapin (1964) has suggested that the emphasis on travel analysis should be placed more on the destination terminus than has historically been the case. It is at that point 
where the most difficult traffic problems occur. Stewart (1948) has suggested the existence of a worker potential field about each workplace. This situation was corroborated by Lapin's destination analysis, and was therein likened to the assumed gravitation field about the residence (Lapin, 으. (cit.). The residential distribution of central business district ( $C B D$ ) workers about the CBD approgches the distribution of all residences about the CED. For non-central areas, however, worker residences are more clustered about the work place (Carrol1, 1952). This situation is attributed primarily to the better established transportation oriented to the CBD (Mitchel \& Rapkin, 1954). The newer peripheral centers do not have the historic transportation base, so workers must cluster nearer to them in order to realize the same level of accessiblity (Mitchel \& Rapkin, ibid.). The distributions of residences about workplaces are similar in most urion areas (Loewenstein, 1965). Eut account may have to be taken for variations within specific urban areas by stratifying accoraing to work type and social group (Loewenstein, ibid.: and Voorlees, 1955). The influence of the social class is seen in ethnic clusters in larger cities. Lapin discusses Osofsky's (1959) approach to a distribution function, and then proposes a similar solution based on a hyperbolic rather than a linear form (Lapin, 1964). This approach is apparently his recomended basis for prediction, although he occasionally alludes to the gravity relationship. 
The distributional patterns of work travel are dependent upon the income of the traveler, the mode of travel, the peaking of trips, and the distribution of employment opportunities about the work place (Voorhees, et al., 1966). Lapin (op. cit.) proposed that these characteristics are sufficiently consistent to be amenable to easy prediction. This is one of the most attractive aspects of a work trip oriented approach to travel analysis. Work travel is consistently proportional to total area population. The consistency of this relation between work travel and population is affected little by income or car ownership (smith, 1961). People must have a livelihood regardless of the rate of earnings or the means of getting there. The number of work trips increases slightly with decrease in occupation class (shuldiner \& Oi, 1962). This is due to "moonlighting" necessary to support a household on a low income skill. Work trips per household Increase with household size but at a slower rate than total trips (Shuldiner \& Oi, ibid.). The increase in travel potential with family size is realized primarily from the non-work trips.

The labor force constitutes around 40 percent of the population in most cities. In a study of 50 cities, work and business trips accounted for nearly 40 percent of the travel to and from the home (Curran \& Stegmaier, 1958). The average family makes seven trips daily, about one-third of which are for the work purpose (Voorhees, 1955). A study of day by day variations indicated that the number of internal person work 
trips per day varies least of all purposes, only \pm 4 percent from the mean (Sullivan, 1963). Contributing to the work trip problem is the low vehicle occupancy rate that occurs for work trips. It is about three-fourths of the average for all purposes and less than that for any other single purpose (Lapin, 1964).

The lengths of work trips in an urban area depend on the size and physical structure of the city, the character of the transportation network and the socio-economic situations that prevail (Voorhees, et al., 1966). In Toronto longer trips were made more often for work than for other purposes (Hill \& Dodd, 1966). The different distributions of worker residences about workplaces in the CBD and the peripheral areas lead to variations in work trip lengths (Lapin, 1964). Hoover and Vernon (1962), however, claim that family amenities are rated more important than work access when choosing a residence. The variation in work trip length has been shown to be related to the 0.6 power of the distribution of opportunities (Voorhees, et al., 1966). The value of the exponent or friction factor is significantly lower for work trips than for any other trip purpose (Whitmore, 1965). This is a further demonstration of workers' willingness to travel farther in order to obtain the right jobs, and yet maintain a desirable atmosphere for their families.

The importance of work travel is emphasized by its distribution over time. Perhaps distribution in the common sense is somewhat of a misnomer in this instance, for the work 
travel in urban areas is characterized by its clustered occurrence. These clusters of trips are commonly termed "rush" hours. In the terms of traffic engineering they are known as "peak" hours, for during these pertods the maximum consistent hourly volumes occur on the transportation system. It is peak hour volume or an approximation to it that is used to design transportation facilities. The peak hour on a given transportation segment may not always be due to work travel. But on an extremely large number of transportation segments within most urban areas, the peak hour volume is composed primarily of work trips (Spiegelman \& Duke, 1963). The U. S. Bureau of Public Roads (1966a) has stated that "work trips alone constitute the majority of trips" during the peak hours.

The peak demand periods occur generally between 7:009:00 in the morning and from 4:00-6:00 in the evening. They are composed principally of work trips, but shopping travel is also present in the afternoon. Auto driver trips are greater in number in the afternoon peak, but trips by all modes are greater in the morning peak (Wynn, 1959). This situation can be attributed to the high volume of school trips by bus included in the morning peak hour person travel. In Baltimore 60-70 percent of the p.m. peak travel was for work, while 20 percent was for shopping (Knox, 1962). During these four hours of heavlest trave 1,39 percent of al1 auto trips and 49 percent of all transit trips occurred (Wynn, 1959). School trips account for 60 percent of the non-auto 
driver peak, 8:00-9:00 a.m. About 55 percent of all employed persons travel between 8:00-9:00 a.m., 80 percent travel between 7:00-10:00 a.m. (Williams \& Robertson, 1965). Variations in.the proportion that peak hour is of total daily travel can be attributed to land use at points of origin and destination (Voorhees, 1958). The morning peak volume is fairly consistent for all week days; the evening peak volume is slightly (10 percent) larger on Friday than during the rest of the week (N1xon, 1961). Varlations in the proportion that peak hour is of total daily travel were attributed to the effects of capacity and total day volume (Nixon, ibid.). The proportion that the peak is of the total day is affected by city size (Lapin, 1964).

A peaking tendency of the magnitude observed for work trips does not occur for other major purposes. One explanation may be complementary use of the system. Non-work trips (except school trips) have even been observed to be uniformly distributed throughout the day (Smith, 1961). In fact, travel purposes other than work and school only become significant after 9:00 a.m. (Williams \& Robertson, 1965). School trips, although significant in person trip considerations in the morning peak, are not really worthy of extensive concern. They were primarily short, local trips on other than major streets and do not contribute to ma for congestion of the system. The composition of the evening peak period has historically included substantial commercial or shopping travel (Wynn, 1959). Th1s has been primar1ly due to suburban 
area shopping that occurs during the fourney from work to home (Voorhees, 1958). Recent trends to evening shopping hours in large suburban centers have led a shift of the evening shopplng peak to 7:00-8:00 p.m. rather than 4:00-5:00 p.m. (Wynn, 1959). In Toronto this broadened the effect of the evening peak hour (Hill \& Dodd, 1966). The peak of travel to shopping in the $\mathrm{CBD}$ occurs at 10:00 a.m. leading to a maximum accumulation of persons in the CBD at between 12:00 noon to 2:00 p.m. (Voorhees, 1958; Lapin, 1964).

The peaking of work trips may require more than the current aggregative analysis. There appears to be sufficient variability in travel character between the several employment groups to warrant examining them separately. Lapin has given considerable time to this aspect of travel character (Lapin, oㅡ. (cit). The work travel of top soclal classes is more concentrated in the peak hour due to similarity in job hour and vehicle availability (Williams \& Robertson, 1965).

The characteristics emphasized in the preceding discussion are to be the subject of the research reported henceforth. It should be apparent that the importance, regularity and stablity of work and peak hour travel are such as to be amenable to their use as a means of prediction. These factors lend themselves well to forecasting. The importance of these elements (work and peak hour travel) are underscored by the extent to which they have been examined by others. But there is one thread missing. In spite of all these obvious advantages no emphasis has been placed on the singular 
use of work as a means of prediction of total urban travel. It is not the purpose of this study to imply that work patterns are identical to the patterns for all travel. It is merely proposed that work travel is so demanding of transportation that its satisfaction will define a system sufficient to serve other purposes or will adequately represent a system that does in fact serve all travel. Similarly, the use of the peak hour as a design standard has been relegated to obscurity for qualitative reasons. It is proposed that the work to follow will examine the feasibility of the approach to transportation planning based only on work and peak hour travel. 


\section{CHAPTER III. PROPOSAL OF THE HYPOTHESES}

It is important to discuss the concept of complementarity as applied here to urban area travel. Complementarity is based on the principle of impenetrability, which states that no two material objects can occupy the same place at the same time. It implies that, of two objects competing for positions, that which has the greater utility for the position will take priority in assignment of the location sought. Uliman (1956) originally proposed the concept in connection with activity occurrence. As applied to urban area travel, 1t implies that purposes which have rigid restrictions of some type (e.g., work) will take precedence over those with less demanding constraints (e.a., shop). Given a fixed transportation system of defined space capacity per unit time, trips with the most inelastic requirements will attain either total satisfaction of their demand or total usurpation of system capacity prior to relinquishing system usage to other trips.

The ramifications of complementarity may be observed in the purpose-time distribution of urban travel. Work trips occur during certain time periods because of the importance of having a job, the punctuality requirements of employers, and the various factors which promote common business hours. 
Work trips dominate these periods because of their large volume in relation to system capacity and the resulting reluctance of persons to travel for less necessary purposes during the same hours. Trips of non-work purposes occur during hours when they do not have to compete with work trips for the transportation system, since their timing is less critica 1.

Based on the complementarity between purposes over time, there is a concomitant relationship between purposes over space or street system capacity. Peak hour traffic, by definition, stresses the highway network more than traffic during any other hour in the day. The travel pattern during the peak hour may thus be assumed to provide the best definition of the highway system, since the maximum stress situation provides the optimal condition for defining any system. The principle of least resistance 1 mplies that total travel in other than the peak hour will use the same basic system, to the extent that origin and destination permit. It follows that since the work purpose dominates peak hour travel, it is responsible for defining the basic street system, the same system that is used by other purpose trips in other than the peak hour. This concept of the representative nature of work travel patterns is the basic thesis of the research reported here:

The existence of a single basic system is quite apparent upon examination of travel patterns in urban areas of most any 
size. Peak hour traffic jams occur on its constituents. Shopping centers develop along its margins. Industry insists on its close proximity for accessibility and advertising advantages. Hosts of commercial establishments develop along it. Residential areas, although not likely to locate on it, want the accessibility to other land uses that it provides. The fact that all traffic uses the one system is apparently due to the universal appeal of the system to every type of non-residential establishment.

The correspondence between the work trip system and the non-work trip system cannot be assumed perfect. The nonwork group contains more purposes and, therefore, has more possible destinations. Non-work trip length is also less, in general, than that for work. This implies relatively more use of perlpheral (local or collector) systems by nonwork trips than by work trips. Non-work trips, therefore, contribute a greater proportion of the volume on the peripheral system than do work trips. But these systems also contalu substantially more miles of street than the major street systems and their design is based on land access rather than traffic service. The resulting number of vehicle-miles of travel is extremely low, implying the relative unimportance of the peripheral systems.

The complementary use of a single basis street system by the several purpose groups implies a highly desirable degree of efficiency. Such efficiency is certainly not complete, nor is it conceivably a conscious objective of urban 
travelers. It is more probably correctly described as a "blind" optimization procedure by which trip makers unwittingly achieve a balance between their multiple resources of time, energy, comfort and convenience. The above emphasizes the importance of the major street system in the transportation planning process.

The representivity exhibited by the work trip in regard to urban travel patterns can be expected to increase as city size decreases. Such an effect would be attributable to the lower absolute volumes of non-work travel and to the less highly developed nature of the peripheral streets. The latter situation requires non-work trips to use the work or basic street system for a greater portion of their length, thereby increasing the amount of agreement observed in street importance. The purpose of trips on streets near a zone centrold is significantly influenced by the function of the zone.

Work travel is a very convenient variable for analysis. The work purpose trip is the most stable and ritualistic component of urban travel (Bureau of Public Roads, 1966a). It occurs between the two most readily predictable land uses. It serves only two activities, the residence and the workplace, and is less influenced by separation than most any other purpose (Bouchard and Pyers, 1965). Work trip generation rates are characteristicaliy stable and predictable. Work is the highest density activity in the urban area. In general, no other function concentrates more people per unit 
of area than the work process. Because of this property, there is a related concentration of traffic at the workplace. Traffic intensity on facllities serving centralized work places or very large single workplaces can extend for considerable distances.

The important role that work oriented travel assumes in the total picture of urban transportation should be apparent from the previous discussion. Travel in nearly every city is dominated by the fourney to work. Only in cities whose function is somehow extraordinary can instances be seen where work travel is of lesser importance. The characteristics of work travel as a sufficient representative of the total urban travel pattern are essential elements of predictability. Based on the attributes enumerated above, it is proposed that work travel would be a valid and sufficient means for prediction of total urban travel patterns. It is hypothesized that, for use in the urban transportation planning process, the pattern of travel developed using work oriented trips alone presents a sufficient representation of the mafor street system used by all urban travel. It is further proposed that this implication is nearly as valid for home-based work trips as for all work trips. These assumtions are to be tested by the several statistical procedures described hereinafter.

The feasibility of representing the distribution pattern of trips of all purposes by the distribution pattern of work purpose trips alone will be tested. These travel 
patterns will be examined over the entire system of major streets and highways. Zone-to-zone travel patterns cannot be used as the basis for testing, however, since they are strictly dominated by the functions of respective zones. Since the desired results of the prediction procedure concern the mafor street system, the links of the network representing this system will be used as the basis for comparison. Iravel of the respective purpose groups will be assigned to the network, and a test of the representivity will be made on a link-by-link basis. In this manner, the zone centroid influence is virtually eliminated in favor of testing the conditions on the major street network.

Throughout the previous discussion it has been implied that the peak hour is an important factor in urban transportation. Similarly, it was argued that work travel is a dominant aspect of the peak hour. It is then apparent that system desizn based on peak hour volumes may be feasible. The principal advantage of this approach is that the result is a functional basis for design. The methods by which average daily traffic ( $A D I$ ) volumes are obtained in current planning practice contain considerable inherent error. Further compounding this by introducing a factor to obtain a design hour volume seems unreasonable. By the time factoring has been accomplished, the care of a very expensive survey might well have been wasted.

The peak hour is the one most consistent and significant point of stress on the transportation system. It would 
seem only too obvious to deal directly with the maximum loading condition rather than to factor to it. The most significant argument raised against peak hour oriented design is that peaks occur at different times at different locations and for different purposes. Such a situation can only be examined empirically, but it seems that the theory of complementarity would be as applicable in this situation as previously. To follow this argument, assume a system based on a single peak hour, say for work. Beyond this system, heavy non-work volumes, whenever their peak, could be accounted for by specialized surveys or analyses. The residential end is served by the work oriented system. Regarding the time shifts of peak volumes, as long as the maximum volume has been defined relative to the system, the location of its occurrence is immaterial. The trips involved are still full trips, from origin to destination, and will sometime during the peak hour contribute to the volume. This situation, of course, is contingent upon a peaking definition such as used here, i.e., maximum trips on the entire system (see Chapter IV).

The hypothesis proposed for test in this second instance involves the representivity of the ADT loadings by peak hour loadings. Continuing then, the reproducibility of peak hour loadings using a survey of work trips alone might also be feasible.

The hypotheses proposed are directed at elimination of the home-interview survey technique and replacement thereof by a special survey of work purpose trips only. Such a survey 
could take any of several forms. One of these, useful principally for an updating function, involves the current proposal to obtain workplace information of employed persons as a portion of the decennial census (Bureau of Public Roads, 1966b). The single question currently proposed would ascertain the address of the location at which the interviewee was most often employed during the week preceding the interview. The possibilities of such an application may be further examined after evaluation of research such as that proposed here. Study of the feasibility of this situation has also been undertaken by the Bureaus of Public Roads and the Census.

One of the main reasons interviewing has traditionally been conducted at the dwelling unit is the requirement to obtain trips of all purposes by all members of the household. Quite naturally if the interest in trip making were confined to a single purpose of travel, the interview place should if possible be oriented to the destination of trips for that purpose. Thus evolves the concept of the destination place interview.

To temporarily diverge somewhat, the concept of a destination place interview can be seen on reflection to be of quite obvious utility. The destination place of any trip purpose group is in every case at least as densely attractive as the residential end of the trip. In most situations the very concept of activity or service provision on a production line basis requires high density trip confluence. The question 
immediately arises of why interview at the household? The ramifications are not immediately obvious although certainly valid. They involve such factors as trip generation potential of the household and its excellent predictability as regards future time travel estimation. Also to be considered is the opportunity to obtain information on travel by all persons in the household. The home is the terminus for 70 percent of trips in the urban area. This adds to the body of knowledge of urban area travel, but its true utility may be questioned in light of the theoretical implications of complementarity. Because of the high cost of home-interview surveys, only a small sample is generally taken. As a result the number of reported work trips, the most important purpose group, is small.

on the other hand, the implication of a concentrationor destination-place travel survey is only too apparent. What traveler has not at some time or another been caugint in a traffic jam in the central business area or near an industrial plant at shift change or near the site of a major recreation area? At all these locations a service or activity is offered which attracts persons from all residential areas to one relatively small location. Such activity can exist only if major interest can be focused upon it and transportation service provided for it. Very rarely, if ever, do traffic problems occur at the location of residence; probably the only case, concerns high density residential areas, which, of course, fall into a destination place type situation. The 
object of transportation planning should be provision of service at locations of maximum stress, i.e., the points of traffic concentration. But for the facets of predictability and multipurpose considerations, the household Interview approach is somewhat less attractive than the destination place survey. Destination place surveys could also, depending on the procedure, obtain measures of non-home trips. The problem reverts again to consideration of the theory of complementar1ty. If the basic system indicated by home-based trips is developed, it will function for non-home-based travel as well, providing the exceptions are taken into account.

The consideration of destination place interviews is not unique or novel. Cherniak (1960) proposed such an approach to travel surveys. He suggested that "for planning future urban expressways, sample trip and correlative data should be assembled, not in the homes but in areas where people are concentrated during the day." "Those are the areas on which traffic converges, where traffic is concentrated...and where...additional...vehicular capacities are... needed (Cherniak, ibid.)." Cherniak further impled that generation studies should be oriented to the concentration points rather than the residential destinations, and that all information from travel surveys should reflect the patterns of peak hour travel. In discussion of the proposals by Cherniak, two points of note were raised. Campbell (1960) suggested that destination point interviews 
would yield "no total frame of reference" as a guide or basis for transportation planning. The implication is that total trips or total vehicle miles of travel are not available when surveying only one facet of travel. No demonstration is given, however, of why total travel is so important to system analysis, especially if valid patterns and design hour volumes are available. Lynch (1960) smplied that a concentration place interview might involve a less "scientifically selected sample" than the home interview. It is not apparent why "scientific" selection of a sample could not as readily be applied to concentration place interviews as otherwise, as long as the nature of the population is considered. Lynch also decried the lack of a universe for expansion and questioned the ability to evaluate result accuracy. His experience with such work, however, may cause concern in regard to his implication that employer cooperation might be difficult to attain.

The applicability of the destination-place interview concept to work oriented travel points to surveys at the place of employment. Depending on whether or not non-home oriented trips are necessary, such a survey would take one of two forms. A survey of home-based travel would be confined to examination of employee records for coding the address of workers' residences. Such a procedure eliminates all response error due to interviewing. Survey costs are reduced to the cost of coding the information. Should it be desirable to obtain information on non-home trips, an alternate procedure 
would be to utilize either a questionnaire or an interview procedure. If vehicle trip information was desired, a means of eliminating non-drivers could easily be determined.

Certain advantages accrue from a survey of this type in comparison to the household interview. The interviewer is dealing with the traveler in an environment which implies good recall of the trip. The trip is very ritualistic and stable; most work travelers could define the exact routes they took to work and why these were chosen. Employer permitting, the interview or form completion should be done during working hours. The psychological implications of the company's interest being sufficient to dedicate "its" time and the unceniably desirable opportunity for the employee to stop work lend an atmospiere very conducive to tre ultimate in cooperation.

Needless to say such interview procenures require an excellent putic relations program directed to the employers in order to obtain the ultimate in their cooperation. Fulfillment of such ideals may be realizea in smaller cities more than in larger cities. The cooperation will probably be better from large than from small emoloyers.

The ritualism of the work trip will provide a reduction in the experimental error of the survey. Contact of a greater proportion of those involved in trips reduces sampling error. A one in twenty sample, such as was used in Indianapolis, yields five percent of the trips in the area. Interviewing at work and obtaining information on say 90 percent of total 
employees within an urban area yields data on ( 90 percent of trips that are 40 percent of the total) over 35 percent of the trips in the area! Reductions of the various error sources offset standard errors of the estimating procedure used. It is even conceivable that the employment place interview could obtain a good proportion of the information obtained in the home interview, particularly if good design of survey procedures was employed. Further advantages in speed of data collection and reduced travel costs for this procedure are apparent.

There will probably occur in any city studied certain specific situations which cannot be hanaled by the proposed prosedures alone. In such cases morifications or augmentation of the basic survey will probably be sufficient to yield valid results. Traffic studies of concentrated movements or travel pattern studies at major generators would projobly provide sufficient additional information to yield adequate system Jefinition. 
CHAPTER IV. DATA PREPARATION PROCEDURES

The data used in this study was obtained from the Indianapolis Regional Transportation and Development study (IRTADS) through one of its sponsors, the Indiana state Highway Comnission. The decision to use the IRTADS data was due to its convenience and availability. It was also current, being from surveys conducted in 1964 as part of a planning process aporoved by the Bureau of Public Roads (BPR). Such approval was important from the aspect that this research was aimed at recommending changes in BPR procedures. The result of the proposea revisions should necessarily reproduce results obtained by the procedures to be changed. Use of data from a study area the size of Indianapolis should imply the generality of any results to any city of simflar character. All surveys were complete and the entire data file used by IRTADS to develop transportation recommendations was available for use in this research.

The specific information selected from the IRTADS data file was the travel data from the home interview survey, as coded and punched on "number 2 " cards. Among other items, these cards included the information listed in Table 1 which was utilized at least in part in some phase of the present research. No use was made of either the truck-taxi or the 
Table 1. Data from Home-Interview Trip Record (No. 2 Card) Used in Various Stages of the Analysis.

1. $\quad$ Sample Number
2.
3. $\quad$ Trip Number
4. $\quad$ Residence Zone
5. $\quad$ Origin Zone
6. $\quad$ Destination Zone
7. $\quad$ From Purpose
3. $\quad$ To Purpose
9. $\quad$ Passenger Purpose
10. $\quad$ Start Time
11. $\quad$ Arrive Time
12. $\quad$ Mode


external survey data since the principal objective of this work was to attack the home interview survey. The inventory of the 1964 street network as punched in standard (BELMN) format was also obtained. Transit network information was not used because the proposed work was principally highway oriented. Transit trips were included in one phase of the analysis only because no network information was required. The complete file of home-interview travel data was pre-prosessed to put it in a suitable form for subsequent manipulation. Dwelling unit (No. 1) cards were not used at a11. All trips with an origin or destination outside the study area were eliminated because there was lack of information on the external terminus and the difference in motivation and character between those trips and the wholly internal trips. Without a home-interview survey, such trips could still be tabulated at external cordon interview stations. This deletion eliminated 2416 trips from the basic file. The remaining trip cards were grouped according to home orientation. Home-based trips, having at least one terminus at the residence of the trip maker, were placed in one file and sorted on zone of residence. Non-home based trips, having no terminus in the residence zone, were placed in a secona file and sorted on zone of origin. These files were the input for the travel data processing programs for the total day condition.

In order to select a representative peak period the combined home- and non-home-based files with externals deleted 
were processed by the program PEAKS (Appendix C). PEAKS scanned the standard trip survey cards for trip purpose, mode, and times of start and arrival. The times were recorded separately according to the mode and purpose of the trip. PEAKS then computed the number of trips entering and leaving the transportation system, by mode and purpose and in tenth of an hour increments throughout the day. PEAKS then aggregated the incremental periods into successive one hour blocks and produced the number of trips in progress, by mode and purpose, for contiguous one hour periods, successively by tenth of an hour increments through the day. The hours during which trips in progress by each mode and purpose reached their maximum were then available. PEAKS also aggregated mores and purposes 1 nto total tables. Optionally PEAKS will yield tenth of an hour accumulations only, in order to permit the user to aggregate peak periods other than a single hour. The output from PEAKS as applied to the IRTADS data is shown in Appendix B. Note that the values shown are card counts, not factored traffic volumes. The peak hour selected for use in the current analysis was that defined for all auto driver trips. This was the condition considered to place the most stress on the highway system. A single hour was selected because the objective in the peak hour phase of this study was to obtain a single hour volume on which to base design recommendations. The peak hour selected for subsequent study was from 16.4 to 17.4 hours ( $4: 24$ to $5: 24$ p.m.). 
Processing of the travel and network data involved extensive use and total reliance on the computer program package disseminated by the Bureau of Public Roads for use in operational transportation planning studies. Use of the system was decided upon because of its ready availability and comparatively error free function. It is designed for high speed, high volume processing of the type required by the subject research. The IRTADS data had been coded according to formats required by the system since IRTADS also used these programs. The package is known as BELMN, and is based on the Bell Telphone Laboratory monitor system for the IBM 7090 computer. BELMN consists of a set of programs that feed between one another in a sequential processing setup under user control with a minimum of external supervision (Bureau of Public Roads, 1964\& 1965). The system worked quite satisfactorily in most instances with the principal problems being due to inadequate documentation.

Several decisions regarding format of the final data to be analyzed had to be made prior to the initiation of bulk processing with the EELMN system. It was decided that trips of three specific purpose groups would be obtained in addition to the all-purpose group. The selected purposes were home-based work, home-based shop, and non-home-based work. The differentiation between home and non-home-based trips has previously been made. A home-based work or shop trip is one that has a purpose on the non-home end of work or shop respectively. Home-based trips must be either to or from the 
zone of residence; the home orientation at either end determines the classification. Non-home-based trips, however, could reasonably be classified by either the to or from purpose since neither is at the place of residence. For the current study a non-home-based work trip is one having a work purpose at either end of the trip.

The three specific purpose categories also included small groups of trips which were of similar respective character. These were serve-passenger trips with passenger purpose the same as the specific group in which it was included. This adition was due to the action by IRTADS interviewers of "Iinking" trips at the time of interview. Thus the normally defined serve passenger trips had been linked out of the IRTAds survey data (Bureau of Public Roads, I964, pp. IV-4). The nominal serve-passenger trips were "busing" trips and should be included in the respective categories. Servepassenger trips that were not of a busing nature retained sufficient influence from the passenger's purpose to permit assumption of the passenger's purpose at the serve-passenger eno. (Iinking is the term used to describe the process of removing from consideration an intermediate trip terminus, the purpose of which is subordinate to the final destination purpose.)

The mojes selected for analysis were auto driver and highway person, reflecting the decision to maintain a highway orientation. The former represented vahicle trips and could be indicative of traffic volume. Highway person trips 
included auto driver trips as well as passengers in automobiles, trucks, and taxis. Use of a person trip orientation in revised survey procedures would, of course, permit development of modal split relations. No transit or school bus trips were included because of the lack of knowledge of a network for either group. Two periods, total day and the single afternoon peak hour, defined the time conditions to be considered.

Further processing of the basic data in preparation for the analysis used the BELMN program package. Program numbers are those of the standard writeups. The shorter of two phases using BELMN involved processing of the street network. The 1964 street inventory had been coded and punched on cards by IRTADS. These cards were then processed according to the diagram in Figure 2. Program PR-6 processed the cards containing among other information the length of, speed on, and node number at the terminals of every Iink in the street system. The description of the network prepared was stored in binary format preparatory to further processing. Program PR-I scanned the network description for link direction and travel time and the terminal node numbers. It then proseeded to build "trees" from each zone to all other zones in the study area. These trees are the link-by-link description of the path taken in moving from one zone to another. Since there could be a very large number of such paths if there were no restrictions on the1r selection, the path which exhibits a selected type of optimality is defined. For the 


\section{STREET FACILITIES \\ INVENTORY}

CODE STREET NETWORK

BUILD NETWORK DESCR IPTION $(P R-6)$

BUILD ZONE-TO-ZONE TREES (PR-I)

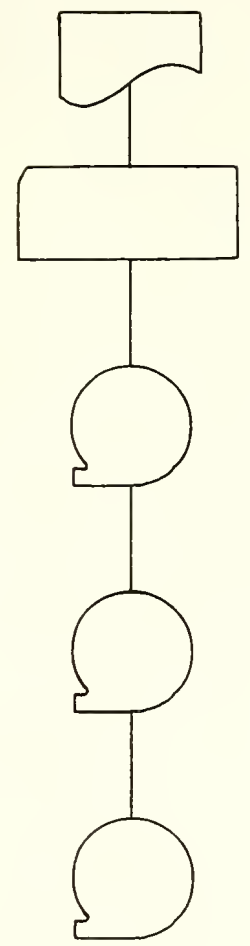

SKIM ZONE-TO-ZONE TREES

$(P R-130)$

Figure 2. Developing the Street Network Data. 
current study, the minimum travel-time path was chosen. Travel-time includes terminal time at both ends of the trip. The procedure for selection of this optimum path is based on an algorithm developed by Moore (1957). PR-1 prepared a binary tape describing the minimun time path trees, Iink-bylink, for all zones in the study area. Program PR-130 further processed the binary tree information by summing the time to traverse the links in each tree, producing the accumulated time to move between each zone pair on the minimum time path. This zone-to-zone cumulative time is known as a "skimmed tree." The skimmed tree data were usea as described in Chapter $V$. The network description and zone-to-zone tree data were used as described below.

The major utilization of the BELMN programs was concerned with processing the travel data. Figure 3 shows the procedure employed and described below. The necessary preprocessing of the trip cards was described previously. Input to program PR-133 was in two phases, home-based and non-homebased trip cards. This separation was necessary because of the requirements of $P R-133$. The procedures were, however, essentially identical, and the results were combined at a later stage. PR-133 accumulated the trips from each origin to each destination zone according to groups based on the trip purpose and travel mode specified previously. Output from PR-133 were "trip tables," cumulative zone-to-zone movements by purpose and mode. The normal PR-133 expansion of the trip data was not used in order to retain exactly the 
TRAVEL SURVEY
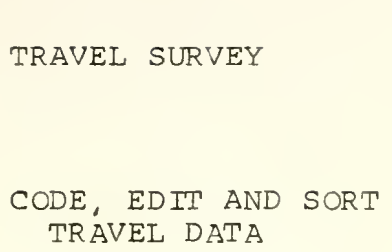

BUILD

TRIP

TABLES

( $P R-133)$

COMBINE TRIP

TABLES (PR-152)

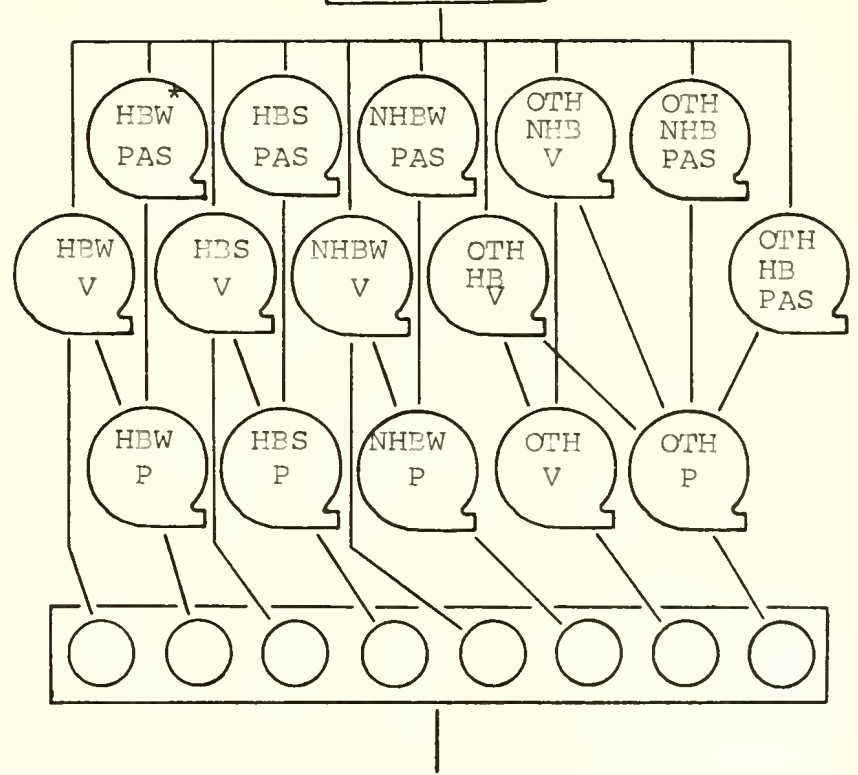

FACTOR TR IP

TABLES (PR-15I)

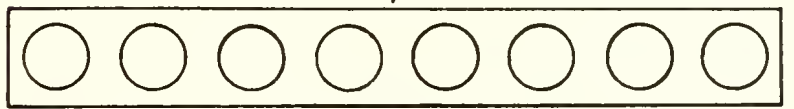

ASSIGN TRIPS TO NETWORK $(P R-2)$

NETWORKS (PR-124)

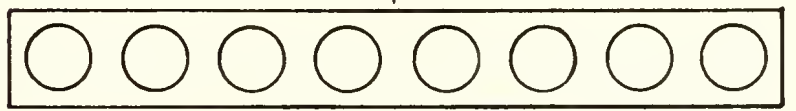

COMPARE AND ANALYZE

LOADED LINKS

$$
\text { ( } B M D 2 V, 2 R \text { ) }
$$

* See page 105 for abbreviation key.

Figure 3. Developing Travel Data. 
character of the sample. The blanket expansion used is explained subsequently. Because of the nature of PR-133, all final trips tables are complementary; i.e., they do not overlap. Program PR-152 was used to merge certa in tables in an additive manner in order to obtain the purpose combinations specified for analysis.

Since trips on links of the network had been selected as the decision variable, the trip tables had to be assigned to the street system. The traffic assignment program, PR-2, uses a factoring procedure to conserve space in core storage and on tape. It divides the actual trip volume by four in order to store the number in a field width of two less positions (binary digits). such a procedure is not critical for high volumes, but proves extremely damaging in cases where there are many low volumes. Since the trip data had not been expanded as would normally have been the case, the discrepancies here were quite serious. As a means of overcoming the problem, it was proposed to multiply the volumes by twenty prior to assignment. This would permit retention of the exact character of the sample and would eliminate the loss of critical volumes. It would also yield figures of a magnitude similar to observed traffic volunes. Program PR-I5I was used to expand the recombined results from PR-152 by a factor of twenty. The entire trip processing and assignment procedure was executed for both the total day and the peak hour situations. 
The traffic assignment process, utilizing program PR-2, assigned to each link of the minimum time path tree the zoneto-zone movements given in the trip table. This process, known as "loading the network," accumulated the trip volumes on each link for all zone-to-zone movements. No attempt was made to apply capacity restraint (iterative assignments to account for the change in travel speed with volume) to the loaded networks, since the differences in absolute volumes would have yielded inconsistent results from such a procedure. The objective of the research was to match the control loading condition; that having been accomplished, restraint procedures would be apolied to the synthesized loadings. There were sixteen separate network loadings, made up ky the twelve specified purpose situations and four totals. The loaded networks were summarized by program PR-124 to ottain a more readily processable output format and a listing of the loading on each link. The output from PR-124 was processed by a data reduction program which summarized for each link the loョding under each of the sixteen specified conditions.

Since the principal influence of the hypothesis was intended to be over the major street system, it was necessary to select the links in this group. In order to provide an objective basis for the selection, the functional street classifications developed by IRTADS were used to group the links. The IRTADS system was composed of five groups: local, collector, arterial, expressway, and freeway. Because of the small number in their groups, expressway and freeway links 
were combined under the latter title. The resulting arterial and freeway groups were considered the major street system. Because of an interest in examining results beyond those on the major street system, the collector group was retained for compatible analysis. All local links, centroid and external node connectors, were removed because of domination of travel on them by the zone represented by the centroid. Links connecting between different groups were considered collectors. The groups at this point represented a modification of the IRTADS system and were referred to as Mod-1 system:

$\begin{array}{lr}\text { Freeway } & 231 \text { links, } \\ \text { Arterials } & 307 \text { links, } \\ \text { Collectors } & 2123 \text { links. }\end{array}$

Examination of the volume distributions in the respective groups indicated certain conditions for which modifications were appropriate. The link volumes for the auto driver, total day, all purpose condition were chosen as the criterion since they were the best available representation of actual traffic volumes. Based on the estimated standara error of the group, all Iinks with volumes less than 140 were deleted. This was because the true volumes on these links in the average situation might be reasonably considered not different from zero. Links that were the only connection between the system and local links were deleted for the same reason as the local links. Links previously classified arterial or freeway, but having volumes less than 1000, were merged with collectors. Collectors with volumes greater than 5000 but 
less than 12,000 were merged with arterials; those with volumes over 12,000 were merged with freeways.

The rationale for these modifications was based on the fact that no capacity restraint was used in the assignment process. As a result, trips were assigned to the absolute minimum time path without consideration for the capacity of the links used. Such a situation would explain the failure of links to carry volumes comensurate with their functional classification. In order to correct for the situation, links having arterial level volumes were defined as arterials, etc. This was the reasoning behind volume considerations when reorganizing the groups. The volume criteria for each group were established by a generalized capacity analysis of the respective street classes.

The Moj-2 systen, used in the final analyses, was composed of the following:

$\begin{array}{lr}\text { Freeways } & 219 \text { links, } \\ \text { Arterisls } & 529 \text { links, } \\ \text { Collectors } & 1793 \text { links. }\end{array}$




\section{CHAPTER V. ANALYTICAL PROCEDURES}

The analytical procedures employed to test the proposed hypotheses fell into two distinct phases. The first was directed toward establishing a basis for consideration of the second. The second phase was directly concerned with testing the principal hypotheses regarding work and poak hour travel. Phase one undertook examination of the hypothesis that the several factors of trip purpose, mode of travel, and time of trip do significantly influence the character of person movement in an urban area. The objective was to obtain a quantitative definition, in probabilistic terms, of that interrelationship which most practitioners have come to accept in a qualitative sense. The variables chosen for examination were travel volume and length of trip. These were considered sufficiently representative of the distributional characteristics of urban travel to permit valid generalization and extension of the effects observed.

Travel volune was defined as the number of trips made, where each survey card represents a trip. Trip length was the time required to complete a given trip on the minimum time path from the zone of origin to the destination zone. The purpose of a trip was that indicated on the survey card at the point of destination. Purpose was considered in six groups : 


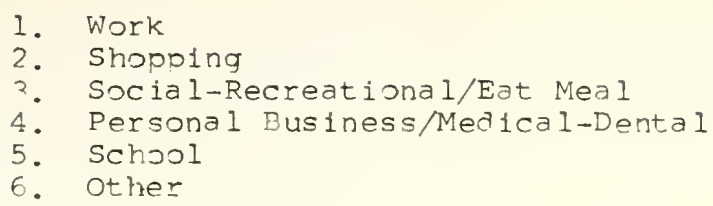

Groups three and four are combinations of purposes originally tabulated separately. The merger was due to assumed similarities in the character of travel for these purposes. Mode of travel was defined in three groups:

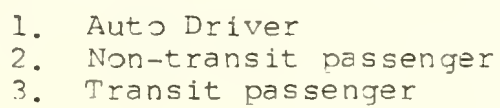

The definition of transit includes school buses as well as other bus vehicles; there is no other form of transit in Indianapolis. The non-transit passenger group includes passengers in private automokiles, taxis, and trucks. Time was defined in 24 one hour groups. The mean of the start and arrive times reoorted for the trip maker was used to place the trip in its time group.

The basic data source was the IRTADS home interview survey file (No. 2 cards) consisting of 76,396 records, each describing one trip, wholly within the area, made by a resident of a household selected for interview. The sampling unit for the survey was the household. The households had been selected in a systematic manner from public utility records and reoresented approximately five percent of the dwelling units in the study area.

The trip records were sorted by zone of trip origin and then by zone of trip destination using the IBM 7094 IESYS 
Generalized sorting system. The length (in time) of travel from each zone to every other zone was computed from the minimum time path tree by a tree skiming program (PR-130) that is part of the BELMN package. The skimmed tree provides the overall time by summing the times to traverse each link in the minimum time path over all links in the path. It is, therefore, the minimum possible zone-to-zone travel time. The appropriate skimmed tree time was then appended to the individual record of each trip by the program LENGTH (Appendix C), Leing made an additional permanent part of each trip record.

The nature of the hypothesis to be tested was appropriate for investigation by the analysis of variance technique (ANOVA). This statistical proceaure involves classification of the observed variable according to several factors, the object of the investigation being to determine the extent to which the factors affect the observed variable. Thus an observation occurring under a particular set of conditions would be grouped only with observations which occurred under similar circumstances. In the type of study undertaken here, termed a complete factorial, there are the same number of such groups, or cells, as there are combinations of possible conditions (levels) of the factors considered. This procedure isolates the quantitative effect that each factor has on the variable analyzed, but also permits evaluation of effects occurring due to factors acting in combination (interaction). 
In order to test the significance of the effects due to factors and interactions, the ANOVA uses an estimate of experimental error, i.e., natural variability, not due to the factors analyzed, to be expected in the occurrence of the variable. One means of obtaining such an estimate in experimentation is to replicate or repeat at least a portion of the experiment, since variability in observations made under identical conditions can be attributed to experimental error. For the present investigation it was decided to select four random subsamples from the basic trip file. These four complete subsamples provided the necessary estimate of experimental error. In order to simplify the sample selection procedure, the observation selected for testing was the mean trip length value over all trips in each cell.

The equations representing the analyses, commonly called analysis of variance morels were:

$$
\begin{aligned}
x_{i j k l} & =\mu+P_{i}+M_{j}+T_{k}+P M_{i j}+P T_{i k}+M T_{j k}+P M T_{i j k} \\
& +\epsilon(i j k) l
\end{aligned}
$$

where:

$$
\begin{aligned}
& x_{i j k l \text { represents trip volume or trip length, depending }} \text { on the analysis, for the } i-t h \text { purpose, by the } \\
& \text { J-th mode, in time period } k \text {, for the } 1-t h \text { sulo- } \\
& \text { sample; } \\
& H_{i} \text { is the respective overall mean; } \\
& P_{i} \quad \text { is the effect of the } i-t h \text { purpose, } i=1, \ldots, 6 \text {; }
\end{aligned}
$$




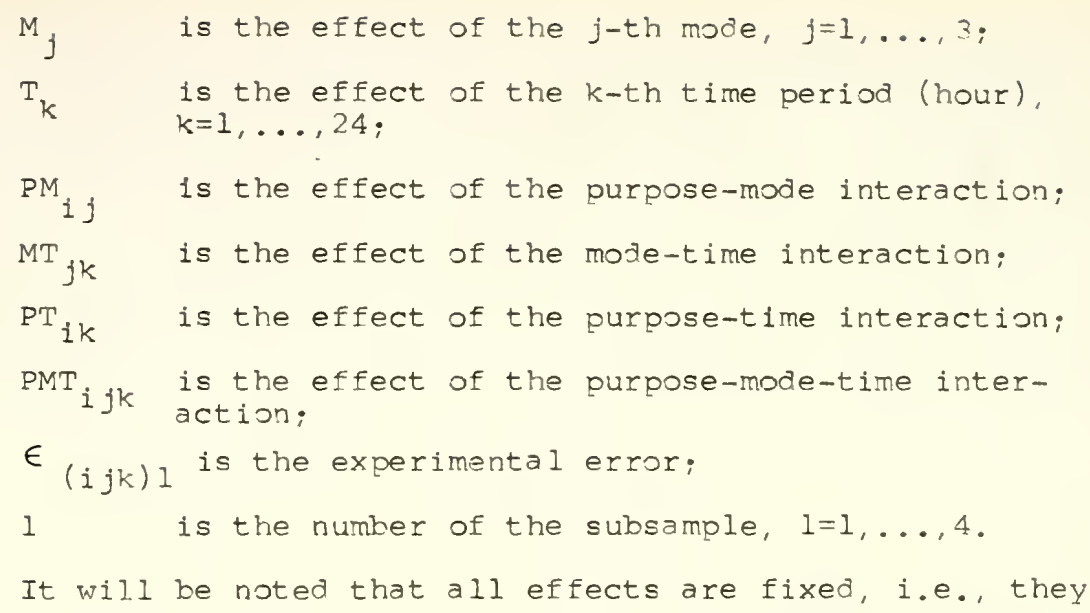
are not randon samoles from an infinite population of such values. The inference permitted can, therefore, only be considered applicable for those levels of the respective factors included in this analysis. The analysis described is known as a complete three-factor factorial analysis with four observations per factor level combination. The assumptions reauired for use of the ANOVA were considered sufficiently satisfied. The effects were additive because of the simplicity of the counting process. The experimental errors were considered normally and independently distributed due to the averaging of the trip length variable.

A theoretical consideration at this point involved the inference space of the results. The objective was to imply validity not only for the city of Indianapolis, but for the nation as a whole. Such an implication is valid if the trip data used is considered a randomly selected single cluster sample from a nationwide population of trips. 
The randon subsamples of the basic systematic sample may be considered random samples of trips in Indianapolis. When four subsamples of 10,000 each were drawn from the original 76,396 trips that represented a five percent sample, each subsamole was effectively a sample of less than one in one hundred and fifty and was considered drawn from an infinite population. Under these circumstances infinite theory was closely approximated, and finite population correction was not necessary.

Selection and processing of the four samples was accomplished by the program SAMPLR (Appendix C). Input to SAMPLR was four sets of unique, sorted random numbers developed by the program RAIDOM (Appendix C), and the sorted trip card file, augmented with trip lengths. The four files of random numbers were stacked on magnetic tape for use by SAMPLR. SAMPLR read the random numbers and, based on each, selected the data occurring in the designated location of the trip card file. The records selected were tabulated by purpose, mode, and time of trip. Each record used was deleted. from the input trip file, and those remaining were written out to await selection of the next sample by the subsequent pass of SAMPLR. The sample selection process was repeated four times. The results of one sample are shown in Appendix B. These data were punched on cards in preparation for their analysis.

The complete factorial analysis of variance computations were executed by program BMD-2V (UCLA, 1966a). The output 
from the computation is presented in Tables Al and A2 of Appendix A. The results of the tests for significance are presented and discussed in Chapter VI.

Phase two of the analysis involved testing the principal hypotheses, concerned with the use of work and peak hour trips to represent total daily travel. The objective of the analysis was to determine the degree to which trips of a single purpose or a particular time perioz could be expected to reproduce the pattern of all travel in an urban area and define the transportation system used thereby. Travel volume on individual links of the righway network was the decision variable selected; the form that the variable took depended on the analysis performed. Reflection on the objective of the research pointed up the necessity of retaining the all-purpose loading as the control condition, against which the hypothesized revisions would be tested. The nature of the situation, with the variable to be predicted containing the variable used to predict, indicated that a regression aporoach would be most appropriate.

The extent of the regression analysis required was investigated by a modification. and extension of the analysis of variance performed in phase one. The objectives of this second ANOVA were to determine which factors should be included in the regression models and what different models were necessary. This analysis was designed to test the effect on individual link volumes of change in the factors purpose, mode, and time. 
Definitions of the factors and variable for this analysis were modified from those applied in the first investigation. In this analysis purpose was considered at three levels: home-based work, non-home-based work, and non-work. This reflected a split of the previous PI (work) and combination of $\mathrm{P}_{2}$ to $\mathrm{P}_{5}$. Mode was included at only two levels, transit trips having been deleted. The time levels were redefined as peak hour, one particular hour, against non-peak hour, the remaining 23 hours combined. The observed variable was relative assigned traffic volume. This variable was obtained by assizning trips (variable in the first analysis) to the links of the highway network and dividing each resulting link volume by the link-trip total over all links for its particular factor level combination. This manipulation eliminated between cell differences attributable only to differences in absolute total volumes of trips observed for respective purposes. The effect of the absolute totals had been examined in the first analysis; the second analysis was to examine the degree to which selected observed effects extended to the highway system. The resulting variable, termed link-relativeimportance (LRI), was indicative of the status the particular link assumed regarding movement of traffic in the area.

If there was no significant difference found due to purpose, it could be reasoned that each link was as important for moving work trips as for moving other trips. Lack of significance due to mode would imply that passenger travel is distributed on the system in the same manner as vehicle travel. 
And no significance attributed to time would infer that peak hour traffic uses the same links as non-peak movement. Should any main effects not be considered significant, regression analysis of that situation would not be necessary. If the main effects were found significant it could be reasoned that sufficient difference occurred between purposes, modes, or time periods for these factors to be considered in the regression analysis.

Of particular interest in this ANOVA was whether the significance of interactions carried through from the first analysis. An interaction implies that the results of varying one factor under the constant level of another factor might not match the results of identical variations of the first factor under different conditions of the second factor. Thus, a significantly different relationship might be found between volume and purpose for auto ariver trips than for passenger trips. Interaction significance would imply a need for different regression molels at each level combination of the interacting factors. This analysis would yield a rational basis for the form of the regression equations and contribute to the understanding of underlying relationships.

Consideration of two requirements of the analysis of variance was necessary.

The ANOVA procedure bases its tests of significance on properties of the normal distribution and requires that the experimental error within the classification groups or cells be normally and independently distributed. Tests of this 
condition utilizing the Komolgorov-Smirnov (K-S) test for goodness of fit (Ostle, 1963), indicated that the raw LRI values were not normally distributed. It was found, however, that after a square root transformation of the raw data was carried out, the K-S test showed significant ( 5 percent level) departures from normality in only a very few cases for the arterial and freeway classes of the MOD-2 highway system. The collector class was discarded from further consideration in the ANOVA examination because the observed departures from normality could not be considered insignificant. Results of the normality test are given in Table A3 of Appendix $A$. The use of the square root transformation has a basis in theory; the data were merely a traffic occurrence or frequency distribution on the highway system, known to be distributed in a Poisson manner (Gerlough, 1955). The square root is the characteristic transformation to a normal distribution for a Poisson distributed variable.

The other ANOVA assumption tested concerned homogeneity of variance between cells. The common test for this condition is that attributed to Bartlett (1937). The square root transformed data were processed by two computer routines which yielded the chi-square values to be tested. These are given in Table A4 of Appendix A. It was apparent that cell variances of the design were quite non-homogeneous. Box (1954) has considered the variance problem also and indicates that the robust nature of the ANOVA is capable of withstanding quite a degree of heteroscedasticity. 
In spite of the lack of variance homogeneity and the minor variations from normality, it was decided to continue with the ANOVA as proposed. The analysis was run separately for the two street classes with no attempt being made to examine between class effects. This decision was based principally on the variation in the number of observations between the classes. The ANOVA models took the form: "

$$
\begin{aligned}
L_{i j k l} & =\mu+P_{i}+M_{j}+T_{k}+P_{i j}+P_{j k}+M_{j k}+P M T_{i j k} \\
& +\epsilon_{(i j k) l}
\end{aligned}
$$

where

$$
\begin{aligned}
& I_{i j k l} \text { is the } \sqrt{\text { link-relative-importance }} \text { for the i-th } \\
& \text { purpose, by the } j \text {-th made, in time period } k \text {, } \\
& \text { for the 1-th observation. } \\
& P_{i} \quad \text { is the effect of the } i-t h \text { purpose, } i=1, \ldots, 3 \text {; } \\
& M_{j} \quad \text { is the effect of the } j \text {-th mode, } j=1, \ldots, 2 \text {; } \\
& T_{k} \quad \text { is the effect of the } k \text {-th time period, } k=1, \ldots, 2 \text {; } \\
& \epsilon_{(i j k) l} \text { is the experimental error: } \\
& 1 \text { represents the link considered, } 1=1, \ldots, 218 \text {, } \\
& \text { for freeways, } \\
& 1=1, \ldots, 529 \text {, } \\
& \text { for arterials. }
\end{aligned}
$$

The interactions are similar to those defined for the first ANOVA. Computations for this analysis were performed by program $3 \mathrm{MD}-2 \mathrm{~V}$; the results are presented and discussed in Chapter VI.

The models for the regression analysis were developed in accordance with the results of the variance analyses, and 
included factors representing purpose, mode, and time. The definitions of the variables and factors for regression were further modified from those used previously. The dependent regression variable ( $Y$ ), in accordance with the control condition defined, was the number of trips for all purposes that were assigned to the individual links of the highway network. This represented a combination of the three purpose levels tested in the second ANOVA. The independent regression variables (X's) were similarly assigned volumes, but represented trips for a specific purpose: home-based work, non-home-based work, and hone-based shop. The first two were identical to classifications in the second ANOVA; the third was an additional factor included because of the general interest and availability of the data. The shop level was not included separately in the purpose factor of the second ANOVA because the objective at that point was to define the effect of work relative to all other purposes combined. Levels of the mode factor were auto driver, identical to $M_{1}$ in both previous analyses, and highway person, a conbination of the $\mathrm{M}_{1}$ and $\mathrm{M}_{2}$ levels of the second ANOVA. Time was treated in a similar manner: peak hour corresponded to $P_{1}$ and total day was the combined $P_{1}$ and $P_{2}$ levels. The definition of the regression factors closely approached the definitions of the original principal hypotheses. The only variation occurred in the second level of purpose; $\mathrm{P}_{2}$ was defined as non-home-based rather than all work because of the build-up approach. Adding nonhome-based work to an equation including home-based work 
implied the desired effect of total work. The factor definitions for the second ANOVA and the regression analysis are listed below together with the nomenclature for the principal hypotheses.

$\begin{array}{llll} & \text { HYPOTHESES } & \text { ANOVA } & \text { REGRESSION } \\ \text { Purpose: } & \text { HBW } & \text { HBW } & \text { HBW } \\ & \text { ALI WORK } & \text { NHBW } & \text { NHBW } \\ & \text { ALL PURPOSES } & \text { NW } & \text { ALL PURPOSES } \\ \text { Mode: } & \text { DRIVER } & \text { DR IVER } & \text { DRIVER } \\ & \text { PERSON } & \text { PASSENGER } & \text { PERSON } \\ \text { T1me: } & \text { PEAK HOUR } & \text { PEAK HOUR } & \text { PEAK HOUR } \\ & \text { TOTAL DAY } & \text { NON-PEAK } & \text { TOTAL DAY } \\ & & \text { HOUR } & \\ & (H: H O M E, \quad \text { B:BASED, W:WORK, N:NON) }\end{array}$

The factor level combinations as combined for the regression variables are listed below.

Independent Variables

1. Home-based work, Auto driver, Total day

2. Non-home-based work, Auto driver, Total day

3. Home-based work, Highway person, Total day

4. Non-home-based work, Highway person, Total day

5. Home-based work, Auto driver, Peak hour

6. Non-hone-based work, Auto driver, Peak hour

7. Home-based work, Highway person, Peak hour

Q. Non-home-based work, Highway person, Peak. hour

9. Home-based shop, Auto driver, Total day

10. Home-based shop, Highway person, Total day

11. Home-based shoo. Auto driver, Peak hour

12. Home-based shop, Highway person, Peak hour

Dependent Variables

1. All purpose trips, Auto driver, Total day

2. All purpose trips, Highway person, Total day

3. All purpose trips, Auto driver, Peak hour

4. All purpose trips, Highway person, Peak hour

The requirements for regression analysis are that each value of $\mathrm{X}$ be measured without error and the experimental 
errors of the $Y$ values for each value of $X$ be normally and independently distributed with mean zero and homogeneous variance. It is not too difficult to tacitly assume that these restrictions are satisfied by the data in this analysis, particularly since there are so many possible values of $X$ and thereby few possible values of $Y$ for each $X$. The basic relationship was assumed to be linear and additive because of the nature of the urban travel situation.

The technique used was to build up a multiple linear regression equation in steps, adding one independent variable at each step. This technique follows the logic of the proposals set down for modifications in survey procedures, i.e., one variable represents one type of survey, an additional one represents a more extensive survey, etc. Thus it is shown fust how much precision (increase in determination) is gained by augmenting basic survey data. The computations for the analysis were performed by computer program $B M D-2 R$ (UCLA, 1966b).

The initial run of the program permitted free selection of that variable which most significantly reduced the error sum of squares of the analysis. The respective variables added were those which caused the greatest increase in the total variation explained by their inclusion. This run eventually included all independent variables. Subsequently, a program option was exercised which selected entrance of independent variables into the equation in the logical order 
of the proposed build-up survey procedure.

Nine sets of equations were developed. Four of these each had dependent and independent variables of the same mode-time combination. The mode-time combination varied between sets. The remaining five sets were developed with dependent variables common for planning and design purposes, but with independent variables of a type more easily surveyed. The latter five sets did not have simllar mode-time combinations for dependent and independent variables. Within each set the dependent variable did not change. The nine equations in each set represented different combinations of the basic street classes. The first three of these treated freeways, arterials and collectors, respectively. Two more were developed by combining freeways and arterials for one (FA) and freeways, arterials and collectors for the other (FAC). The remainder included all freeway and arterial links as well as subsets of the collector group based on volume: collectors with day vehicular volume not less than 4000, 3000, 2000, and 1000 . The results of the regression analyses are presented in Chapter VI and Appendix A. 
CHAPTER VI. ANALYTICAL RESULTS

The analyses described in Chapter IV were designed to test the following hypotheses:

1. There are no significant effects on trip volume and trip length due to the purpose, mode, and time factors and their interactions, which define trip conditions.

2. The pattern of travel for the work purpose adequately describes a street system sufficient to serve trips for all purposes, thereby implying feasible reorientations in travel pattern surveys.

3. The pattern of travel in the peak hour adequately describes a street system sufficient to serve trips made during the entire day; thereby implying a feasible reorientation in the procedure for obtaining a design hour volume.

The degree to which these hypotheses were acceptable and the ramifications of the results of the tests employed are discussed below.

The first hypothesis is concerned with a situation recognized by most practitioners. The quantitative nature of the proposed effects have been known for some time, but tests of significance have not been run. Tables Al and A2 in Appendix $A$ are the analyses of variance for trip volume and trip 
length respectively.

All main effects and interactions were significant $(a=0.01)$, implying rejection of the first hypothesis stated. The high significance of the main effects had been expected. It implied that the volume and length of trips observed in Indianapolis differed significantly with variation in the purpose of trip, the mode of travel, and the time of observation. The high significance of the interactions was not anticipated. It implied, for example, that the relationships between volume or trip length and the single factors (e.g., purpose) were inconsistent if any other factor was not held constant. The results of this analysis emphasized the fact that the factors being examined in regard to travel pattern development were very worthy of further consideration. They also indicated that further analyses would have to account for the interactions.

The second and third hypotheses were investigated simultaneously due to use of the same decision variable and identical statistical procedures. The second stage of the investigation involved defining the factors and models for the regression analysis. The variable was LRI and the factors examined in the ANOVA were, generally, purpose, mode and time. The LRI values were observed on the MOD-2 freeway and arterial classes only, due to the normality of their distributions. The significance level chosen for testing the $F$ ratios was 0.25 . This choice was based on the fact that probability of "type II" or " $\beta$ " error (accepting a false 
hypothesis) was of importance. Increasing the " $a$, " or probability of type I error (rejecting a true hypothesis), to the level of 0.25 reduces the probability of $\beta$ error. The low $\beta$ error was considered necessary because the objective of the test was to determine which effects were not significant and could thereby be eliminated from consideration in model development. The hypothesis proposed for this test was: the purpose, mode, and time factors described here have no significant effect on relative link volume. The ANOVA for these tests are shown in Tables 2 and 3 . All significance tests were made using an $F$ ratio with only the error mean square, since the model was composed completely of fixed effects.

The tests on the freeway links indicated significant results due to the main effects of time, purpose and mode. No effect on LRI was noted due to interaction. It can be concluded that LRI does vary between the peak and non-peak periods, due to change in consideration of the work or the non-work purpose, and due to travel mode. The implications are that, for freeways, separate models describing peak and non-peak traffic would yield better results than a single model. Further, there is sufficient effect due to the work purpose and mode that models describing travel must include recognition of the work purpose and means of travel. The extension of these results is valid and consistent only over the factors and levels considered here. 
Table 2. Analysis of Variance for Freeway L.R.I.

\begin{tabular}{|c|c|c|c|c|}
\hline Factor & $\begin{array}{c}\text { Degrees } \\
\text { of } \\
\text { Freedom }\end{array}$ & $\begin{array}{l}\text { Sum of } \\
\text { Squares }\end{array}$ & $\begin{array}{l}\text { Mean } \\
\text { Square }\end{array}$ & F Ratio \\
\hline$T^{* *}$ & 1 & 28.37 & 28.37 & $3.31 *$ \\
\hline$M$ & 1 & 17.67 & 17.67 & $2.06 *$ \\
\hline $\mathrm{P}$ & 2 & 511.07 & 225.54 & $26.7 *$ \\
\hline TM & 1 & 2.31 & 2.31 & 0.27 \\
\hline $\mathrm{TP}$ & 2 & 3.23 & 1.61 & 0.19 \\
\hline$M P$ & 2 & 0.41 & 0.20 & 0.23 \\
\hline $\mathrm{TMP}$ & 2 & 15.90 & 7.95 & 0.93 \\
\hline Error & 2604 & $22,318,74$ & 8.57 & ---- \\
\hline Tota 1 & 2615 & $22,897.68$ & & \\
\hline
\end{tabular}

*

Significant at $\alpha=0.25$

* *

See page 105 for abbreviation key. 
Table 3. Analysis of Variance for Arterial L.R.I.

\begin{tabular}{|c|c|c|c|c|}
\hline Factor & $\begin{array}{c}\text { Degrees } \\
\text { of } \\
\text { Ereedom }\end{array}$ & $\begin{array}{l}\text { Sum of } \\
\text { Squares }\end{array}$ & $\begin{array}{l}\text { Mean } \\
\text { Square }\end{array}$ & F Ratio \\
\hline$I^{*}$ & 1 & 39.28 & 39.28 & $4.95 *$ \\
\hline M & 1 & 253.22 & 253.22 & $31.8 *$ \\
\hline$P$ & 2 & $1,783.42$ & 891.71 & $112.2 *$ \\
\hline$T M$ & 1 & 3.84 & 3.84 & 0.48 \\
\hline$T P$ & 2 & 9.01 & 4.00 & 0.50 \\
\hline$M P$ & 2 & 67.98 & 33.99 & 4.38 * \\
\hline$T M P$ & 2 & 19.23 & 9.11 & 1.15 \\
\hline Error & 6,336 & $50,380.69$ & 7.95 & ---- \\
\hline JotaI & 6,347 & $52,554.68$ & & \\
\hline
\end{tabular}

*

Significant at $a=0.25$

** See page 105 for abbreviation key. 
The tests in the ANOVA for arterials indicated the same effects observed for freeways as well as a significant mode-purpose interaction. This additional effect may reflect the change in orientation of traffic from movement to land service as street class decreases. The variability in the influence on volume exerted by work purposes cannot be considered the same for all modes, and conversely, as was the case for freeways. This implies a need for more models to account for interaction.

The hypothesis for the ANOVA of relative volumes was rejected for the purpose, mode, and time main effects on freeway links and for these as well as the mode-purpose interaction on arterial links. The remaining effects could not be rejected at $a=0.25$. The meaning of these results must be tempered by the failure of the data to satisfy the criterion of homoscedasticity. Reflection on the trends observed gives cause for contemplation on the results which might have occurred had the collector class exhibited normality.

The equation forms used in the regression analysis reflected the results of the variance analyses. The models developed predicted trip volumes for all purposes on links of the highway network. The means of prediction were trip volumes observed on the same links for specific purposes, i.e., work. Separate models were developed for each combination of the levels of the mode and time factors. The ANOVA results indicated that the use of each additional level of 
the purpose factor would increase the variation explained. Further, each mode-time combination would yield different levels of predictability, each of which was consistent within time, but not necessarily within mode. The regression equations represent the relations within the condition groups or cells of the ANOVA. The feasibility of the development approach employed was checked by permitting variables to enter the equations in a stepwise manner, according to the significance of their contribution. The final relationships were then selected, on an intultive basis, and the respective results were compared. It should be emphasized that the following analysis was not oriented to developing predictive relationships, but rather to determining the degree to which variation in the all-purpose group was explained by variations in specific purpose groups. It is not inferred that the equations shown are applicable elsewhere, but rather that variation explained $\left(R^{2}\right)$ may be universal and that the respective expansion ratios (slopes) are typical.

The first regression analysis developed simple, linear relationships between peak hour and total day volumes. The equations shown in Table 4 predict total day volume based on peak hour volume. Only the all-purpose condition is presented because the objective was to demonstrate the representivity of all traffic in the peak hour. Results are shown for both modes and for three separate street classes: freeways, arterials and collectors. The variation explained $\left(R^{2}\right)$. varies between modes by a maximum of 0.018 ; the difference in $R^{2}$ between modes increases from freeways to collectors. The prediction 
Table 4. Simple Regression Analysis.

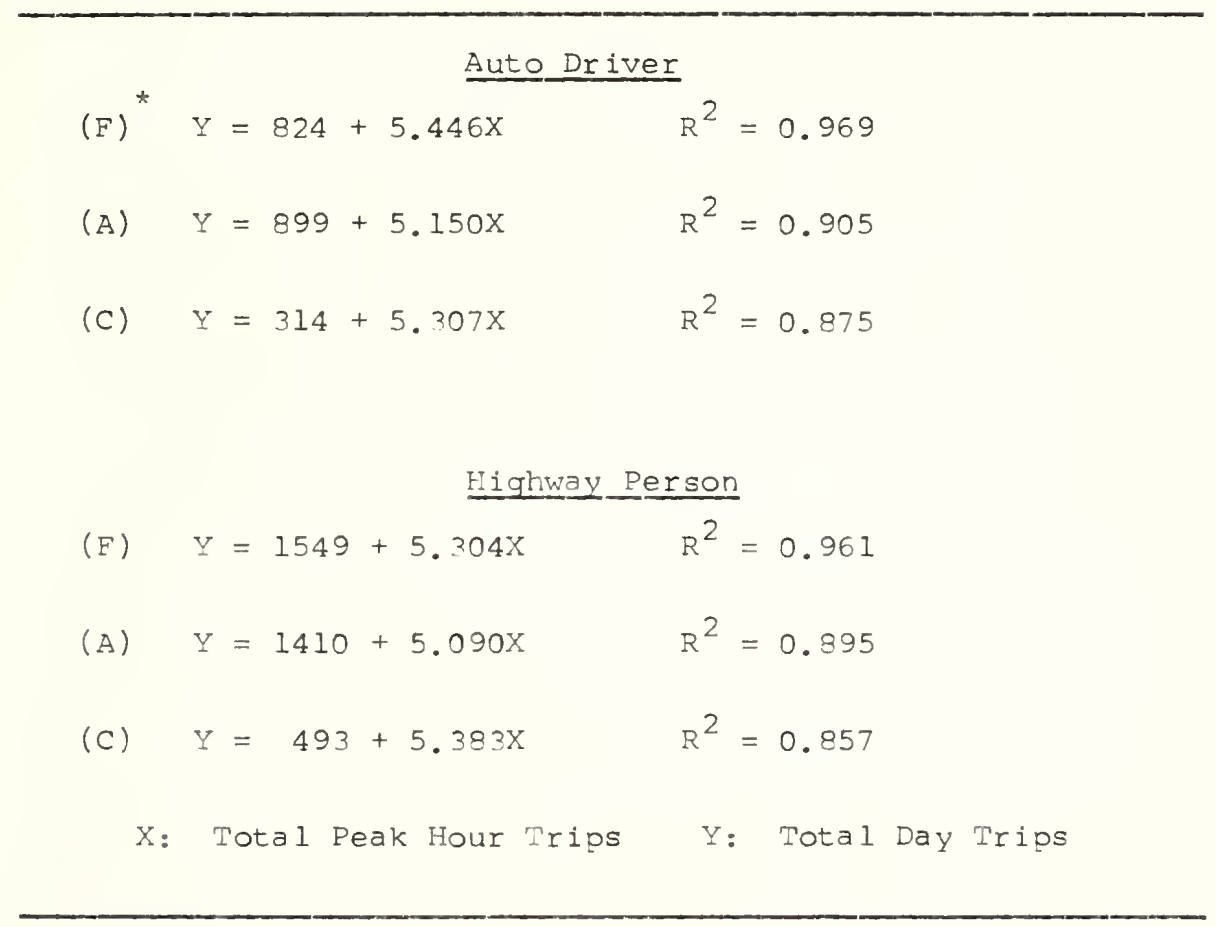

* See page 105 for abbreviation key. 
of total traffic based on peak hour traffic is quite reliable for all street classes. The prediction is better on higher type facilities because they are the ones most utilized in the peak hour. These positive results give credence to a basic hypothesis of this research and form a basis for further study of peak hour travel by purpose.

The multiple linear regression analyses examined the three separate street classes and several combinations of these. The examination of several street groups was undertaken in order to determine the changes in predictivity for various single classes and combinations within the total street system. Within each street group several mode-time combinations for the variables were used. In four of these cases, the mode-time condition was the same for the dependent and independent variables. In the remaining cases, the modetime condition of the independent variable represented a more practicable survey procedure than did the mode-time combination of the predicted variable. All dependent variables represented mode-time combinations useful in planning and design.

The four homogeneous sets were concerned with predicting the total day (D) and peak hour (H) trips by highway oriented persons (P) and vehicles (V). Selection of the proper relationship would be based on the mode and time orediction desired; that same mode-time combination would be surveyed. Three of the other five relationships predicted peak hour vehicle (HV) trips using total day person (DP), total day 
vehicle (DV), and peak hour person trips (HP). The results of these would be design hour traffic volumes, based on surveys of all employees, all those driving to work, and all those traveling in the peak hour respectively. The remaining two relationships used total day person trips (DP) to predict total day vehicle (DV) and peak hour person trips (HP). These represented a survey of all employees to predict daily vehicle traffic or a person trip design hour.

Tables A5 through A8 in Appendix A show results of the regressions for the free entry situation. In this situation the variables enter solution one at a time, in the order of the additional explained variation $\left(R^{2}\right)$ that their inclusion will yield. The variable entering also causes the greatest reduction in the error sum of squares of all variables not in solution. The tables show the order of entry of the four most significant independent variables for each street class or combination for prediction of the four different mode-time conditions of all purpose trips. Also given are the cumulative $\mathrm{R}^{2}$, standard error of the estimate, and coefficient of variation at each step.

The $\mathrm{R}^{2}$ values describe the proportion of variability in the predicted trips explained by the factors included in the equation at that step. Here the standard error of estimate provides the upper confidence limit on each prediction. It is indicative of the possible error that the . prediction procedure may be expected to exhibit. Adding one standard error to a predicted volume assures 0.84 probability that the true volume is not greater than the result; two 
standard errors implies 0.97 probability of enclosing the true value. The standard error indicates the possible error in capacity due to use of a design hour volume obtained from the procedure described here. The coefficient of variation is the proportion that the standard error is of the mean. It is an indication of relative precision of the estimate. The increase in $\mathrm{R}^{2}$ and decrease in the standard error and coefficient of variation must be balanced against the increased cost of survey necessary in order to attain these.

All independent (single purpose) variables were available for selection in the free entry regressions. The entry order and parameters of fit were affected by the individual street classes or combination of street classes considered. The entry order for a given dependent variable for the separate classes was somewhat erratic, but for the combinations it was fairly uniform. The home-based work trip that was consistent with the mode-time condition of the dependent variable was the first variable to enter in all regressions. Predictions of total day volume usually chose shopping trips second, followed by the respective non-home-based work group. The reverse was true for predicting peak hour trips. It is apparent that shopping travel is more important in total day than in peak hour travel. The fourth entry was generally too erratic to permit valid conclusions.

The $R^{2}$ values were better for peak hour prediction than For total day, and better for vehicle trips than for person trips. The $\mathrm{R}^{2}$ decreased with mean volume of the street group 
considered. The $\mathrm{R}^{2}$ values for the FA and FAC classes were very similar, and the FA class was slightly higher in all situations but one. As more of the collector class was included with FA, the $R^{2}$ decreased slightly, until at the $T 1$ group it began to increase. The standard errors decreased with the mean volume of the analysis group. The comparison of coefficients of variation showed an increase as more links were included in the analysis group and the group mean volume decreased. The coefficients were consistently greater for person than for vehicle trips, and were larger for total day than for peak hour trips. These results indicated which variables were most important for predicting trips of various time-mode groups. They form a basis for comparison of the results of selected variable situations. It is significant that the basic element of the proposed revised survey procedure was always the most important predictive variable.

The destination place survey procedure previously proposed implied a logical order of variable entry into prediction equations. The most elemental survey would involve homebasẹd work trips. Next would come, in addition, non-homebased work trips. The third step would involve home-based shopping trips as well. The results discussed henceforth are for regressions on these selected variables, indicating the cumulative results (fit) as each additional variable was selected for the equation.

The regressions were run for nine street class groups and nine prediction situations within each group. Tables A9 
through Al6 in Appendix A show results of the regressions for all groups and situations. Tables 5, 6, 7 and 8 in this chapter show more detailed results for the FAC and FA street class combination groups. The $R^{2}$ and coefficient of variation values exhibited trends between street groups similar to those observed in the free entry situation. Comparisons of the results using person shopping trips versus vehicle shopping trips indicated that the vehicle trips usually explained more variation than the person group. As a result the vehicle mode was used for all home-based shop variables included in the analysis. Use of the vehicle mode permits a license plate survey of shop trips.

When using the same mode-time condition for both depencent and independent variables, the FAC group (all street system Iinks) was second in prediction $\left(R^{2}\right)$ only to the freeway class (Table A9). The two groups were very close in all cases. The difference in $R^{2}$ between separate street classes was greater than between orogressive groups combining collectors with the FA group. The standard errors of the estimates decrease as more of the collector links are included with those in the FA group (Table AlO). The FAC group exhibits the lowest standard errors in most situations. The coefficients of variation were less (Table All). If precision is important, the FA group is better than the FAC, since the coefficients of variation are less. If capacity error is more important, the FAC group is better, since the standard errors are less. A good balance in this decision 


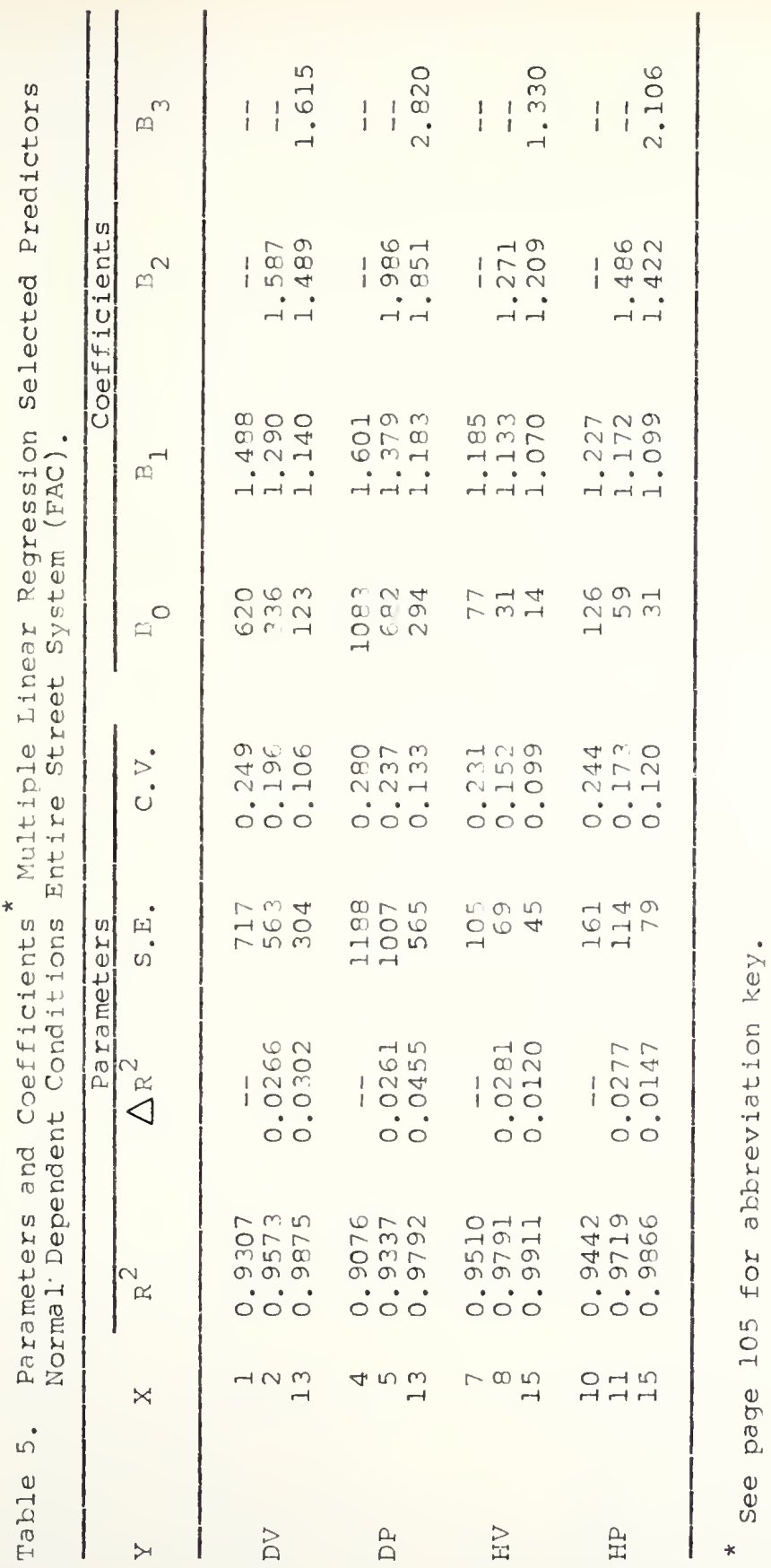




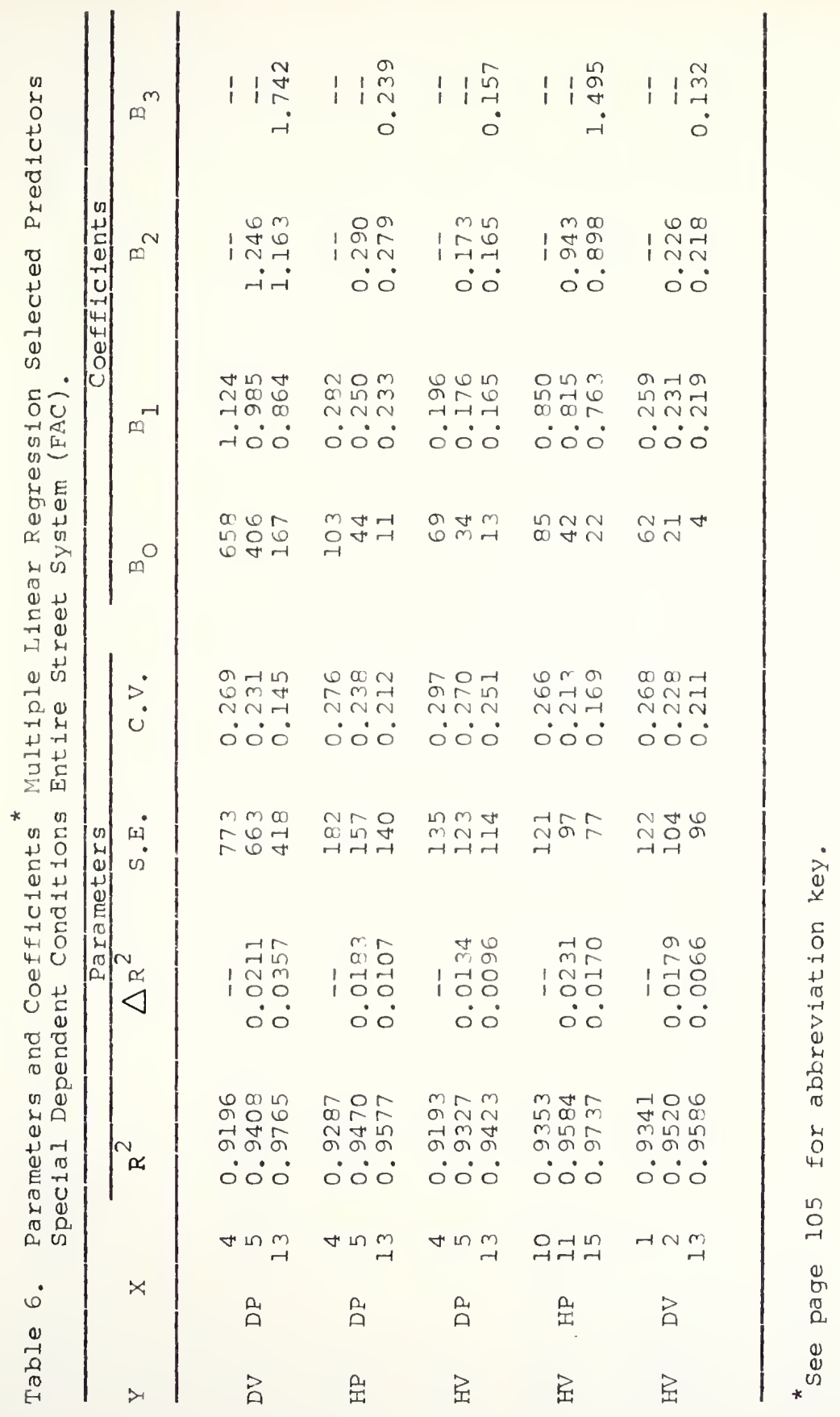




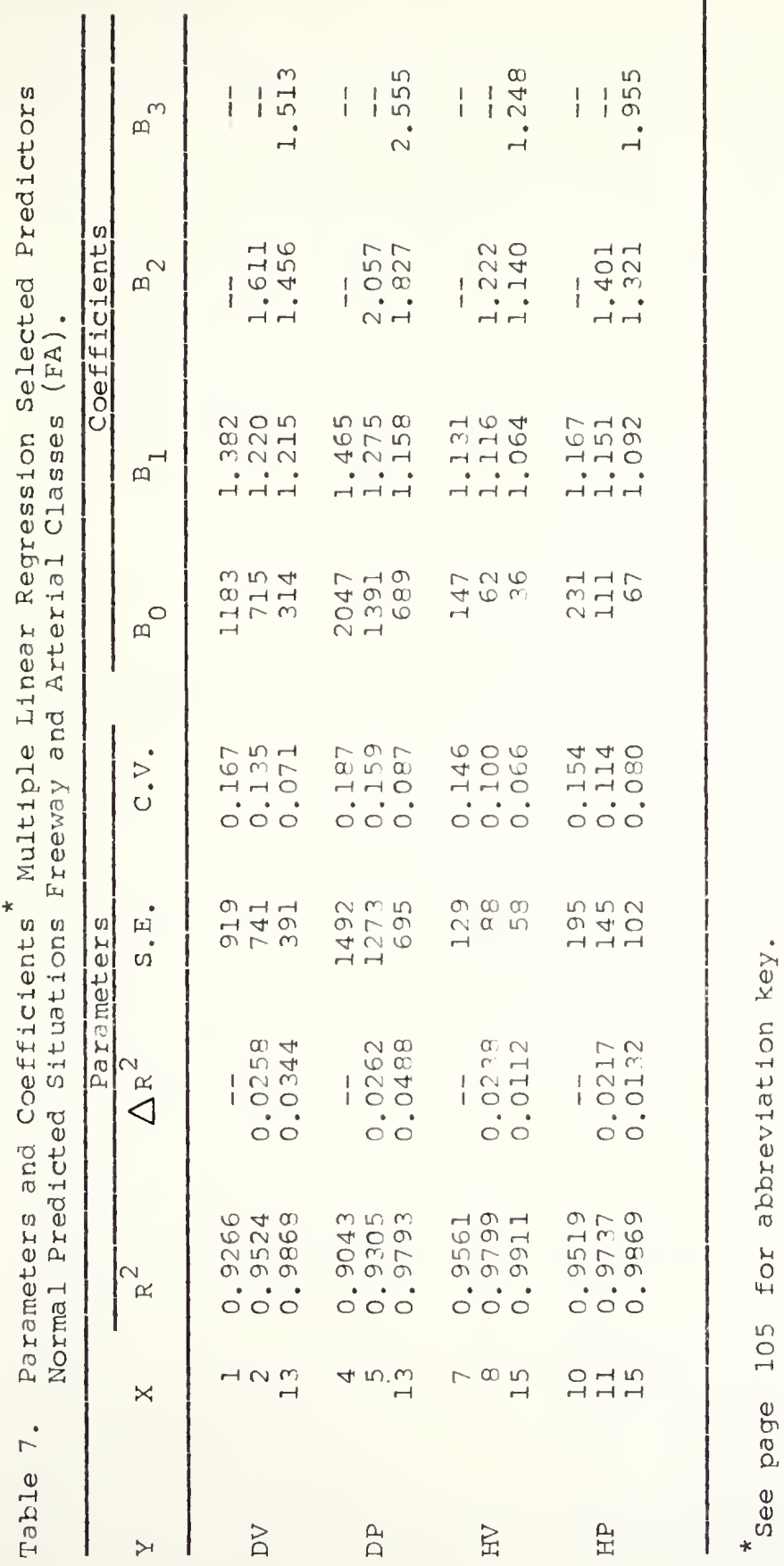




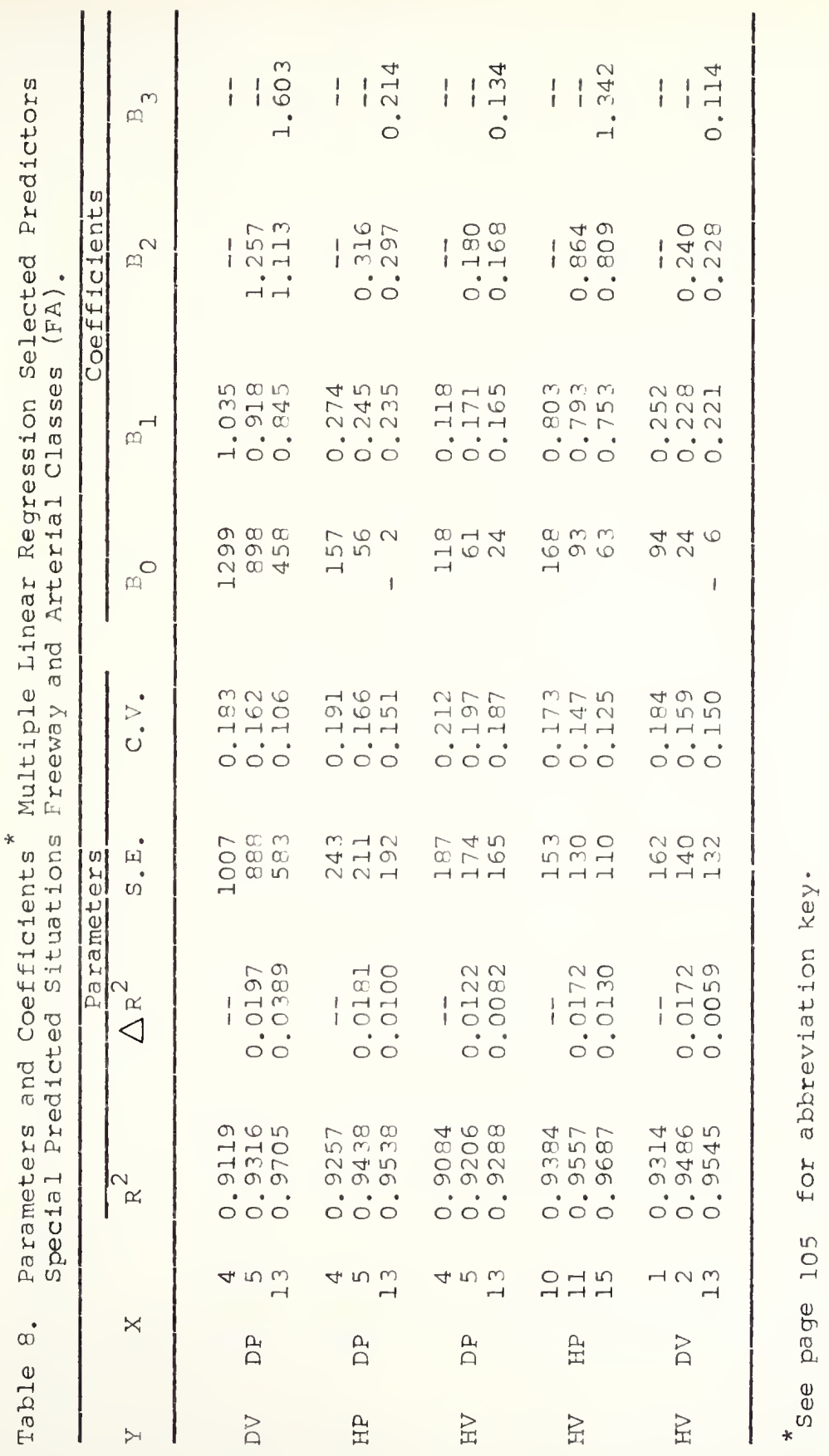


is desirable, but standard errors are more readily translatable into effects, $1 . e .$, design errors.

The regression coefficients shown in Tables 5 through 8 are related to the proportion that the several purpose groups are of total travel. The regression equation constants are indicative of the travel attributable to purposes not accounted for ky the variables in the equation. The current research proposes no more than that these coefficients may be generally applicable. Their validity must be further tested to verify this premise.

The regressions involving dependent and independent variables of different mode-time groups are summarized in Tables Al2 to Al5 of Appendix A. The precision exhibited was not as good as in the homogeneous cases. The differences were slight in all cases, however, and probably easily rationalized in light of survey cost savings. The general trends of all parameters are similar to those observed in the homogeneous cases. Some discrepancies which are unexplainable may probably be best attributed to anomalies of the data or analysis. The important fact is that the generally excellent predictivity is exhibited in these situations which imply more feasible survey procedures.

The implications of these results are important to the selection of survey procedures. Based on the increase in $R^{2}$ and the decrease in standard error of estimate and coefficient of variation, the order of survey complexity follows directly. 
The same progression follows for all mode and time groups. A home-based work, vehicle trip survey requires employer records of those employees driving to work. A home-based work person trip survey requires tabulation of all employee records and a tabulation regarding mode. An all work trip (home- and non-home-based) survey requires interview of drivers or all employees, depending on the mode of 1nterest. Extension to include shopping trips requires, in addition, a license plate survey at shopping districts. Decisions on the form of any revised survey procedure are best made according to costs and feasibility. This research has provided the study director with alternative procedures for replacing the costly homeinterview survey. It must be his decision, in light of the communty conditions, to select a feasible alternative which will provide valid travel patterns at the least possible cost. 


\section{CHAPTER VII. APPLICATION OF THE METHOD}

The techniques discussed in the preceding chapters were proposed to eliminate the need for a home-interview survey to establish the patterns of urban travel. It is the purpose of this chapter to suggest how the techniques proposed from the results of Chapter VI would be implemented in the urban transportation planning process. It is important to carry the results of the revised survey procedure through the stages of the planning process in order to demonstrate the revisions which must be made therein to account for the different data.

The geographical organization can proceed in a normal manner, defining the study area, zones and the transportation networks. The land use survey required would be limited for all classes except residential to defining the location, size of plot and extent of development. Since work is the only purpose group to be surveyed and employment is the generation parameter for work trips, there is no need to collect conventional land use data. Employment will be obtained at the time of the workplace contact. The economic base and population studies would be executed as usual. It is possible that further refinements of the proposed approach might require more detail from these socio-economic surveys. The 
truck-taxi surveys would be executed in typical fashion. The external survey would be performed as usual but would eliminate all internal terminating trips for non-work purposes.

The major revisions concern the home-interview survey. If an all-purpose, peak hour analysis has been selected, the only revision will be elimination from the home-interview data of all but peak hour (as defined by the user) trips. Use of a work trip oriented approach would imply complete elimination of the home-interview. Further decisions on procedure rest on the extent of analysis desired. A home-based work oriented analysis requires only examination of employer records. The basic information to be obtained is the adaress of the employee's residence. Additional information regarding salary and family characteristics might also be obtained to refine the analysis and do special studies, providing necessary permission can be obtained. If the analysis is to consider trips during the entire day, all employees would be tabulated. A peak hour orientation would require definition of the shift or reporting (or leaving) time of the workers, selecting only those which would necessarily be traveling during the peak hour chosen. Use of vehicle trips only, or a need to determine mode for all travelers would employ a procedure such as having employees place their time cards in different bins, according to their travel mode. An alternative approach would involve mode tabulation for each worker by either supervisors or survey personnel. 
Decision to include all work trips in the analysis would require a more involved survey. In essence, each worker would have to be interviewed in some manner. The interviews could be conducted one at a time by either supervisors or study staff personnel. Alternatively the workers could be surveyed by use of a questionnaire. Direction in completion of the questionnaire could be given either locally by monitors or to the entire work force simultaneously by means of a public address system. The basic data sought would be the address of the origin and destination of all trips made to or from the employment place. A "contact" survey could also obtain such information as mode, time, and routing of the work trip as well as attitudes regarding work travel. Use of a questionnaire is less satisfactory than an interview, but it is also less expensive and time consuming (Wohl, et al., 1959). The balance in difficulty and cost would have to be weighed against utility. Further extension of the proposed procedures to include shopping travel would involve tabulation of arrivals at major (defined by the analyst) shopping areas. Use of only home-based shopping trips by vehicles would merely require tabulation of license plates. This could include the usual parking study as an adjunct. Including all home-based shopping person trips would require tabulation of the number of persons arriving in each vehicle. Shopping trips by transit would be prohibitively difficult to survey. 
A comparison of costs to obtain data would be of value at this point. Table 9 indicates the relative cost in hours of three approaches being discussed. The figures are based on a coding procedure developed at Purdue that would be an appropriate approach to handing employee records only (Zimmerman, 1967). The rate for employment place interviews was estimated at 20 per hour. One last note would be in regard to another alternative to the above proposed technique. Use of a city directory could provide similar information at a further cost reduction (Udy, 1962).

Depending on the survey procedure and approach selected, expansion of the survey results might be necessary in order to obtain true traffic volumes. The expansion could be made according to typical figures which have been shown to be quite stable and reliable (see Lapin, Chapter II). Alternatively the expansion could be based on figures from microsample home-interviews or questionnaires sent home with workers interviewed in the principal survey. The regression coefficients developed in the previous analysis may provide at least a good first approximation to expansion factors. The results of the survey or the expansion, as applicable, would be assigned to the street network in the same manner as usual, followed by the appropriate capacity restraint iterations. Development of the distribution model would use work and residential trip ends developed from the survey in the same manner as usually employed. The model results would be expanded by the traffic volume factors discussed previously 
Table 9. Relative Cost in Hours of Three Alternative Survey Procedures.

\begin{tabular}{lcr} 
& Lafayette & Indianapolis \\
\hline $\begin{array}{l}\text { Coding Employee Records } \\
(60 \text { per hour })\end{array}$ & 353 & 5,627 \\
$\begin{array}{l}\text { Employee Interviews } \\
(20 \text { per hour })\end{array}$ & 1,059 & 16,880 \\
$\begin{array}{l}\text { Home- Interview } \\
(5 \text { percent sample }) \\
(1,842 \text { hours each })\end{array}$ & 1,641 & 20,598 \\
\end{tabular}

*Based on Data from Austin, Texas, Transportation Study, Published by the Texas Fighway Department. 
in order to perform screenline and cordon checks where appropriate.

Development of the future travel potential would, of course, be based on the economic base and population studies. These would be combined with the existing land use information to determine the future pattern of employment generating activities. After allocating employment and residential activities, the work trips would be distributed as before. The traffic expansion factors, modified to account for changes over time, are then used to obtain total volumes. These are assigned to the comitted network and the assignments are adjusted as necessary by capacity restraint. The deficiencies are then taken into consideration in developing the new facilities of the target year transportation system. 


\section{CHAPTER VIII. CONCLUSIONS}

From the previous analysis, several conclusions can be drawn regarding the proposed hypotheses and related relationships:

1. The variance analysis proved to be of considerable value in development of the regression relationships.

2. The travel patterns of home-based work trips represent an excellent approximation to the travel patterns of trips of all purposes for peak hour or total daily travel.

3. Use of all work trips improves the above relationship slightly.

4. Use of shopping trips in adition to work trips further improves the representivity slightly.

5. The relationships discussed above were appropriate for travel by all highway oriented modes. Use of highway person trips showed marginally better results than auto driver trips.

6. The improved results observed in moving from statement 2 to statement 5 are aue to the increased information obtained from the survey. The marginal improvements must be weighed against the increased cost due to the more extensive survey procedure. 
7. Travel for all purposes during a peak hour showed excellent results in representing travel for all purposes during the entire day.

8. Total day travel for the work purpose was a good representative of the peak hour travel by all purposes.

9. Typical results of the regression analyses performed on IRTADS data are shown below.

a. Predicting all purpose travel using all work and home-based shopping trips, for peak hour vehicle travel on the entire highway system:

$$
R^{2}=0.9911 \quad \text { S.E. }=45 \quad \text { C. V. }=0.099
$$

I. Predicting all purpose travel using all work and home-based shopping trips, for the total day vehicle travel on the entire highway system: $R^{2}=0.9875 \quad$ S.E. $=204 \quad$ C.V. $=0.106$

c. Predicting all purpose peak hour vehicle travel using all work and home-based shopoing person trios for the total day on the entire highway system:
$R^{2}=0.942^{2}$
S.E. = 114
C.V. $=0.250$

d. Predicting total day vehicle travel for all purposes using total day person trips for all work and home-based shopping purposes, on the freewey and arteriel classes:

$$
R^{2}=0.9705 \quad \text { S.E. }=583 \quad \text { C.V. }=0.106
$$

10. The data used in these analyses were samples from all work trips. The proposal survey procedures would include only trips to major employment concentrations. 
CHAPTER IX. RECOMMENDED EXTENSIONS AND RESEARCH

3ased on the preceding analyses and conclusions, the following further study is recomended:

1. The regression coefficients of the prediction equations established for the IRADS data should be tested on data from other urban areas. If no significant differences are found, the survey expansion procedure would be greatly simplified.

2. The representivity of the work trip for all purpose travel should be examined in different size urban areas in order to define the effect of size on representivity.

3. The surveys proposed in this research should be executed simultaneously with a traditional travel survey in order to define the relative strengths of each approach.

4. Further investigations should be made of the effect of characteristics of the place and type of employment on the observed relationships in order to improve the estimates of work trip generation. This seems appropriate because of the importance that work travel will assume in prediction of total urban travel. 
5. Study should be made of the effect the number of the employees in each work place has on the observed relationship in order to better define the extent of survey required.

6. More detailed investigation should be made of the implications of various types of industrial and residential land use locations since this will become highly important in planning based on the procedure proposed here.

7. A study should be made of the effect on prediction of total travel by using only those trips to major employment concentrations. These effects should be established for urban areas of varying size. 
LIST OF REFERENCES 


\section{LIST OF REEERENCES}

Adams and Mackesey, 1955; Adams, L. P., and Mackesey, T. W. Commuting Patterns of Industrial Workers, Cornel1 University Housing Research Center, 1955.

Bartlett, 1937; Bartlett, M. S., "Some Examples of Statistical Methods of Research in Agriculture and Applied - Biology," Journal of the Royal Statistical Society, Volume 4,1937 .

Beyer, 1951; Beyer, G. H., Housing and the Journey to Work, Cornell University Agricultural Experiment station, 1951.

Bouchard and Pyers, 1965; Bouchard, R. J., and Pyers, C. E., "Use of Gravity Model for Describing Urban Trave1," Record 88, Highway Research Board, 1965.

Box, 1954; Box, G. E. P.. "Some Theorems on Quadratic Eorms Applied in the Study of Analysis of Variance Problems," Annals of Mathematical Statistics, June, 1954.

Bureau of Public Roads, 1964; Bureau of Public Roads, U. S. Department of Comerce, Traffic Assignment Manua 1, Washington, D. C., U. S. Government Printing Office, 1964.

Bureau of Public Roals, 1965; Bureau of Public Roads, U. S. Department of Commerce, Calihrating and Testing A Gravity Model for Any Size Urban Area, Washington, D. C., U. S. Government Printing Office, 1965.

Bureau of Public Roads, 1966a; Bureau of Public Roads, U. S. Department of Transportation, Preamble to a generally issued set of Research Problem Statements.

Bureau of Public Roads, 196fb; Bureau of Public Roads, U. S. Department of Transportation, Personal communication regarding census questions.

Campbe11, 1960; Campbe11, E. W., discussion in "Critique of Home-Interview Type O-D Surveys in Urban Areas," Bulletin 253, Highway Research Board, 1960. 
Carroll, 1950; Carroll, J. D., Jr., Home-Work Relationships of Industrial Workers, Unpublished Ph.D. Thesis, Harvard University, 1950.

Carroll, 1952; Carroll, J. D., Jr., "The Relations of Homes to Work Places and the Spatial Pattern of Cities," Social Forces, Volume XXX, March, 1952.

Cherniak, 1960; Cherniak, H. H., "Critique of Home-Interview Type O-D Surveys in Urban Area, "Bulletin 253, Highway Research Board, 1960.

Curran and Stegmaier, 1958; Curran, F. B., and Stegmaier, J. T., "Travel Patterns in 50 Cities," Bulletin 203, Highway Research Board, 1958.

Gerlough, 1955; Gerlough, D. L., Poisson and Traffic, Saugatuck, Connecticut, The Eno Foundation for Highway Traffic Control, 1955.

Glass, 1956; Glass, R., "London on the Move," London Times, June 18-19, 1956 .

Hill and Dodd, 1966, Hill, D. M., and Dodd, N., "Studies of Trends and Travel Retween 1954 and 1964 in a Large Metropolitan Area," Record 141, Highway Research Board, 1966 .

Hixon, 1961; Hixon, C. D., "An Analysis of Urban Travel Mimes and Traffic Volume Characteristics," Eulletin 30?,

Eighway Research Board, 1961.

Hoover and Vernon, 1962; Hoover, E. M., and Vernon, R., Anatomy of a Metropolis, Garden City, New York, Doubleday and Company, 1962.

Knox, 1962; Knax, N. H., "A Simplified Traffic Model for Small Cities," Traffic Quarterly, Volume 16, July, 1962.

Lapin, 1964; Lapin, H. S., Structuring the Journey to Work, Philadelphia, University of Pennsylvania Press, 1964.

Liepmann, 1944; Liepmann, K. K., The Journey to Work Its Significance Eor Industrial and Community Life, New

Loewenstein, 1965; Loewenstein, L. K., Residences and Work Places in Urban Areas, New York, The Scarecrow Press, Inc., 1965 .

London Transit System, 1949; London Travel Survey 1949 , London Transport Executive, 1950. 
Lynch, 1960; Lynch, J. T., discussion in "Critique of HomeInterview Type O-D Surveys in Urban Areas," Bulletin 253, Highway Research Board, 1960.

Mitchell and Rapkin, 1954; Mitchell, R. B., and Rapkin, C., Urban Traffic, A Function of Land Use, New York, Columbia University Press; 1954.

Moore, 1957; Moore, E. F., "The Shortest Path Through a Maze," Proceedings, International Symposium on the Theory of Switching; Harvard University, 1957.

Osofsky, 1959; Osofsky, S., "The Multiple Regression Method of Forecasting Traffic Volumes," Traffic Quarterly, Volume 13, July, 1959.

Ostle, 1962; Ostle, 3.. Statistics in Research, Ames, Iowa, The Iowa state University Press, 196?.

Parkes, 1941; Parkes, C. B., Bourneville Village Trust, When We Build Again, London, Eeorge Allen and University, Ltd., 1941.

Shuldiner and Oi, 1952; Shuldiner, P. W., and Oi, W. Y.. An Analysis of Urban Travel Demands, Evanston, Illinois, Northwestern University Press, 1962.

Smith, 1961; Wilbur Smith and Associates, Future Highways and Urban Growth, comissioned by the Automobile Manufacturers Association, New Haven, Connecticut, 1961.

Spiegelman and Duke, 1962; Spiegelman, R. G., and Duke, K. E., "Projecting Travel Demand for Urban Transportation studies," Traffic Quarterly, Volume 17, July, 196 ?.

Stewart, 1948; Stewart, J. Q., "Demographic Gravitation: Evidence and Application," Sociometry, Volume XI, February, 1948 .

Sullivan, 196?: Sullivan, S. W., "Variations in Personal Travel Habits by Day of Week, "Record 4l, Highway Research Board, $196^{2}$.

Turner, 1967; Turner, F. C., Speech to Western Association of State Highway Officials; Honolulu, Hawaii, July 11, 1967.

Udy, 1962; Udy, S. H., Jr., "Occupation, Commuting, and Limited Access Highway Use," Bulletin 347, Highway Research Board, 1962 .

Ullman, 1956; Ullman, E. L., "The Role of Transportation and the Bases for Interaction," in Man's Role in Changing the Face of the Earth, Chicago, University of Chicago Press, 1956. 
APPENDIX A 
U. S. Congress, 1939; Toll Roads and Free Roads; House Document No. 272; 76th Congress; 1939.

U. S. Congress, 1944; Federal Aid Hiahwav Act of 1944: Public Law 78-840; 78th Congress, second Session, 1944.

U. S. Congress, 1952; Federal Aid Highivay Act of 1952; Public Law 82-413, 82nd Congress, Second Session, 1952.

U. S. Congress, 1956; Federal Aid Highway Act of 1956; Public Law 84-627; 84th Congress; Second Session; 1956.

U. S. Congress, 1962; Federal Aid Highway Act of 1962; Public Law 87-866, 87th Congress, Second Session; 1962 .

U. C. L. A. 1966a; University of California at Los Angeles, Health Sciences Computino Facility, Computer Program "BMD-2V, Analysis of Variance for a Factorial Design," March 10, 1966.

U. C. L. A. 1966b; University of California at Los Angeles, Health Sciences Computing Facility, Computer Program, "BMD-2R , Stepwise Regression," May 2, 1966.

Voorhees, 1955; Voorhees, A. M., "A General Theory of Traffic Movement," Proceedings, Institute of Traffic Engineers, 1955.

Voorhees, 1958; Voorhees, A. M., "Forecasting Peak Hours of Travel," Bulletin 203, Highway Research Board, 1958.

Vocrhees, et. al., 1966; Voorhees, A. M., Bellomo, S. J., Schofer, J. L., and Cleveland, D. E., "Factors in Work Trip Lengtrs;" Record 141, Highway Research Board, 1966 .

Westergaard, 1957; Westergard, J., "Journeys to Work in The London Region," The Town Planning Review, April, 1957.

Whitmore, 1965; Whitmore, R. E., Graphical and Mathematical. Investigation of the Differences in Traveltime Factors for the Gravity Model Trip Distribution Formula in Several Specific Urban Areas, Knoxville, Civil Engineering Department, University of Tennessee, 1965.

Williams and Robertson, 1965; Williams, T. E. H., and Robertson, D. M., "Traffic Generated by Households; Peak Period," Traffic Engineering and Control, Volume 6, March, 1965 . 
Wohl, et. al., 1959; Wohl, M., Bone, A. J., Rose, B., "Traffic Characteristics of Massachusetts Route 128," Bulletin 230, Highway Research Board, 1959.

Wynn, 1959; Wynn, F. H., "Studies of Trip Generation in the Naticn's Capital, 1956-58," Bulletin 230, Highway Research Board, 1959.

Zimmerman, 1967; Zimmerman, M. A., "The Journey to Work," a paper submitted for course CE612 Urban Land Use Planning, at Purdue University, May, 1967. 
APPENDIX A

\section{Abbreviation Key}

Dependent Variables (Y)

DV

DP

HV

HP

\section{1}

Total Day Vehicle Trips

Total Day Person Trips

Peak Hour Vehicle Trips

Peak Hour Person Trips

Independent Variables (X)

Home-Based Work, Vehicle, Total Day

Non-Home-Based Work, Vehicle, Total Day

Home-Based Work, Person, Total Day

Non-Home-Based Work, Person, Total Day

Home-Based Work, Vehicle, Peak Hour

Non-Home-Based Work, Vehicle, Peak Hour

Fiome-Based Work, Person, Peak Hour

Non-Home Based Work, Person, Peak Hour

Home-Based Shop, Vehicle, Total Day

Home-Based Shop, Person, Total Day

Home-Based Shop, Vehicle, Peak Hour

Home-Based Shop, Person, Peak Hour

Freeways

Arterials

Collectors 
FA

Combined Freeways and Arterials

FAC

Combined Freeways, Arterials and Collectors

T4

Freeways, Arterials and Collectors with volume greater than 4000

T3

Freeways, Arterials and Collectors with volume greater than 3000

$\mathrm{T} 2$

Freeways, Arterials and Collectors with volume greater than 2000

T1

Freeways, Arterials and Collectors with volume greater than 1000

$\mathrm{H}$

Home

N

Non

B

Based

W

Work

S

Shop

PAS

Passenger

$\mathrm{OTH}$

other

D

Total Day

$\mathrm{H}$

Peak Hour

V

Vehicle

P

Highway Person

$\mathrm{R}^{2}$

Explained variation

$\Delta R^{2}$

Increase in Explained variation

S. E.

Standard Error of the estimate

C.V.

Coefficient of variation

Bo

Regression Equation Constant

B.

Regression Coefficient of First Variable

${ }^{B}$

Regression Coefficient of Second Variable

5

Regression Coefficient of Third Variable 
Table Al. Analysis of Variance for Travel Volume.

\begin{tabular}{lrrrr}
\hline Factor & $\begin{array}{c}\text { Degrees } \\
\text { of } \\
\text { Freedom }\end{array}$ & $\begin{array}{c}\text { Sum of } \\
\text { Squares }\end{array}$ & $\begin{array}{c}\text { Mean } \\
\text { Square }\end{array}$ & F Ratio \\
\hline M & 2 & $390,696.9$ & $195,348,4$ & $*$ \\
T & 23 & $492,524.0$ & $21,414.1$ & $*$ \\
MT & 5 & $467,009.9$ & $93,402.0$ & $*$ \\
MP & 46 & $227,956.2$ & $4,955.6$ & $*$ \\
TP & 10 & $585,531.9$ & $58,553.2$ & $*$ \\
MTP & 115 & $1,057,252.5$ & $9,193.5$ & $*$ \\
Error & 230 & $752,825.5$ & $3,273.2$ & $*$ \\
& 1,296 & $28,157.0$ & 21.7 & $*$ \\
Total & 1,727 & $4,001,963.9$ & & \\
\end{tabular}

F ratios are not shown because of the obvious significance of every factor and interaction. 
Table A2. Analysis of Variance for Average Trio Length.

\begin{tabular}{|c|c|c|c|c|}
\hline Factor & $\begin{array}{c}\text { Degrees } \\
\text { of } \\
\text { Freedom }\end{array}$ & $\begin{array}{l}\text { Sum of } \\
\text { Squares }\end{array}$ & $\begin{array}{c}\text { Mean } \\
\text { Square }\end{array}$ & F Ratio \\
\hline M & 2 & $4,388.9$ & $2,194.4$ & + \\
\hline$T$ & 23 & $15,708.4$ & 683.0 & * \\
\hline$P$ & 5 & $10,766.2$ & $2,15.3 .2$ & * \\
\hline$M=$ & 46 & $5,261.0$ & 114.4 & * \\
\hline MP & 10 & $1,721.7$ & 173.2 & * \\
\hline$T P$ & 115 & $9,045.9$ & 78.7 & * \\
\hline$M P$ & 230 & $10,649.1$ & 46.3 & * \\
\hline Error & 1,296 & $39,177.6$ & 22.5 & - \\
\hline Total & 1.727 & $96,728.9$ & & \\
\hline
\end{tabular}

${ }^{*}$ E ratios are not shown because of the obvious significance of every factor and interaction. 
Table A?. Kolmogorov-Smirnov Test for Normality Maximum Differences for MOD-2 L.R.I.

\begin{tabular}{|c|c|c|c|}
\hline & Freeways & Arterials & Collectors \\
\hline 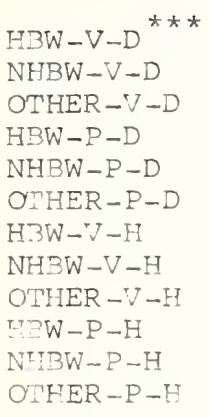 & $\begin{array}{l}0.0845 \\
0.1185 * \\
0.0448 \\
0.1024 \\
0.0688 \\
0.0313 \\
0.0974 \\
0.0961 \\
0.0670 \\
0.1061 \\
0.1953 * \\
0.0348\end{array}$ & $\begin{array}{l}0.0571 \\
0.0296 \\
0.0371 \\
0.0621 \\
0.0911 * \\
0.0443 \\
0.0538 \\
0.0624 \\
0.0336 \\
0.0546 \\
0.2012 * \\
0.0458\end{array}$ & $\begin{array}{c}0.0475^{*} \\
0.0772^{*} \\
0.0641 * \\
0.0490^{*} \\
0.4398^{*} \\
0.0420^{*} \\
0.0812^{*} \\
0.1770^{*} \\
0.1016^{*} \\
-- \\
--\end{array}$ \\
\hline SAMPLE & 218 & 529 & 1793 \\
\hline
\end{tabular}

Significant at $a=0.01$.

** Fests made on square root transformed data.

***

See page 105 for abbreviation key. 


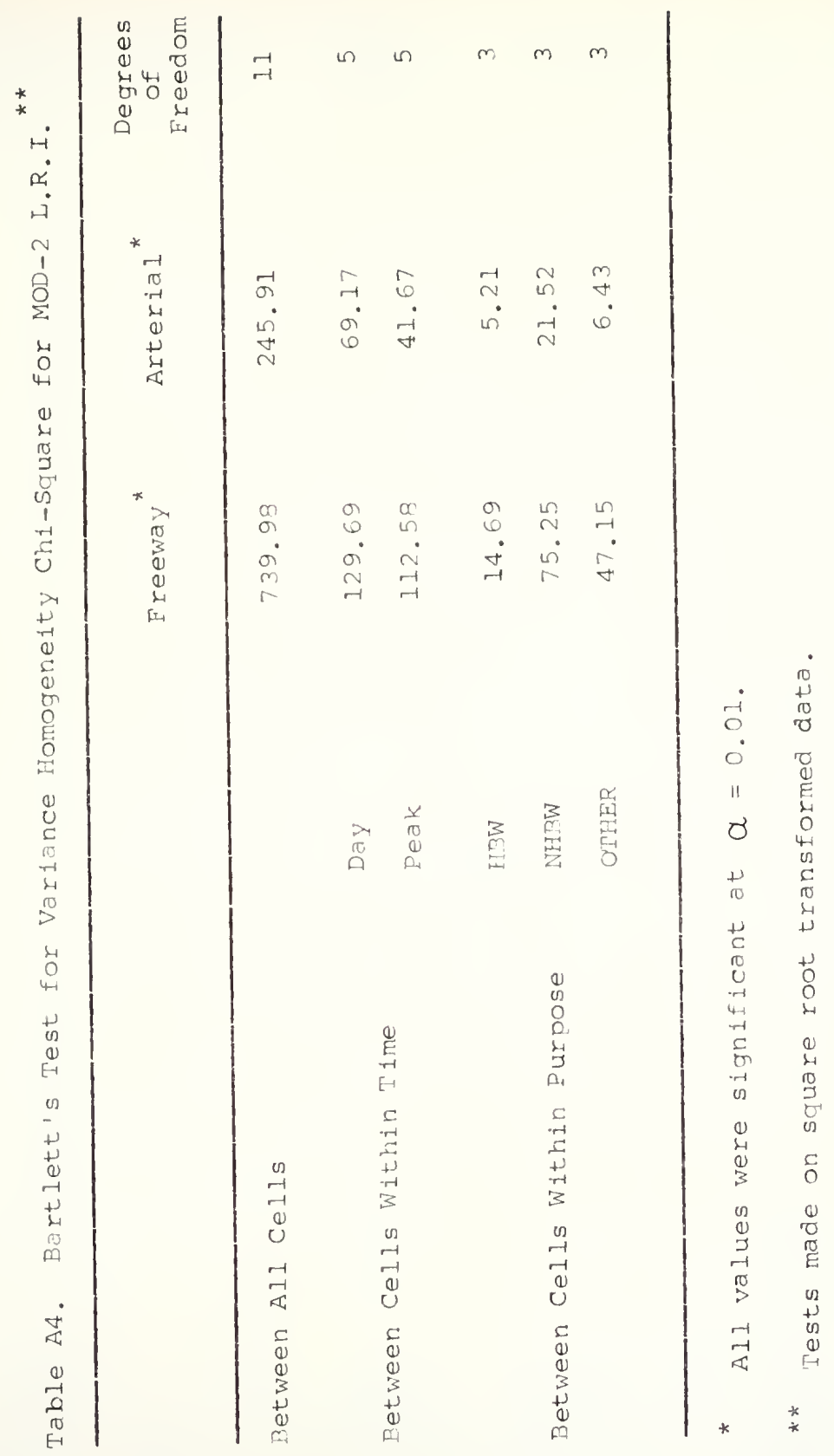




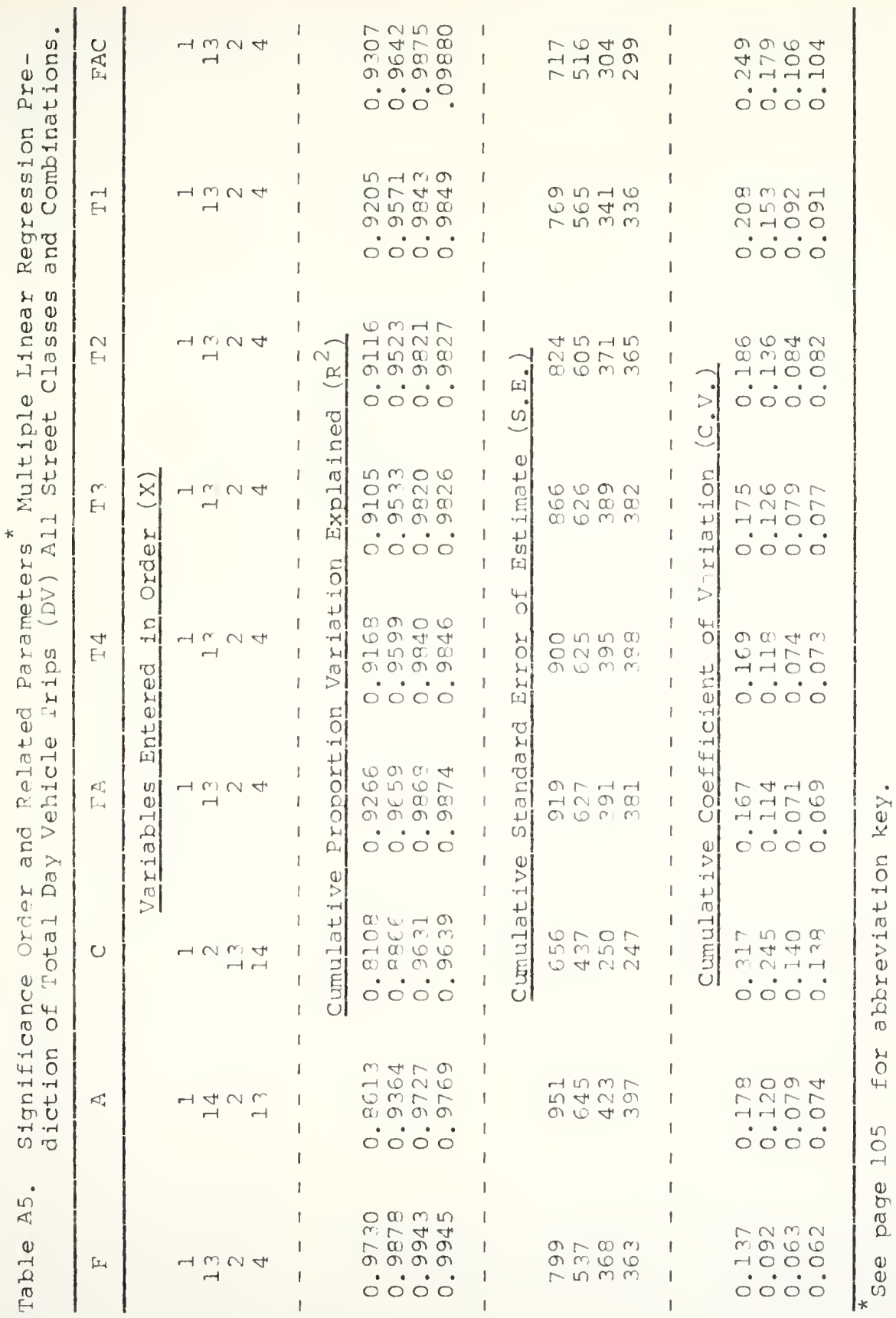




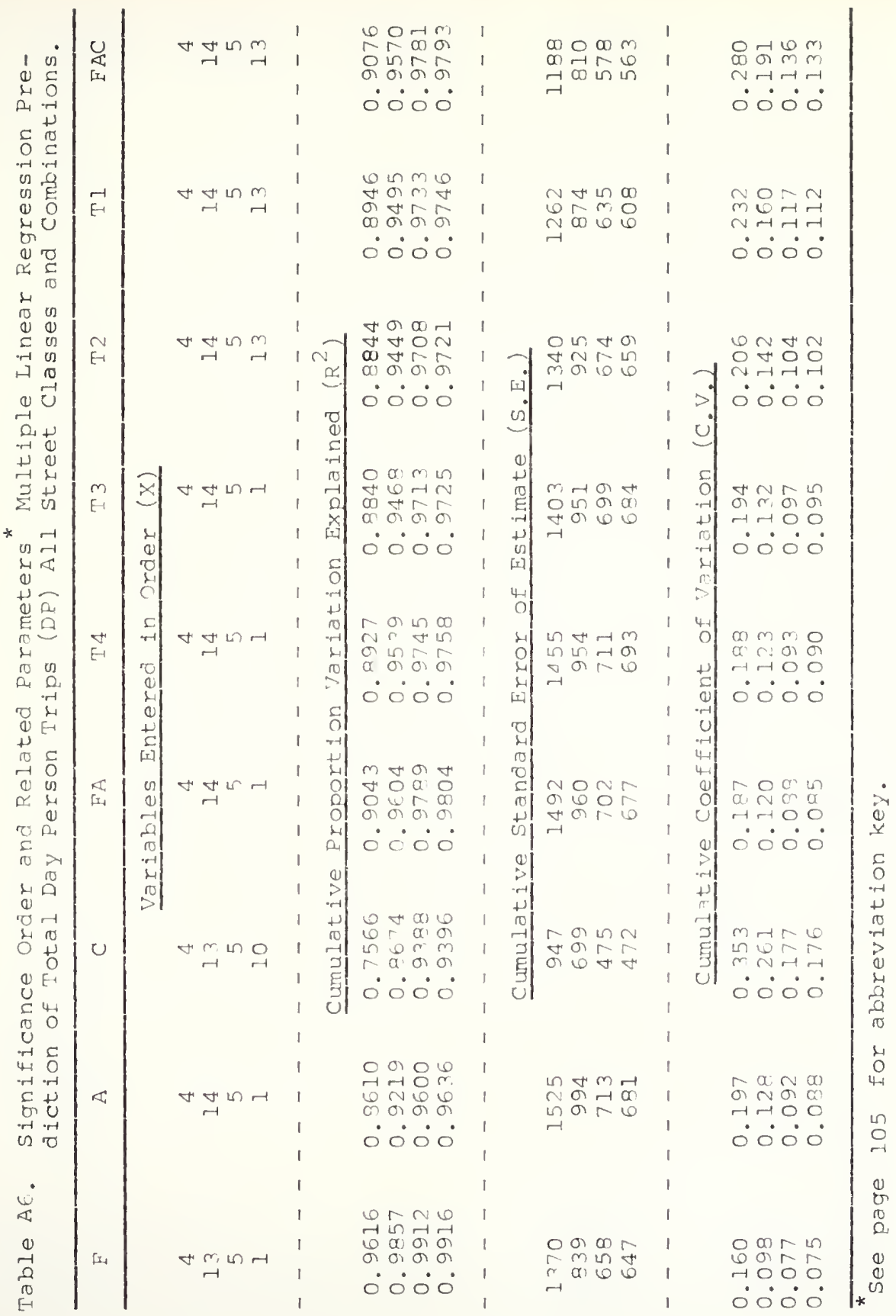


113

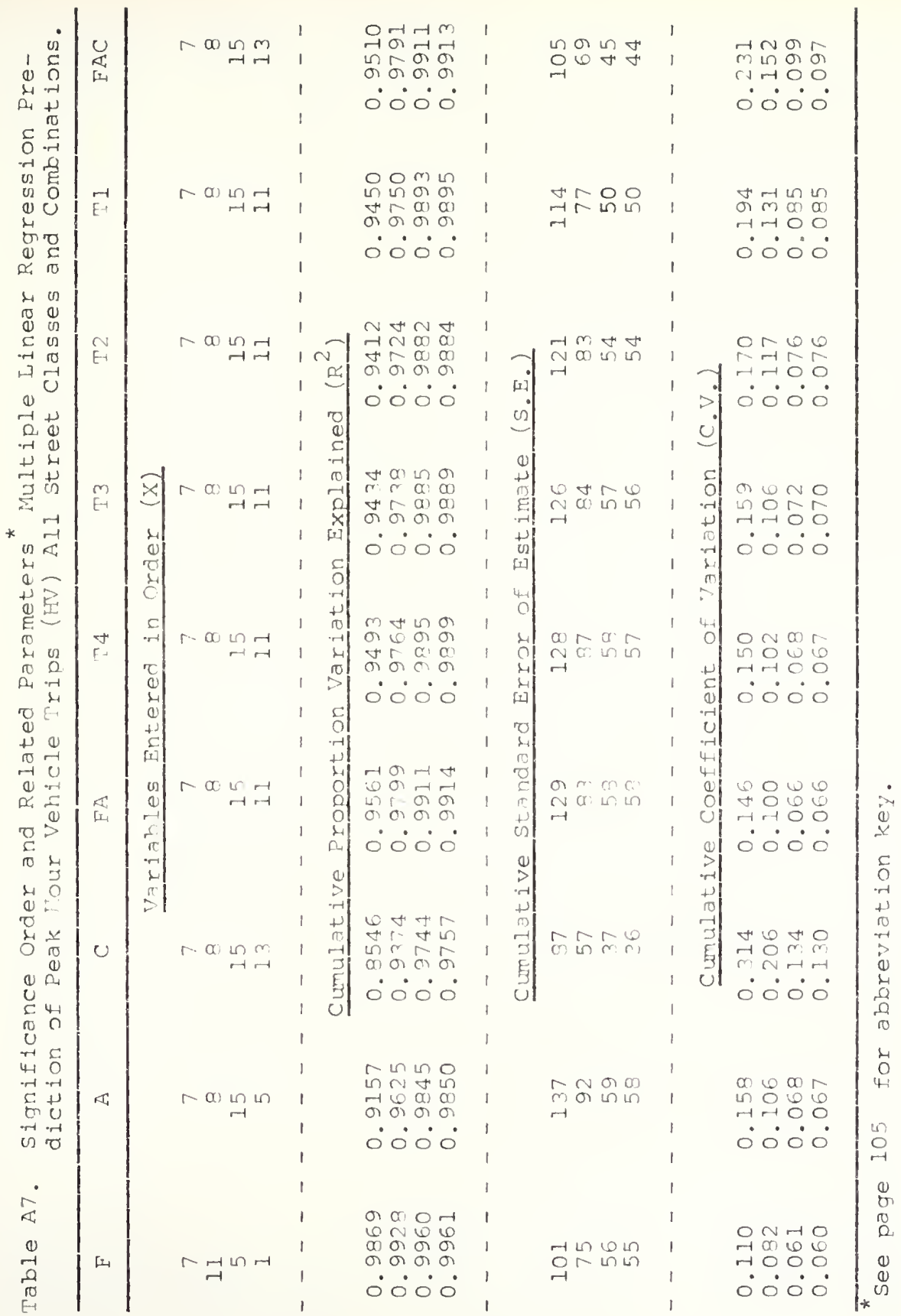




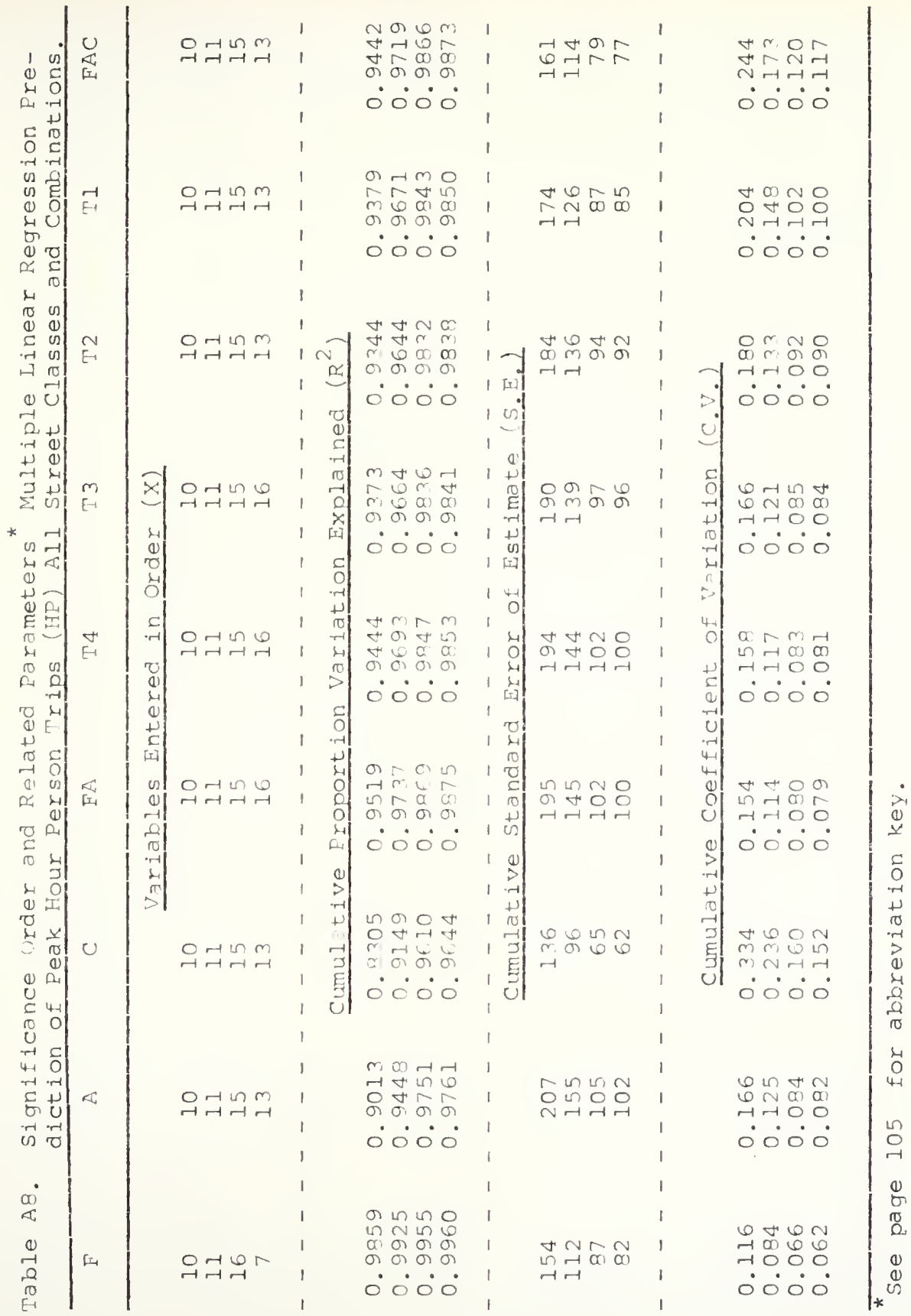




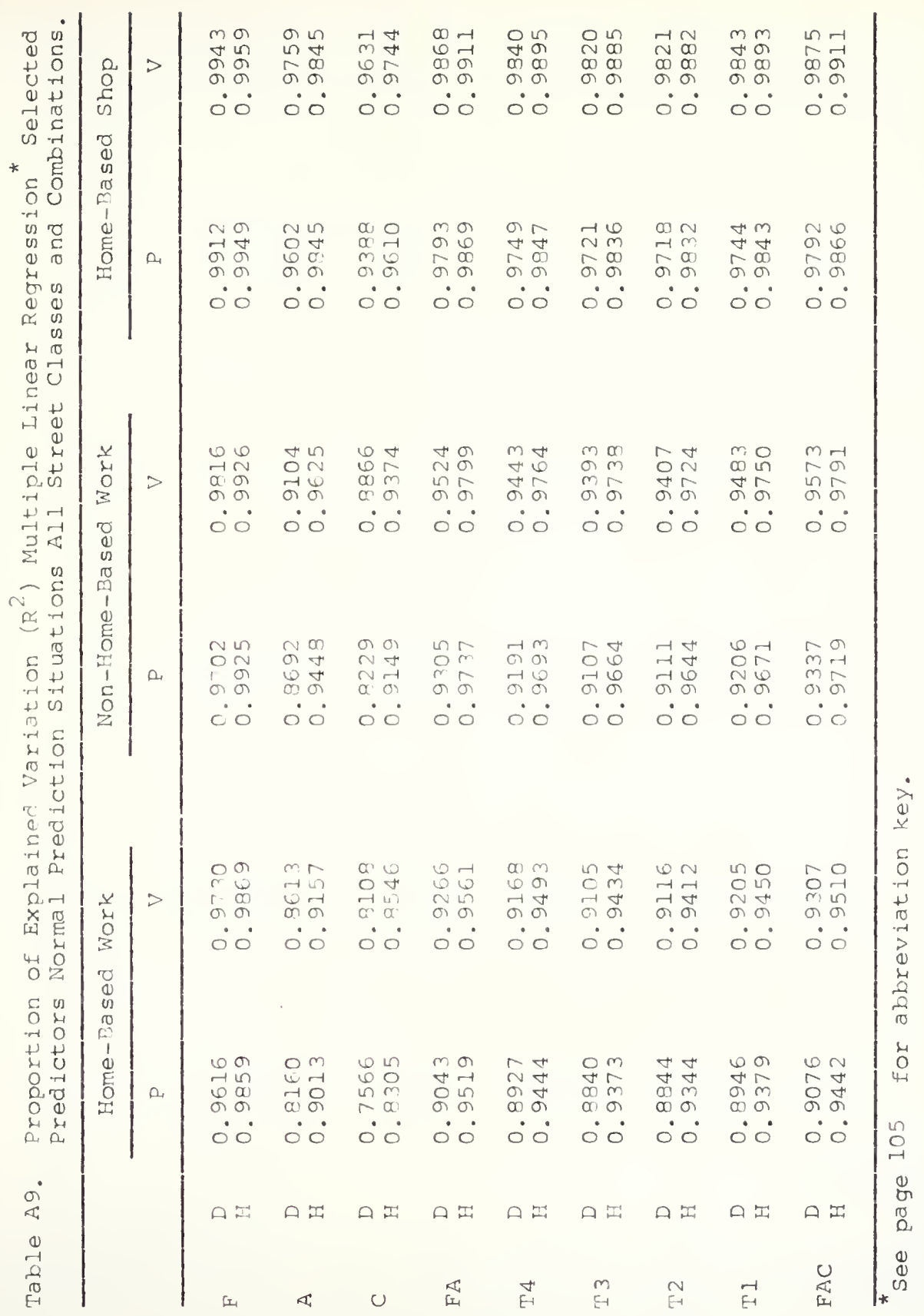




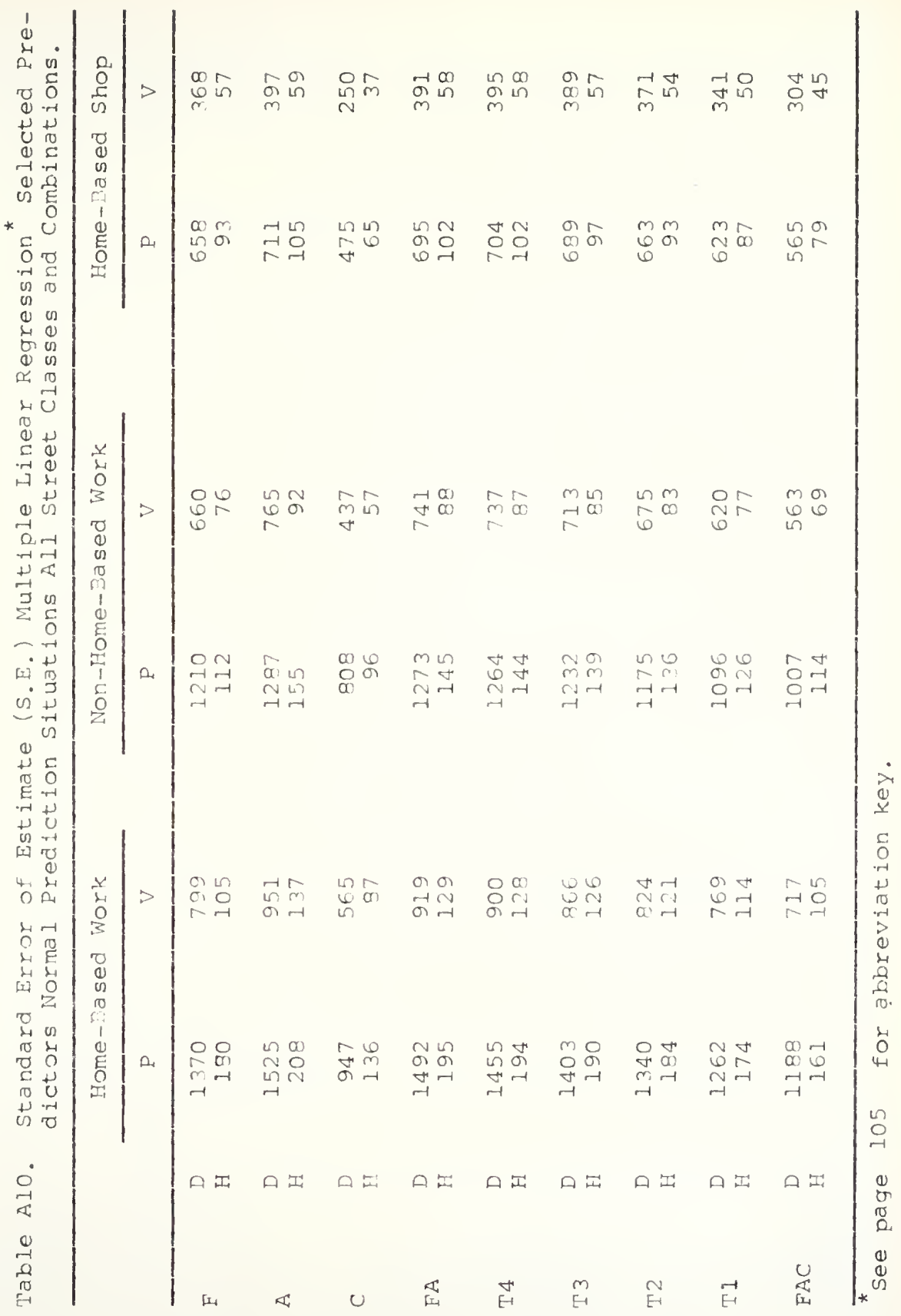




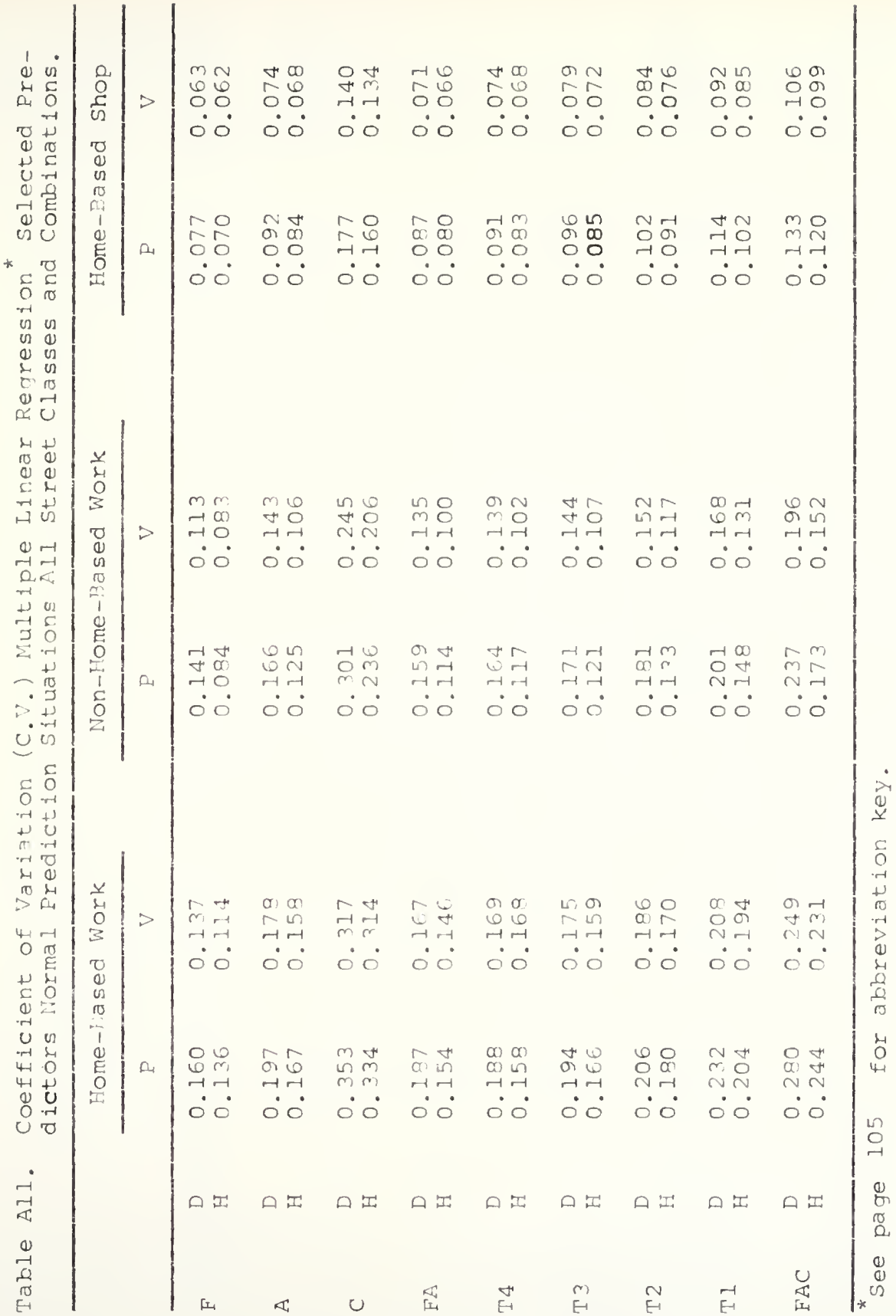




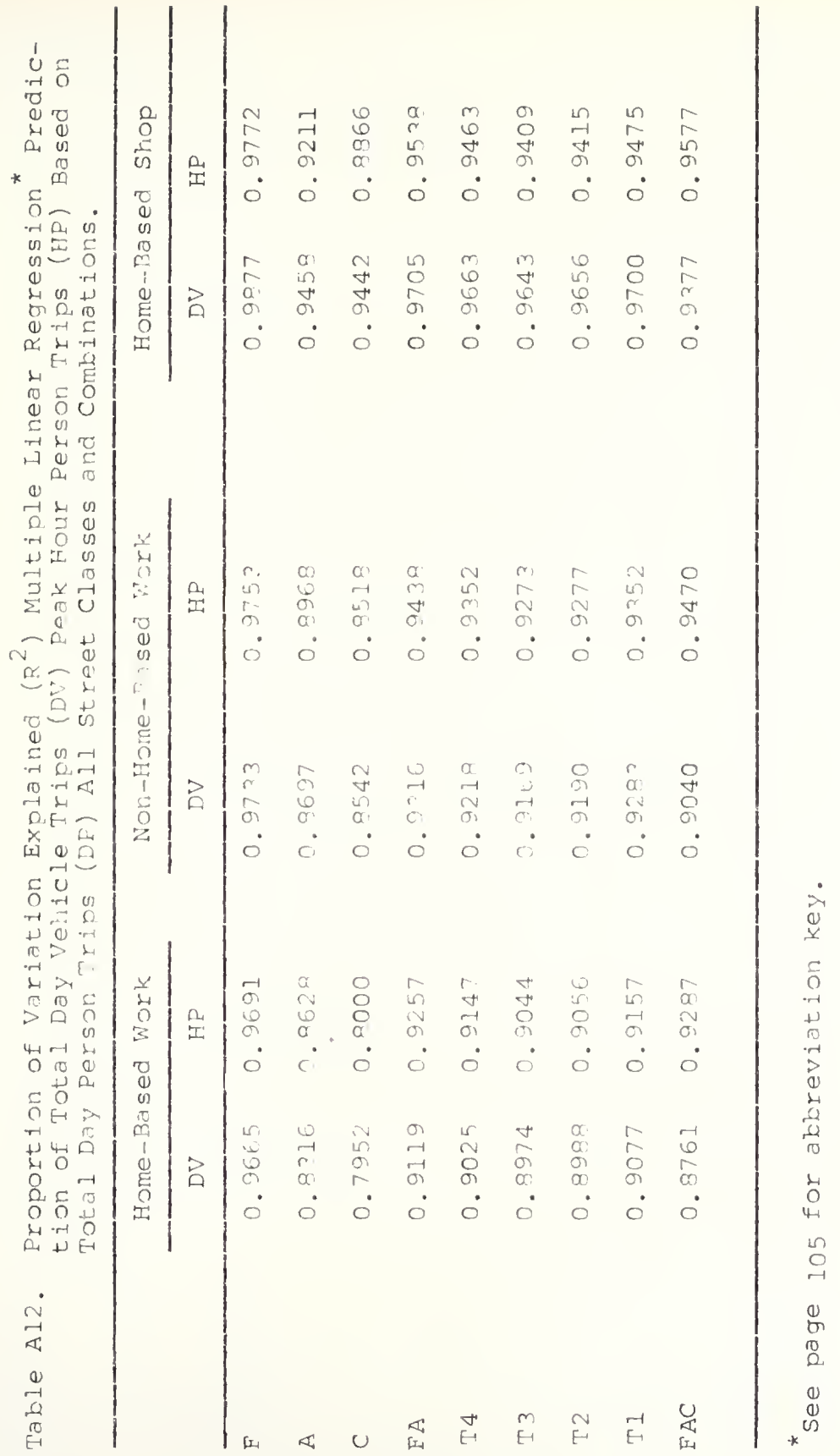




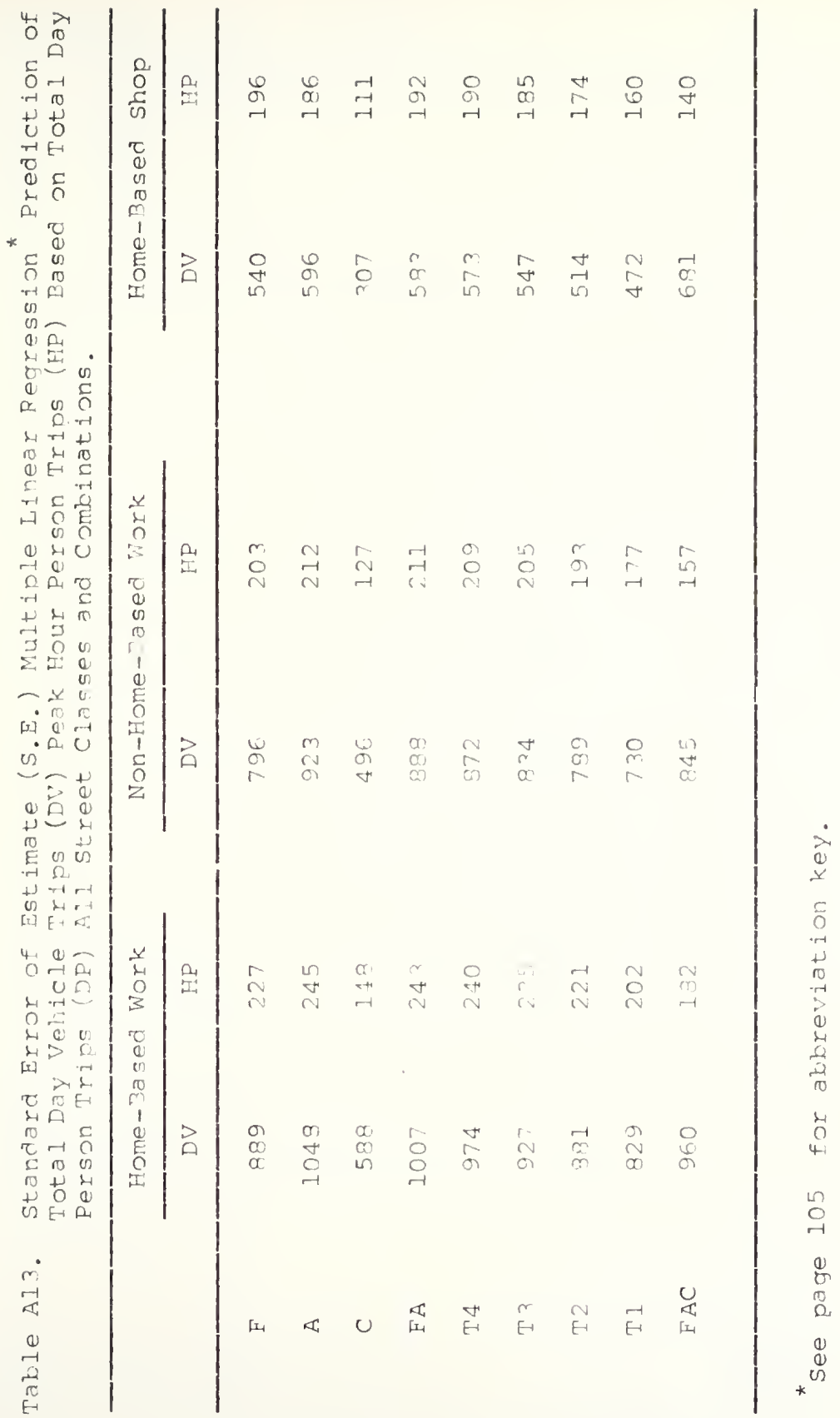




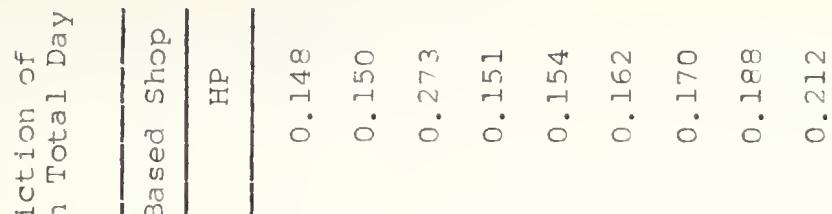

कृ

म 0 * 0 |

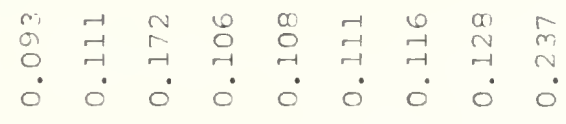
○

ง)

U日

बढ

点

(1) 0.7

Q⿻

L 140

(1) $ᄃ \stackrel{2}{2}$

तन

$\begin{array}{lll}4 & 4 & 0\end{array}$

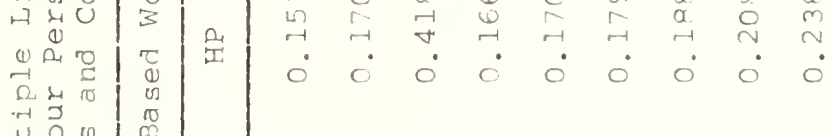

H

\begin{tabular}{lll|l}
-1 & 1 & 0 & 1 \\
3 & 0 & 0 \\
3 & $x$ & 01 & 0
\end{tabular}

$\sum \begin{array}{ll}x & 0 \\ 10 & \pi\end{array}$

- घu

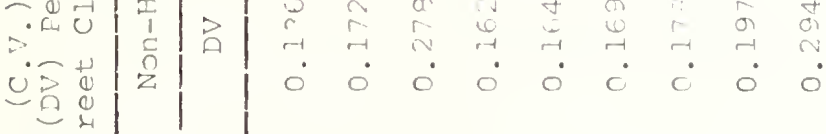

可以范

$\therefore 8$

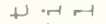

$C$
-1

$\begin{array}{rll}4 & & -1 \\ \pi & 0 & 0\end{array}$

$>$ म

$\because \subseteq$

$\begin{array}{rll}0 & 0 \\ > & 0\end{array}$

$\sum_{2}>-1$

$\underset{0}{\pi} \mathrm{F}$

$4 \rightarrow C$
फ

प1 10 on

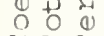

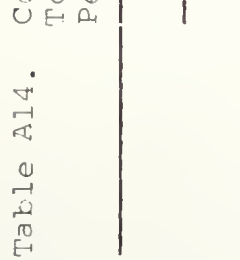

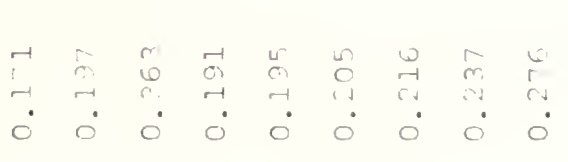

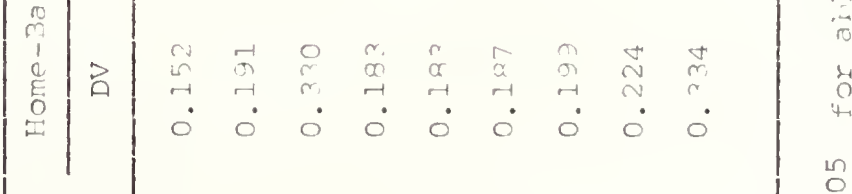

$\dot{\Delta}$

i)

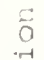

$+$

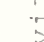

2

范

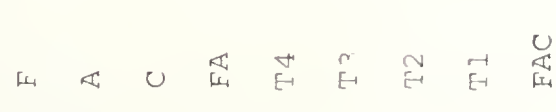

$\underset{-1}{10}$

0
品
0

0
$*$
$*$ 
Table Al5. Proportion of Variation Explained $\left(R^{2}\right)$ Multiple Linear Regression "Prediction of Peak Hour Vehicle Trips (HV) Three Special Prediction Situations All street Classes and Combinations.

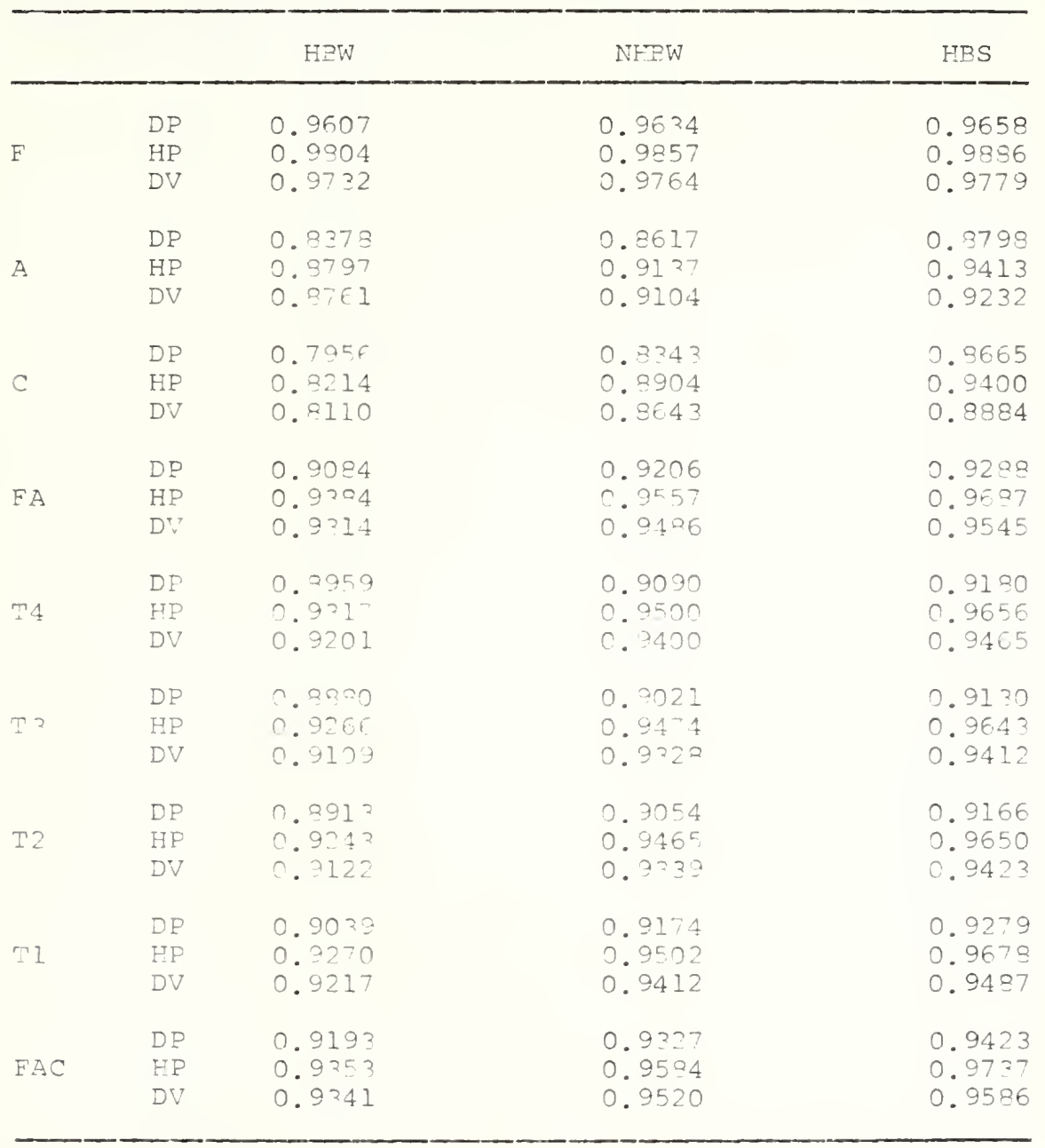

* See page 105 for abkreviation key. 
Table Al6. Standard Error of Estimate (S.E.) Coefficient of Variation (C.V.) Multiple Linear Regression Prediction of Peak Hour Vehicle Trips (HV) Three Special Prediction Situations All Street Classes and Combinations.

\begin{tabular}{|c|c|c|c|c|c|c|c|}
\hline & & & $\begin{array}{l}\text { dard E } \\
(S . E .)\end{array}$ & & Coeff & $\begin{array}{l}\text { ent of } \\
(\mathrm{C} . \mathrm{V} .)\end{array}$ & ation \\
\hline & & $\mathrm{HBW}$ & NHBW & HBS & $\mathrm{HBW}$ & NHBW & $\mathrm{HBS}$ \\
\hline & $\mathrm{DP}$ & 174 & 168 & 163 & 0.189 & 0.183 & 0.177 \\
\hline$F$ & $\mathrm{HP}$ & 123 & 107 & 94 & 0.134 & 0.116 & 0.102 \\
\hline & DV & 144 & 135 & 131 & 0.157 & 0.147 & 0.142 \\
\hline & $\mathrm{DP}$ & 190 & 176 & 164 & 0.219 & 0.203 & 0.189 \\
\hline$A$ & $\mathrm{HP}$ & 164 & 139 & 115 & 0.189 & 0.160 & 0.133 \\
\hline & DV & 166 & 141 & 131 & 0.192 & 0.162 & 0.151 \\
\hline & $D P$ & 103 & 93 & 84 & 0.372 & 0.336 & 0.203 \\
\hline$C$ & $\mathrm{HP}$ & 97 & 76 & 56 & 0.350 & 0.274 & 0.202 \\
\hline & DV & 99 & 94 & 77 & 0.357 & 0.303 & .0278 \\
\hline & $\mathrm{DP}$ & 137 & 174 & 155 & 0.212 & 0.137 & 0.187 \\
\hline $\mathrm{FA}$ & $\mathrm{HP}$ & 152 & 1.30 & 110 & 0.177 & 0.147 & 0.125 \\
\hline & DV & 162 & 140 & $1=2$ & 0.184 & 0.159 & 0.150 \\
\hline & $D P$ & 184 & 172 & $16^{2}$ & 0.215 & 0.201 & 0.190 \\
\hline T4 & $\mathrm{HP}$ & 149 & 127 & $10 E$ & 0.174 & 0.148 & 0.124 \\
\hline & DV & 161 & 140 & 122 & 0.188 & 0.164 & 0.154 \\
\hline & $\mathrm{DP}$ & 177 & $I \in 5$ & 156 & 0.224 & 0.208 & 0.196 \\
\hline$T 3$ & EP & 144 & 121 & 100 & 0.180 & 0.152 & 0.126 \\
\hline & DV & $I \subseteq ?$ & 137 & 129 & 0.190 & 0.172 & 0.161 \\
\hline & $\mathrm{DP}$ & $1 \in 5$ & 154 & 145 & 0.232 & 0.217 & 0.204 \\
\hline $\mathrm{T} 2$ & $\mathrm{HP}$ & 128 & 116 & 94 & 0.194 & $0.16 ?$ & 0.122 \\
\hline & DV & 142 & 129 & 120 & 0.208 & 0.182 & 0.169 \\
\hline & DP & 151 & 129 & 130 & 0.256 & 0.236 & 0.221 \\
\hline $\mathrm{Tl}$ & $\mathrm{HP}$ & 121 & 108 & 87 & 0.222 & 0.183 & 0.148 \\
\hline & DV & 136 & 118 & 110 & 0.231 & 0.200 & 0.187 \\
\hline & $\mathrm{DP}$ & 135 & 123 & 114 & 0.297 & 0.270 & 0.250 \\
\hline FAC & $\mathrm{HP}$ & 121 & 97 & 77 & 0.266 & 0.213 & 0.169 \\
\hline & DV & 122 & 104 & 96 & $0.26 \mathrm{a}$ & 0.228 & 0.211 \\
\hline
\end{tabular}

* See page 105 for abbreviation key. 


\section{APPENDIX 8}

等

严

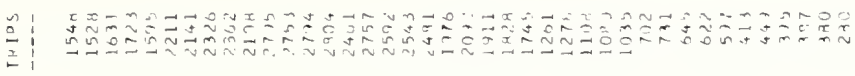

萑

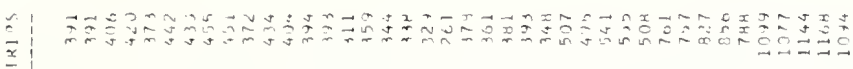

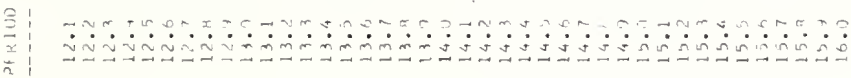

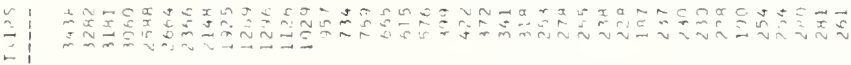

葆

定

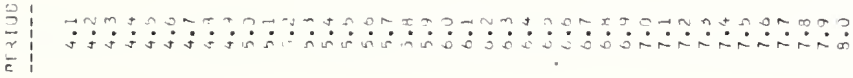

全: -

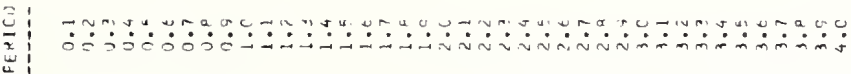




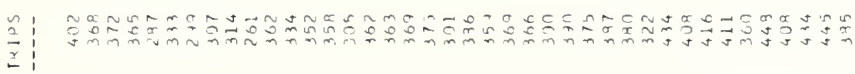

O

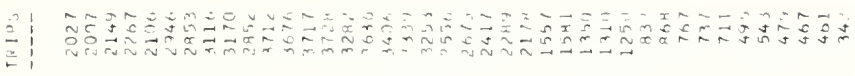

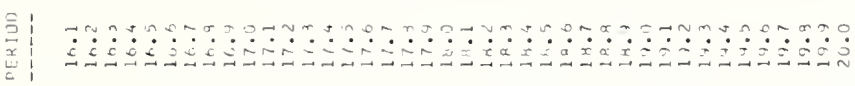

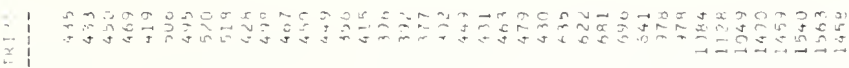

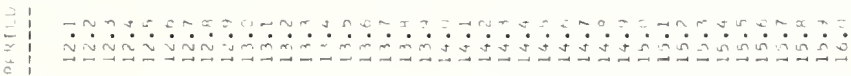

(1)

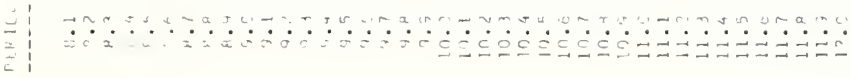

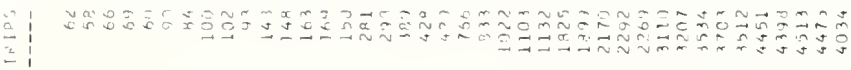

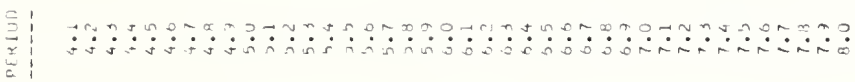

$\hat{2}$

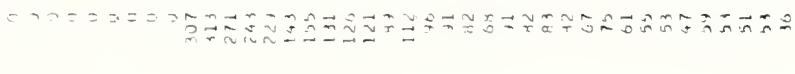

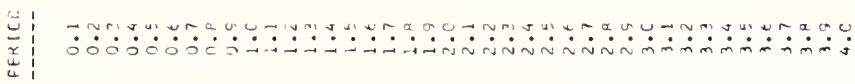


APPENDIX B 


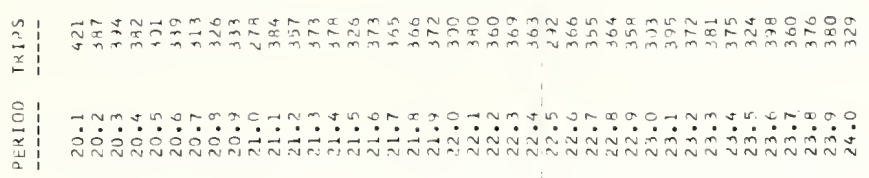

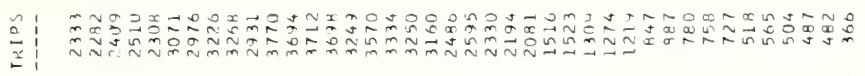

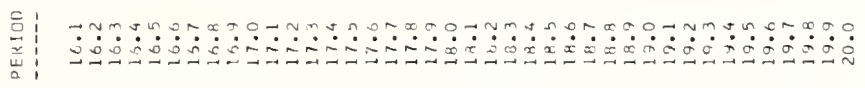

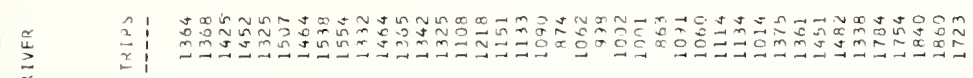

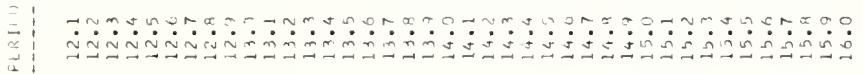

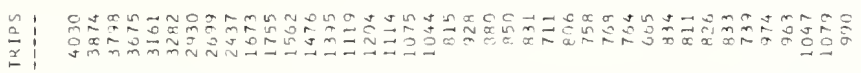

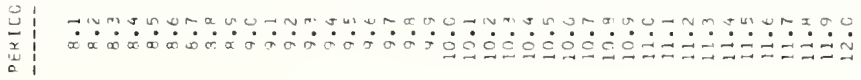

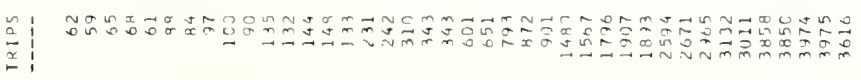

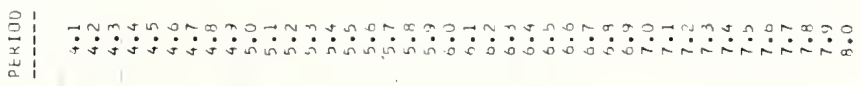

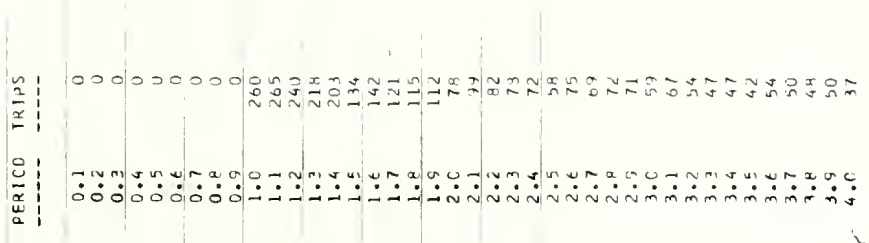

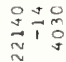

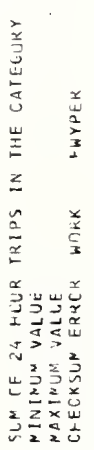




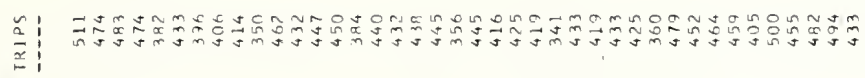

象

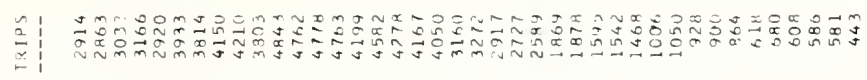

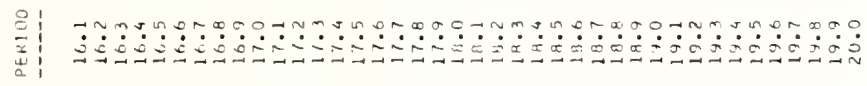

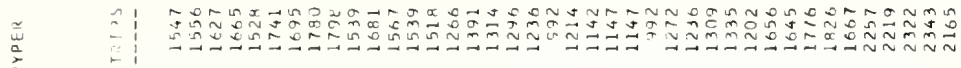

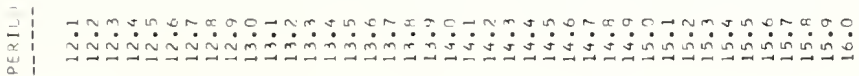

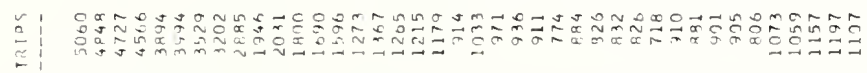

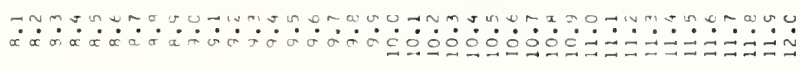

岁:

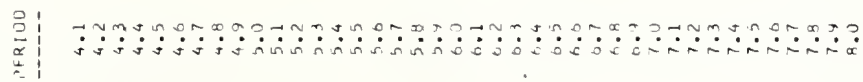

等

焉 
落:

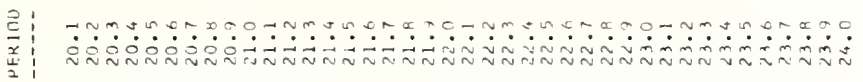

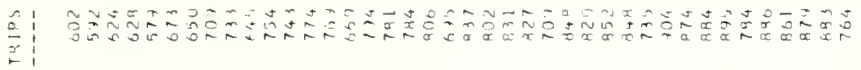

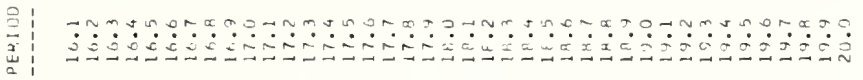

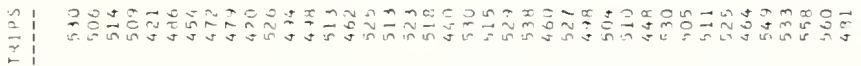

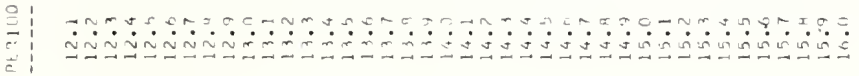

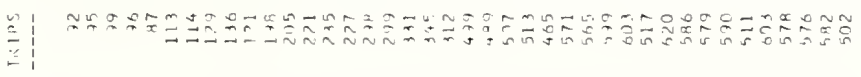

|

$\frac{2}{x}$

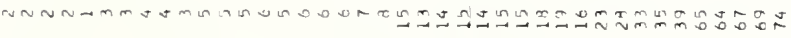

茬 


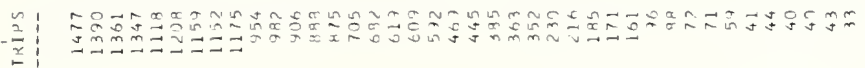

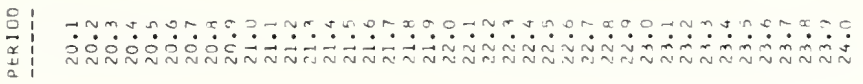

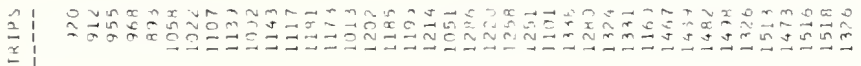

要

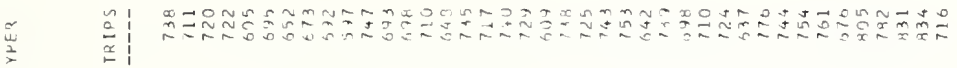

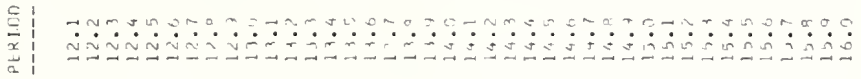

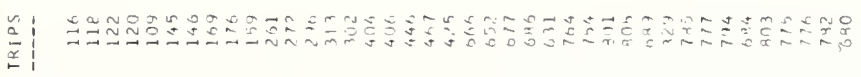

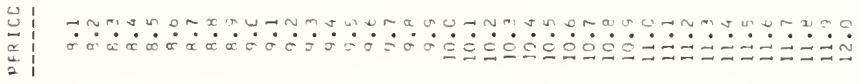

$\stackrel{2}{2}$

n n N

兽|

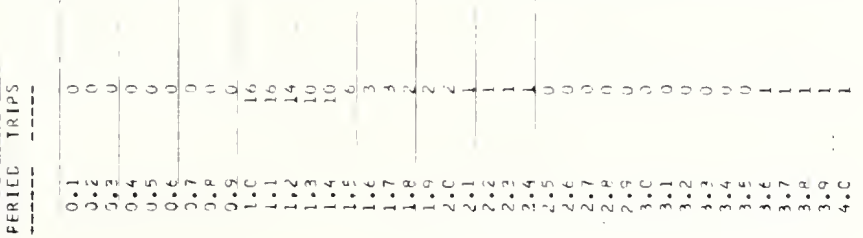




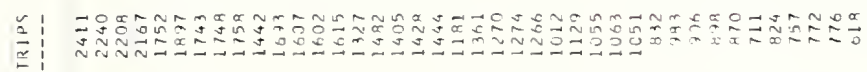

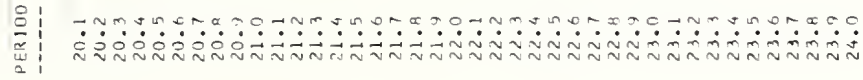

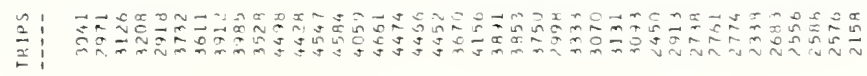

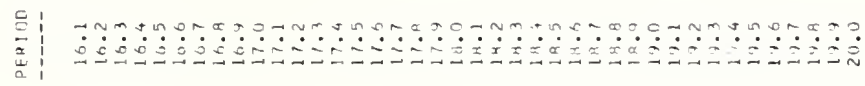

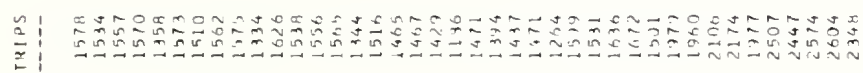

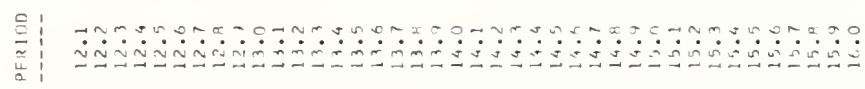

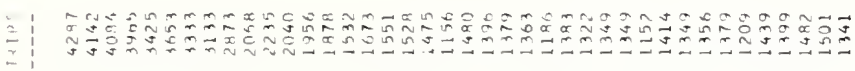

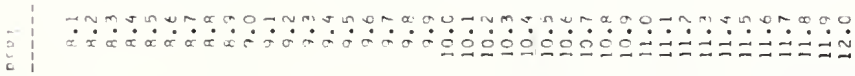

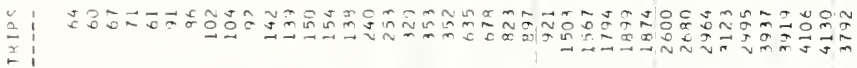

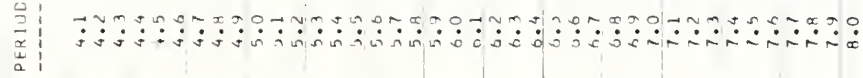

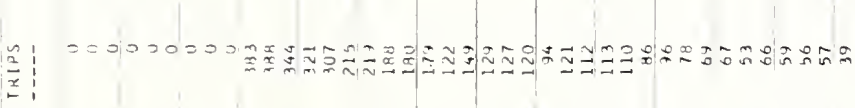

它 


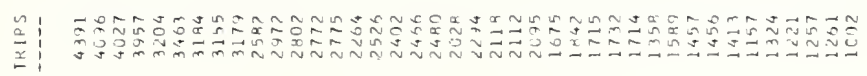

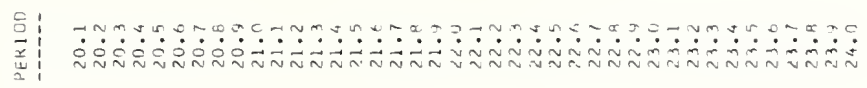

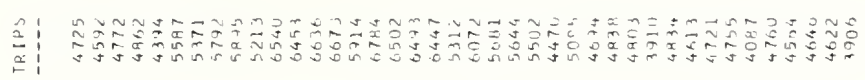

音|

논

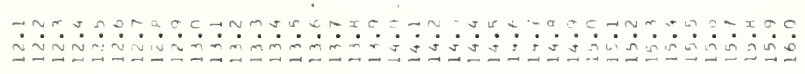

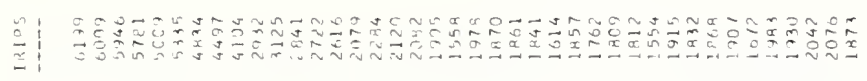

F

1)

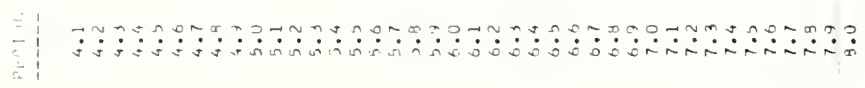

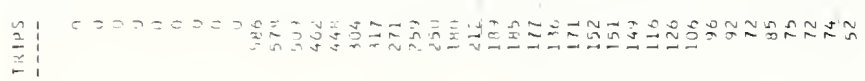

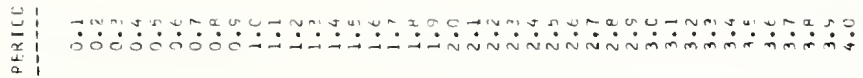


等

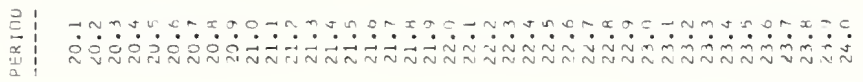

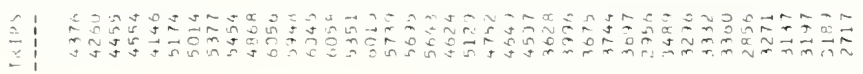

:

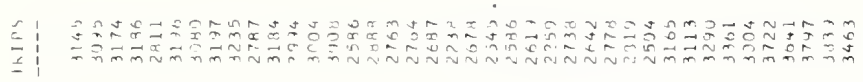

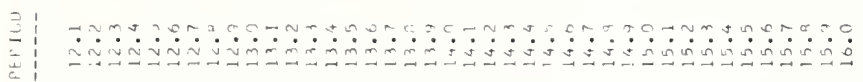

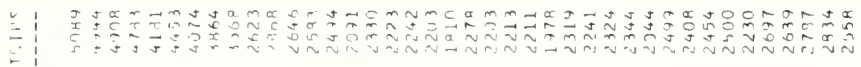

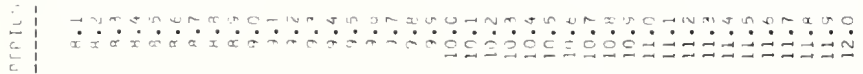

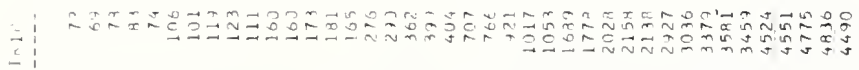

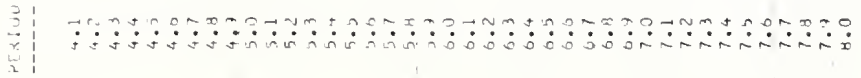

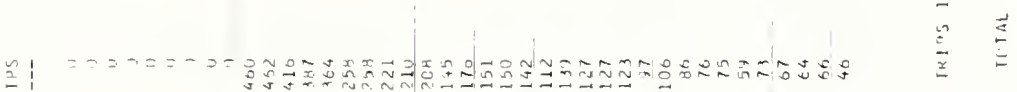

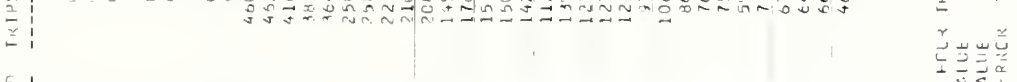

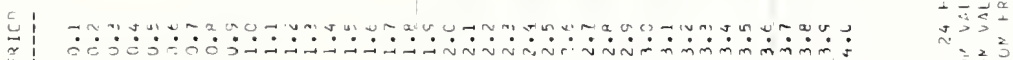

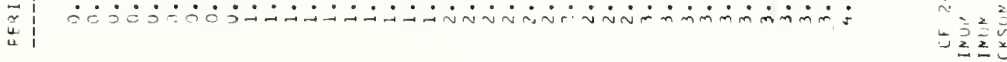




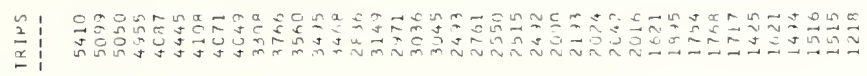

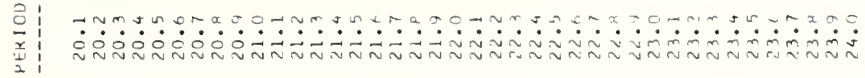

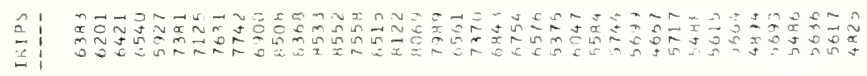

新

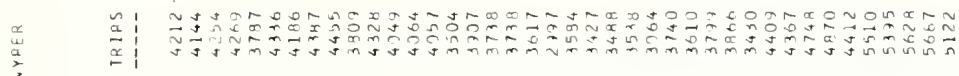

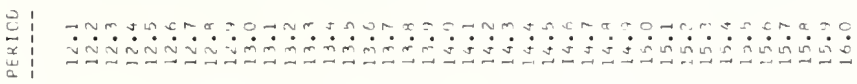

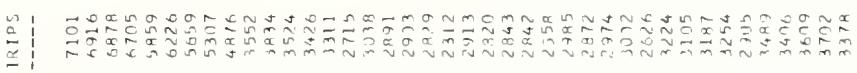

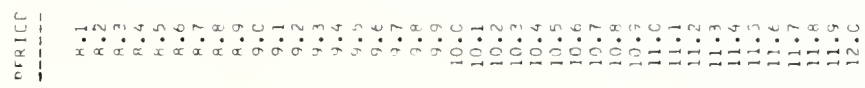

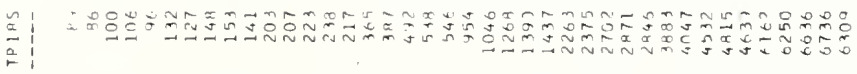

章

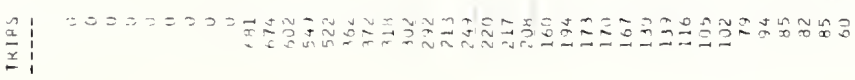

落| 


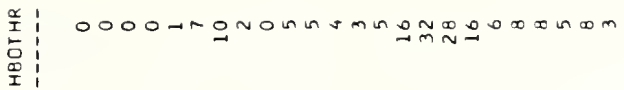

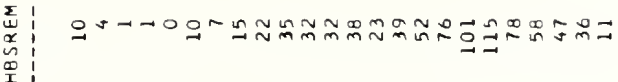

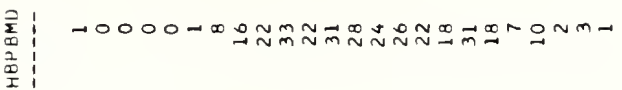

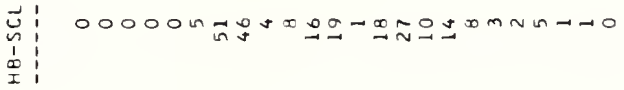

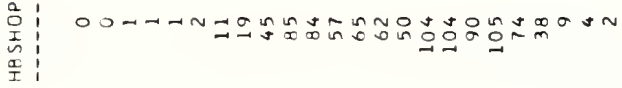

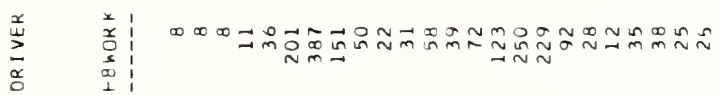

$-$

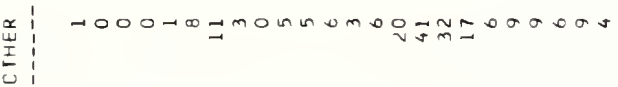

$\frac{a}{2}$

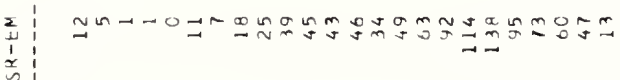

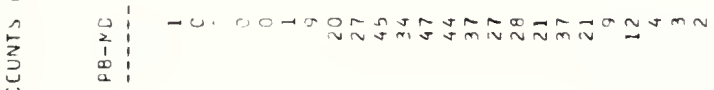

$\frac{a}{x}$

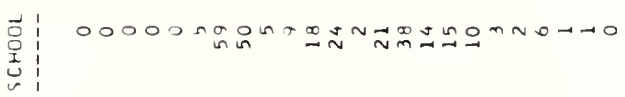

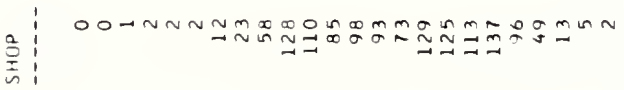

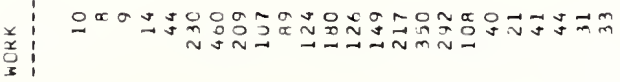

总 


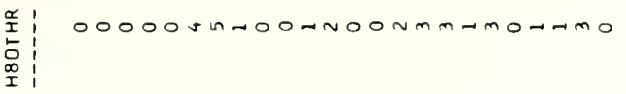

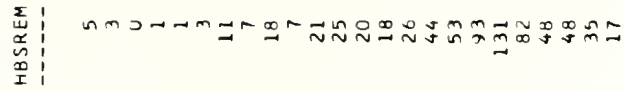

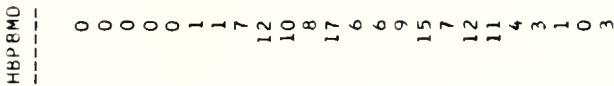

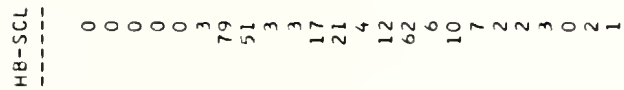

兵 I I

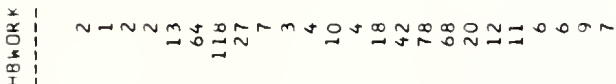

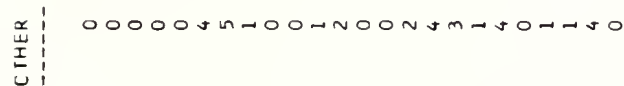

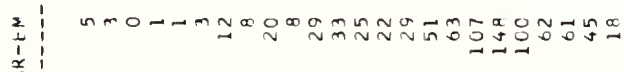

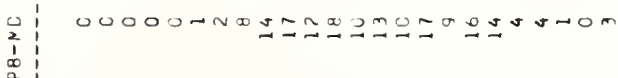

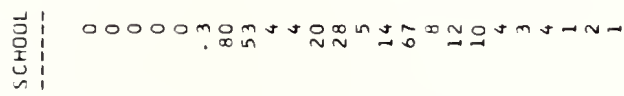

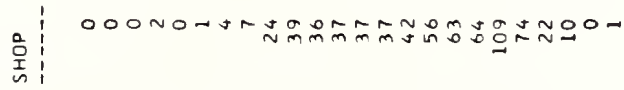

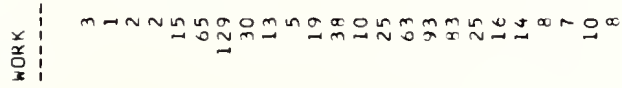
公: 一Nmง 


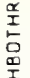

$0000000000000 \rightarrow H N 0 m 000000$

唄

I:

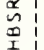

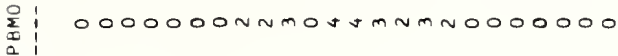

:

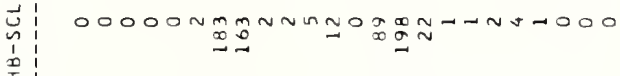

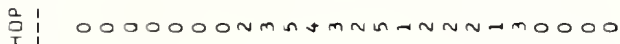

I :

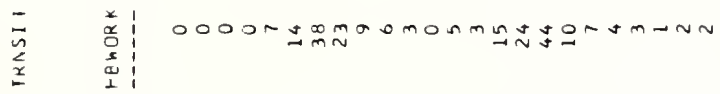

崖

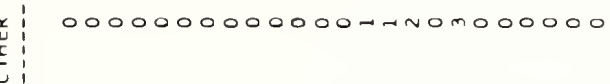

o0000-70-00-0000mn-n-7-0

\begin{tabular}{l|l}
$\Sigma$ & \\
$\dot{w}$ & 1 \\
$\alpha$ & 1
\end{tabular}

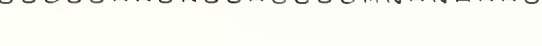

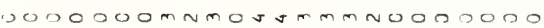

$\begin{array}{ll:} & \\ 2 & 1 \\ 1 & 1 \\ 0 & 1\end{array}$

Jol

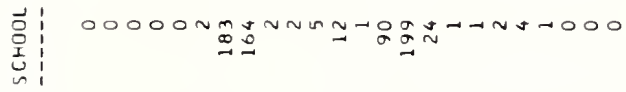

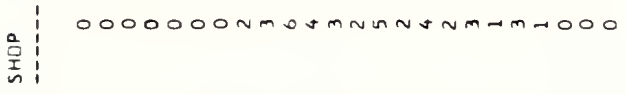

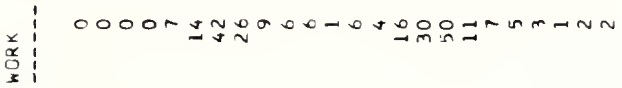

矛: 
至

恙

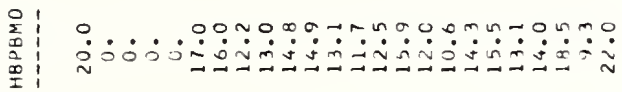

岂

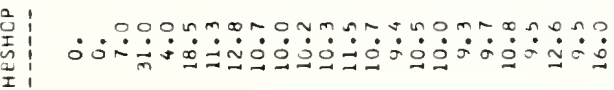

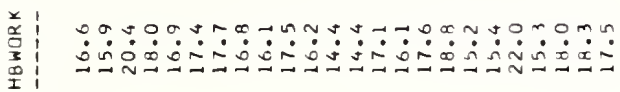

至

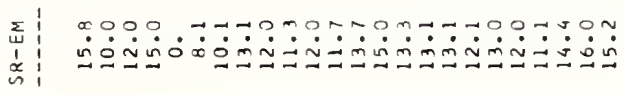

至

葆

茥

等

至 
䍃

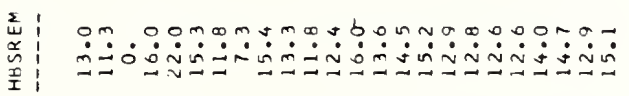

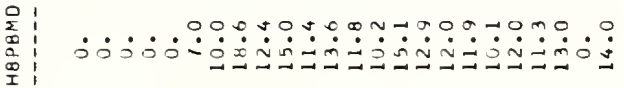

岂

荺

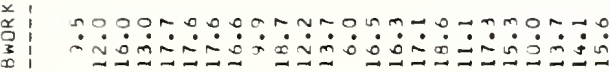

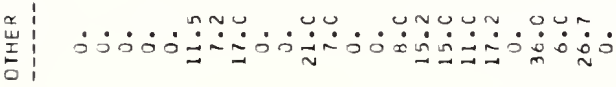

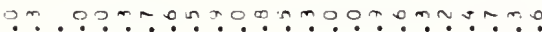

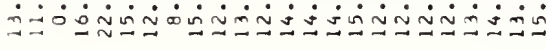

㱚

苨

至

要

姜 
至

忩

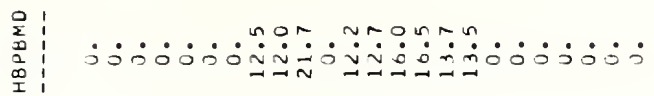

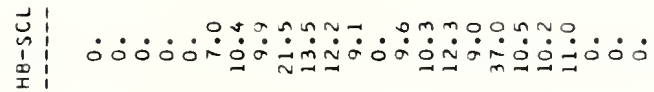

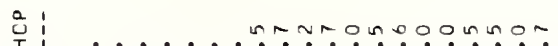

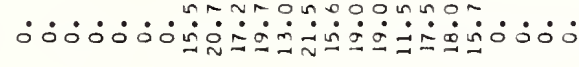

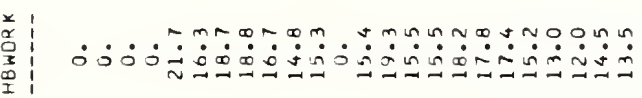

崖

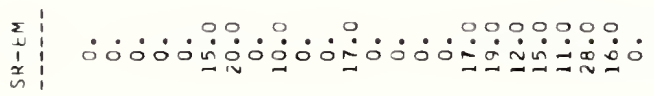

齐

雚

茥

茥

美 
APPENDIX C 


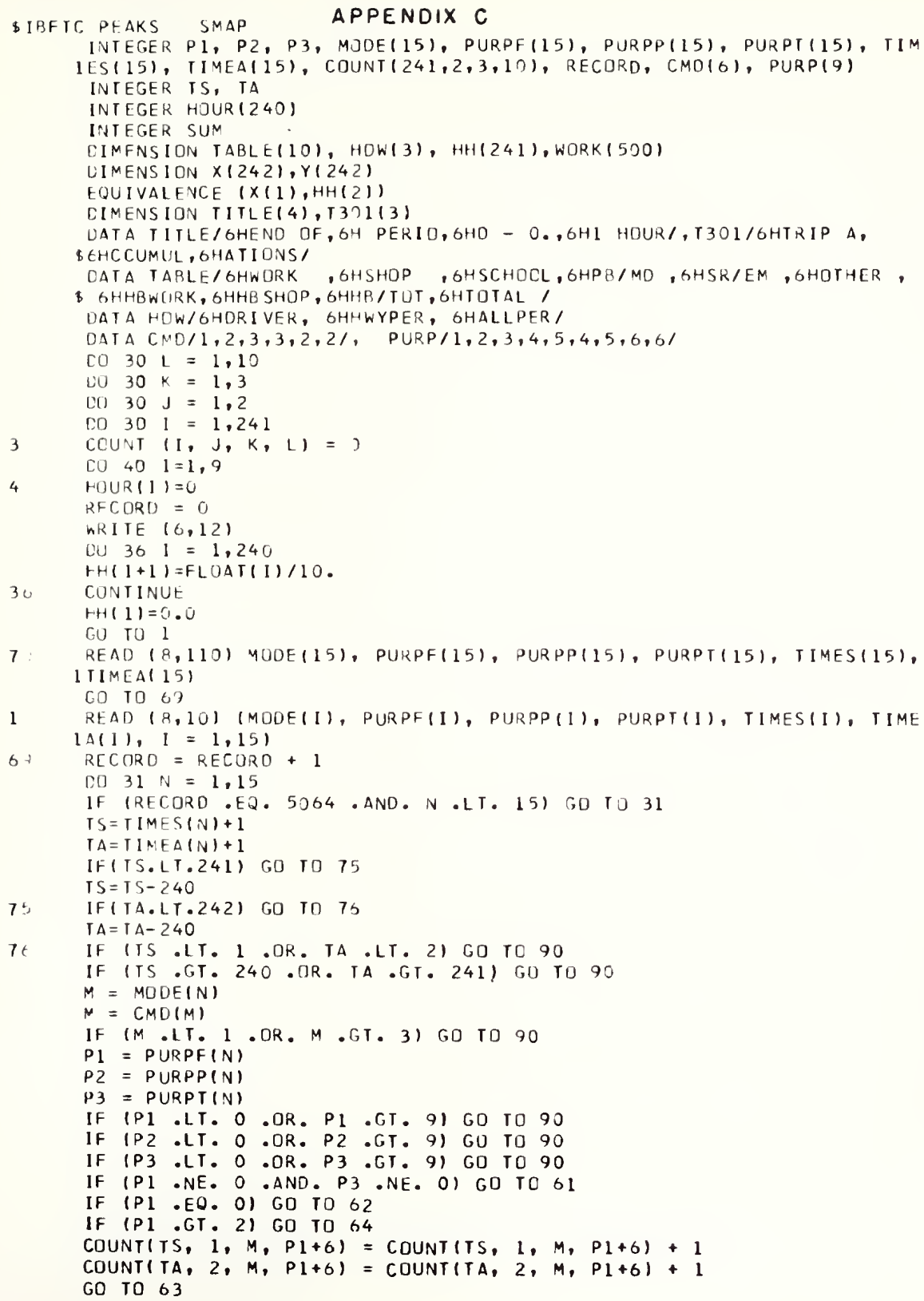




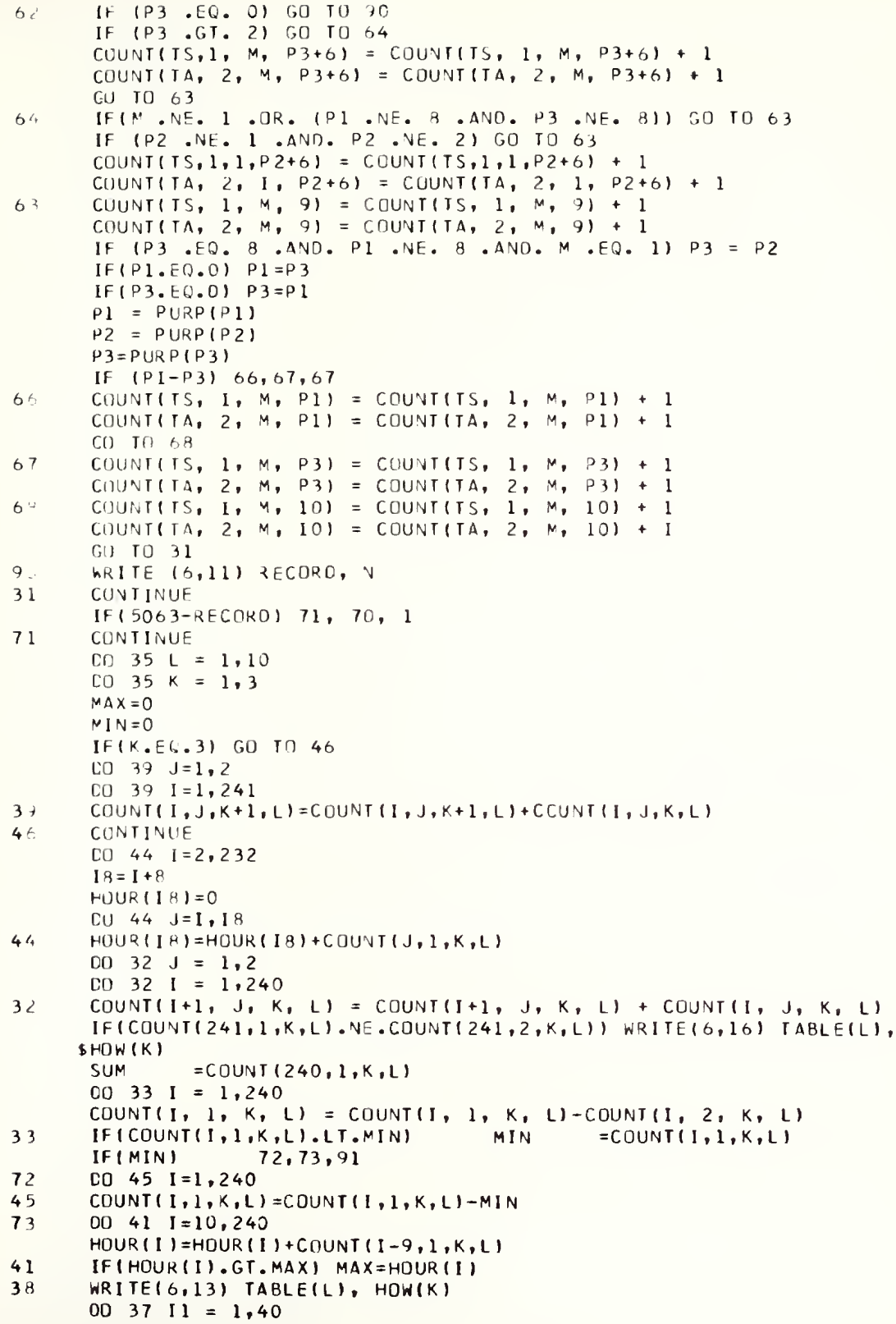




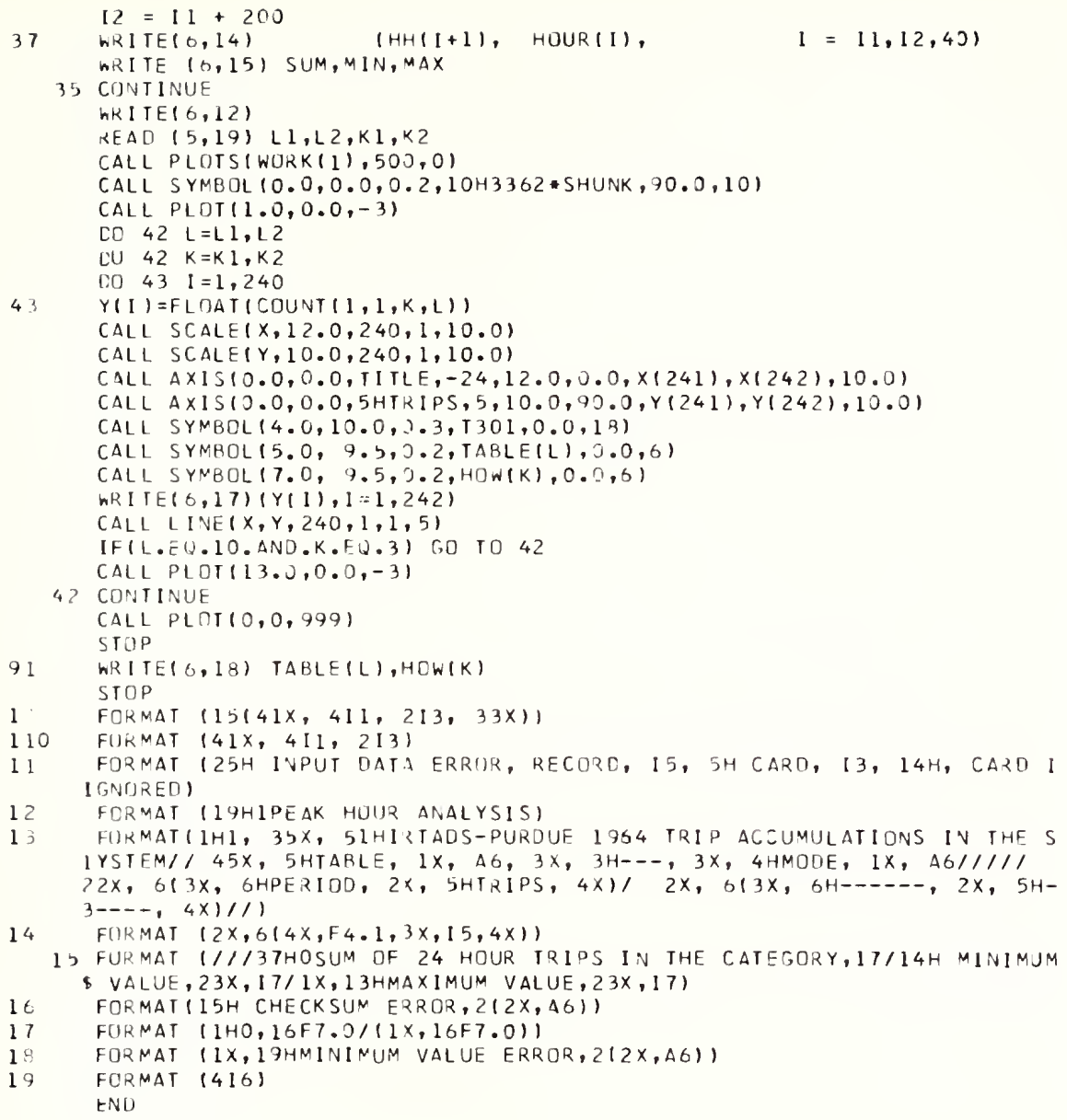




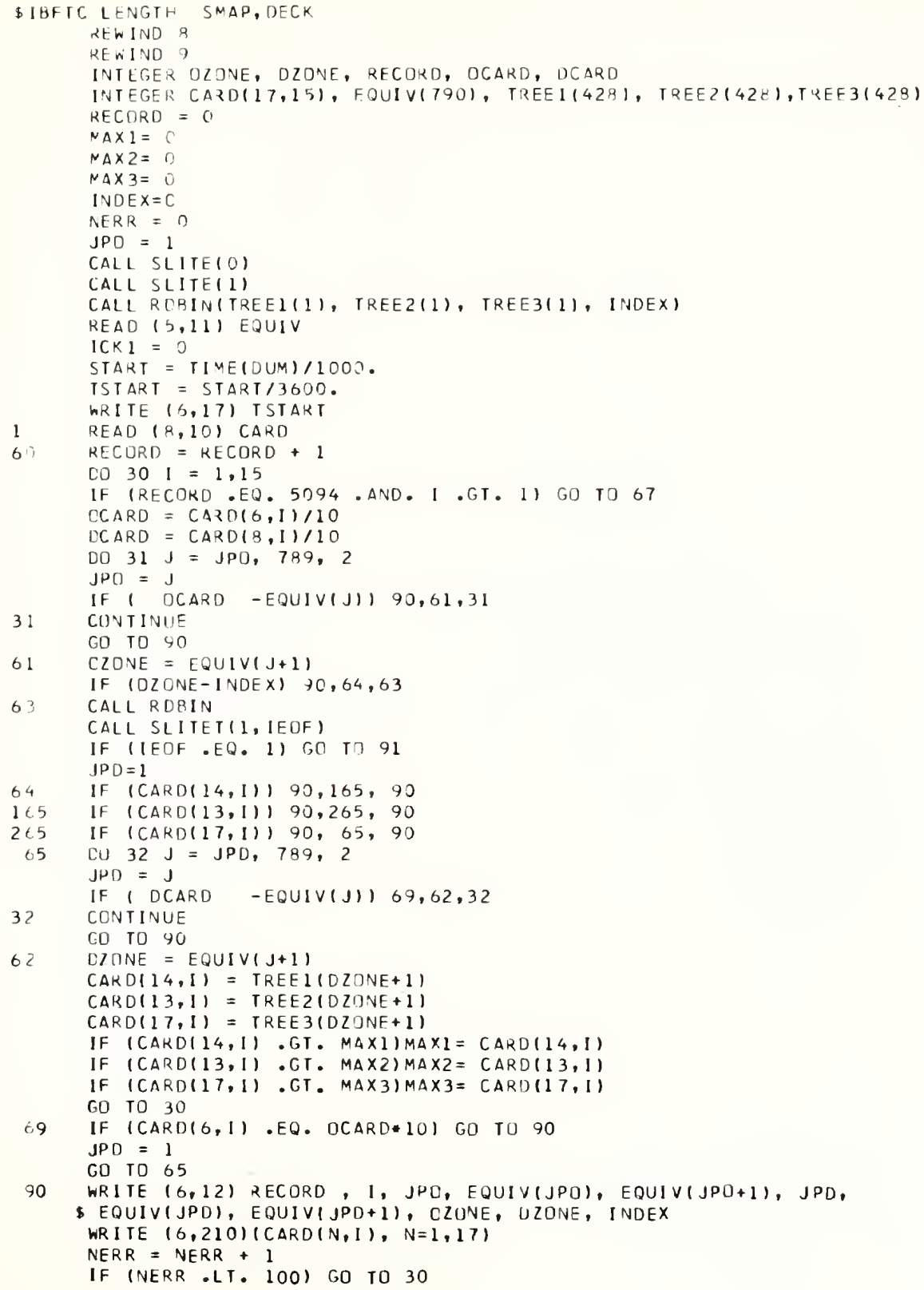




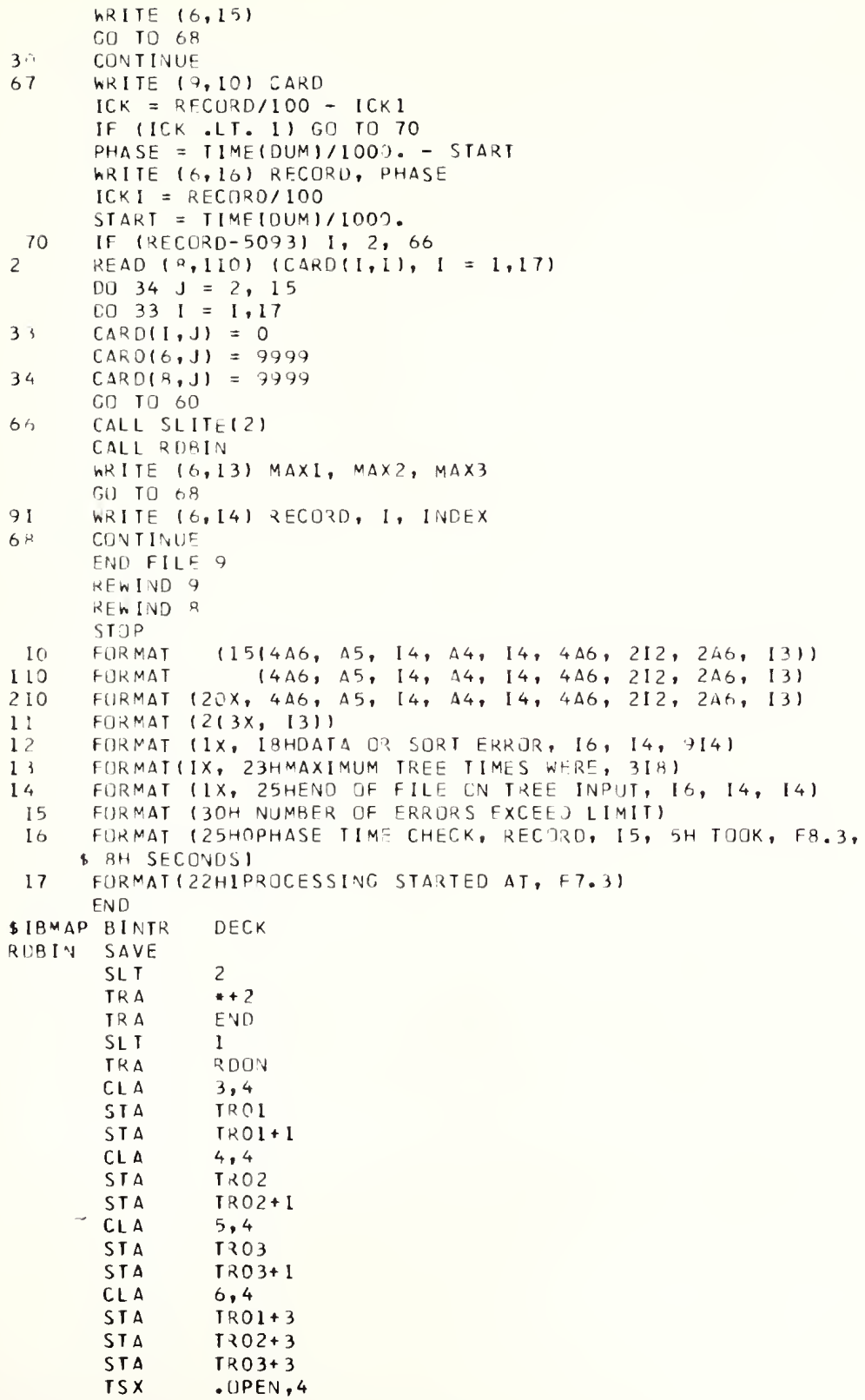




\begin{tabular}{|c|c|c|}
\hline & $P Z E$ & TঝEEO 1 \\
\hline & TS $x$ & . OPEN, 4 \\
\hline & $P Z E$ & TREEO 2 \\
\hline & Is $x$ & - UPEN, 4 \\
\hline & PZE & TREEO 3 \\
\hline & TKA & $B A C K$ \\
\hline \multirow[t]{3}{*}{ R CON } & TSX & - READ, 4 \\
\hline & $P Z E$ & TREEO 1, , ERR \\
\hline & $P Z E$ & EOF, ERR \\
\hline \multirow[t]{7}{*}{$\mathbf{T}<01$} & IURT & $* *, \ldots$ \\
\hline & CLA & $*$ \\
\hline & AKS & 19 \\
\hline & STO & $* *$ \\
\hline & T SX & . READ, 4 \\
\hline & $P Z E$ & JREEO 2, ,ERR \\
\hline & $P Z E$ & $E O F$, ERR \\
\hline \multirow[t]{10}{*}{$T R O 2$} & IORT & $* \ldots, \ldots$ \\
\hline & CLA & $*$ \\
\hline & ARS & 18 \\
\hline & $C A S$ & $* *$ \\
\hline & IRA & ERROR \\
\hline & TRA & $*+2$ \\
\hline & TRA & ERROR \\
\hline & Is $x$ & - READ, 4 \\
\hline & $\rho Z E$ & TREEO3, , ERR \\
\hline & $P Z E$ & EOF, , ERR \\
\hline \multirow[t]{7}{*}{$\mathrm{TRO}_{3}$} & IORT & $* *, \ldots *$ \\
\hline & $\mathrm{CLA}$ & $* *$ \\
\hline & ARS & 18 \\
\hline & CAS & $*$ \\
\hline & TRA & ERROR \\
\hline & TRA & $*+2$ \\
\hline & TRA & ERRDR \\
\hline$B A C X$ & RETURN & RDBIN \\
\hline$E C F$ & SLN & 1 \\
\hline \multirow[t]{7}{*}{ END } & TS $x$ & - CLOSE, 4 \\
\hline & PIE & TREEOI \\
\hline & IS $x$ & - CLOSE, 4 \\
\hline & $P Z E$ & TREEO 2 \\
\hline & IS $x$ & - CLOSE, 4 \\
\hline & $P Z E$ & TREE0 3 \\
\hline & TRA & $B A C K$ \\
\hline \multirow[t]{4}{*}{$E R R D R$} & TS $x$ & -WRITE, 4 \\
\hline & $P Z E$ & . UNO6., ERRR \\
\hline & IORT & MESAG,, 5 \\
\hline & TRA & EOF \\
\hline EQR & TRA & SYSDMP \\
\hline TREEOI & FILE & , UT5, BLK $=428, L O W, B$ IN, HOLD, INPUT, MOUNT \\
\hline THEEO2 & FILE & , UT6, BLK $=428$, LOW, BIN, HOLU, INPUT, MOUUNT \\
\hline TQEEO3 & FILE & , JT 7, BLK $=428$, LOW, RIN, HOLD, INPUT, MOUNT \\
\hline \multirow[t]{2}{*}{ MESAG } & $B C I$ & 5. ERROR IN TREE CORRELATICN \\
\hline & ENO & \\
\hline
\end{tabular}




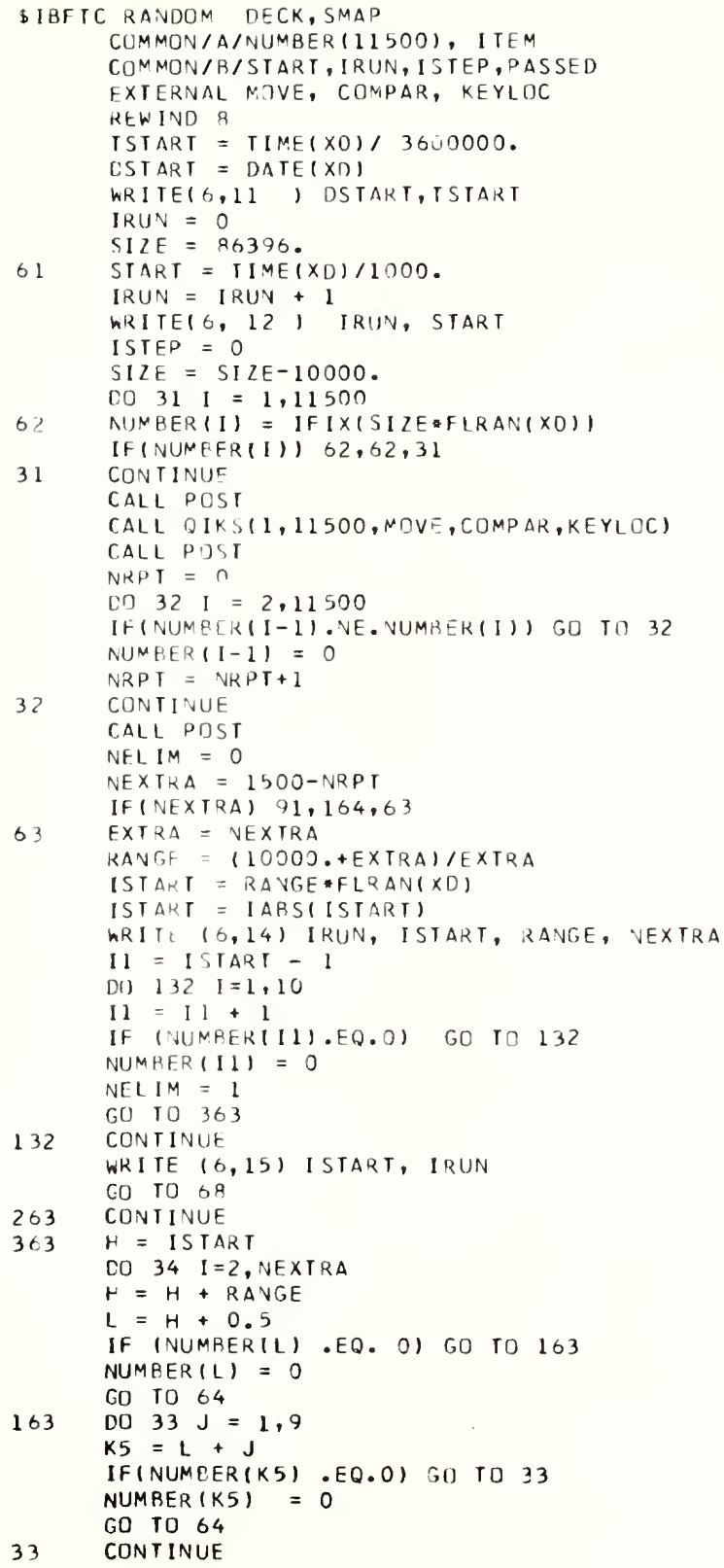




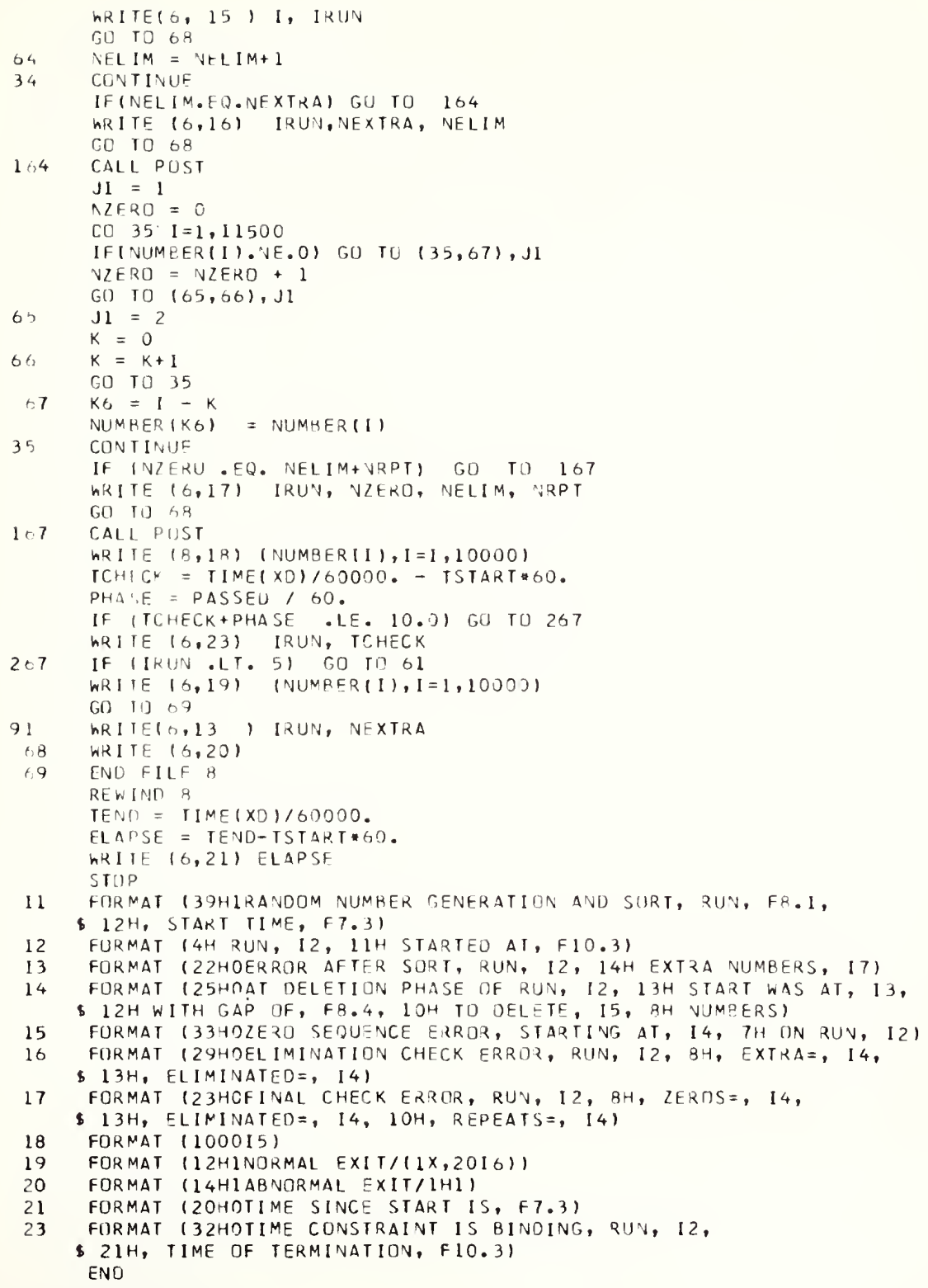




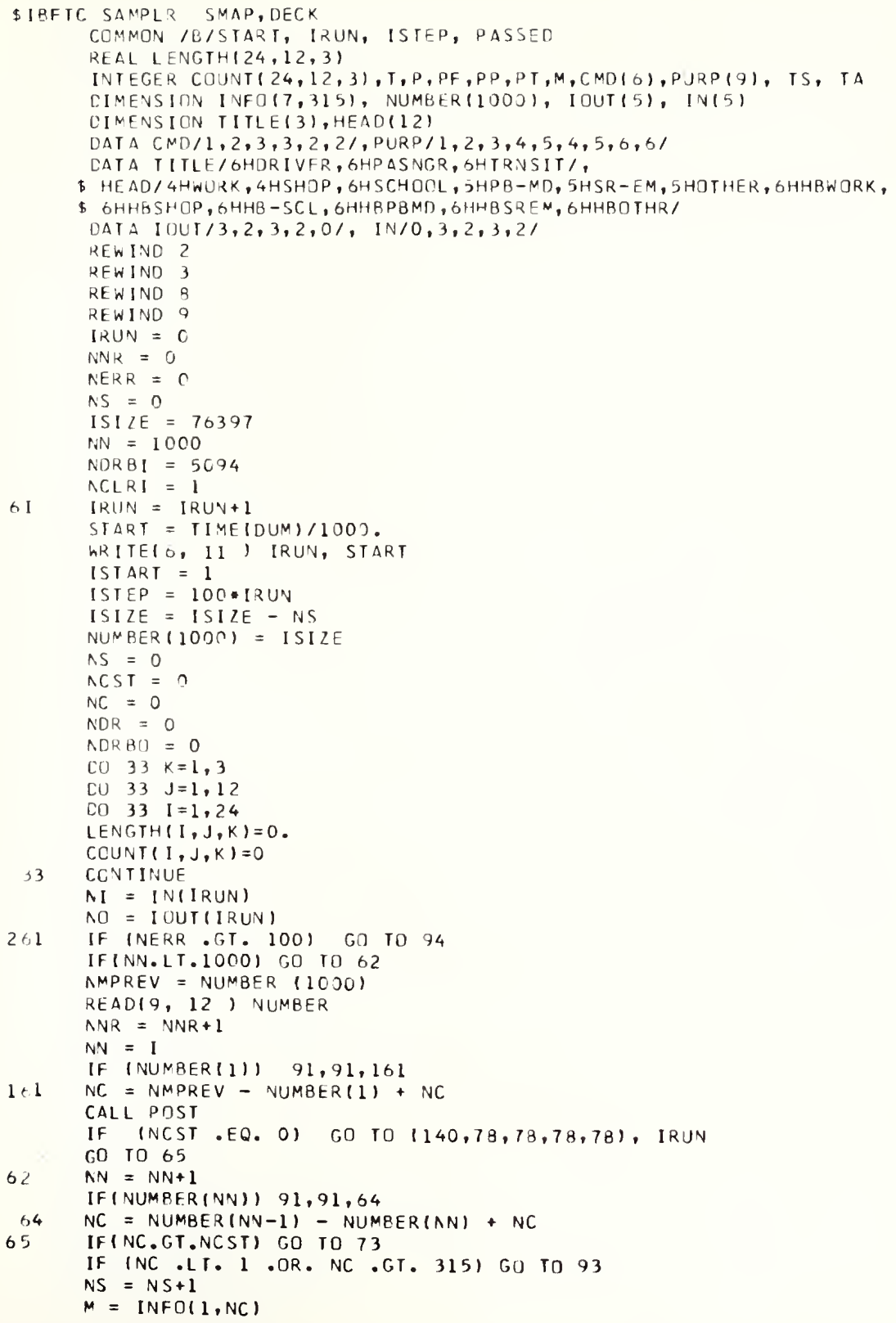




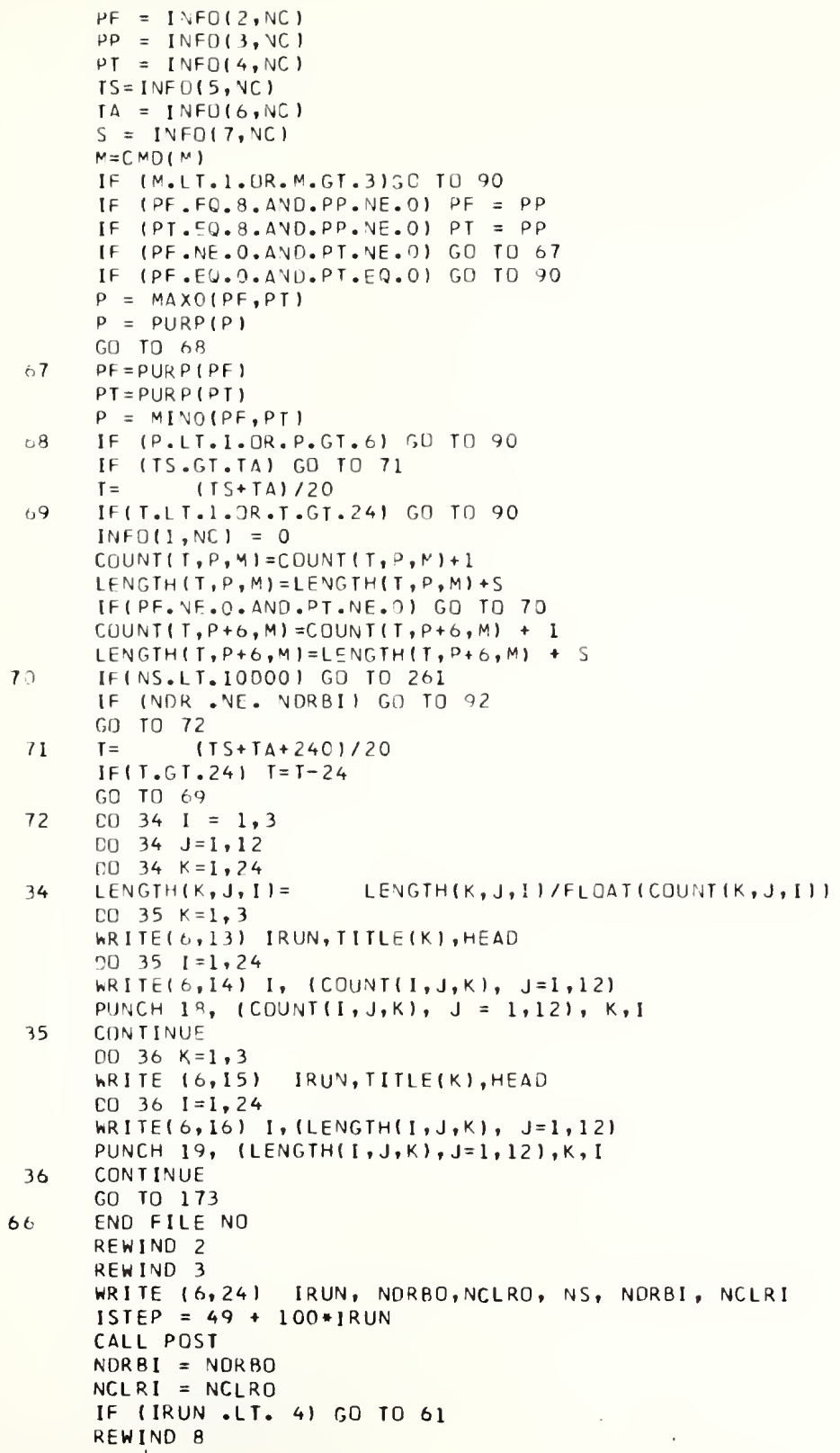




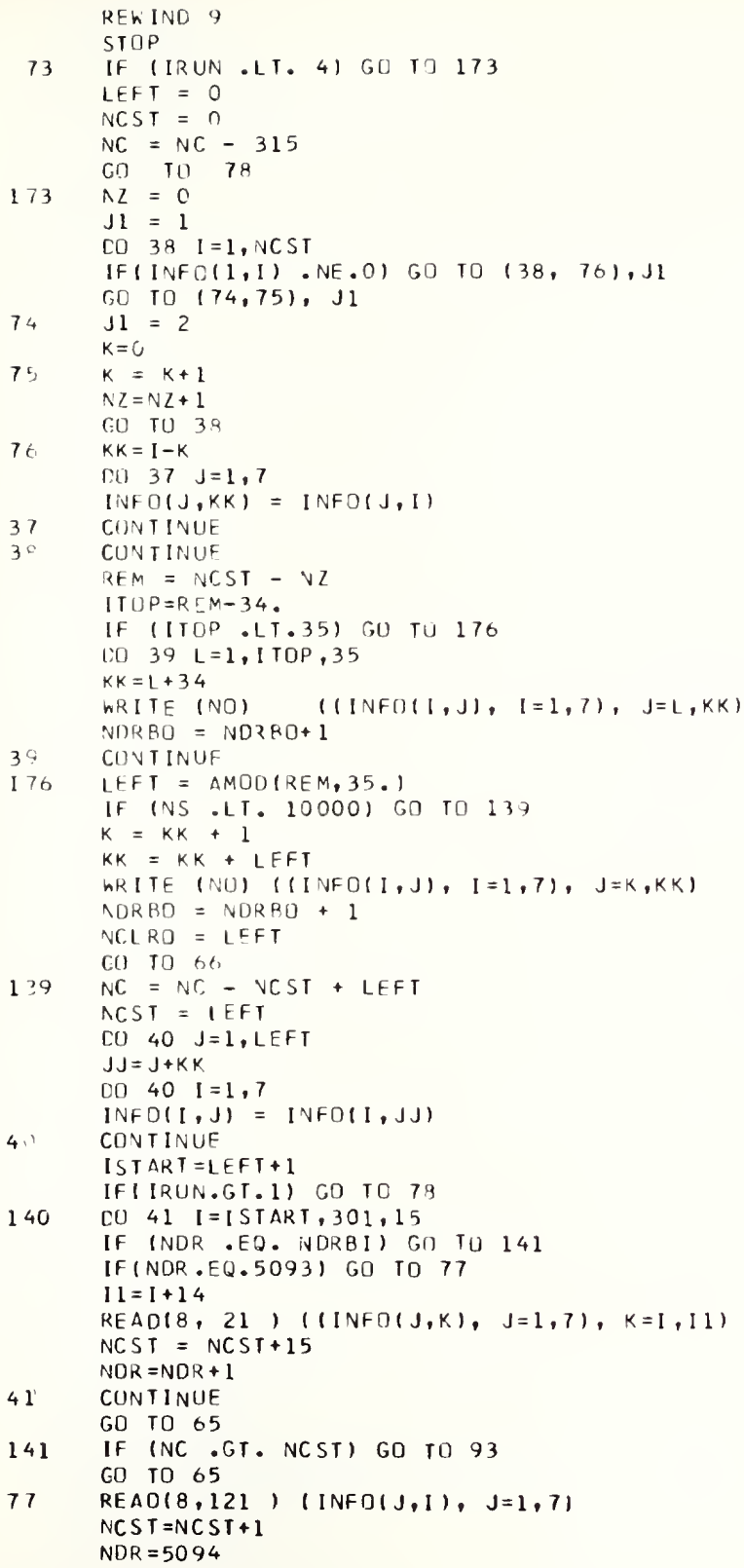




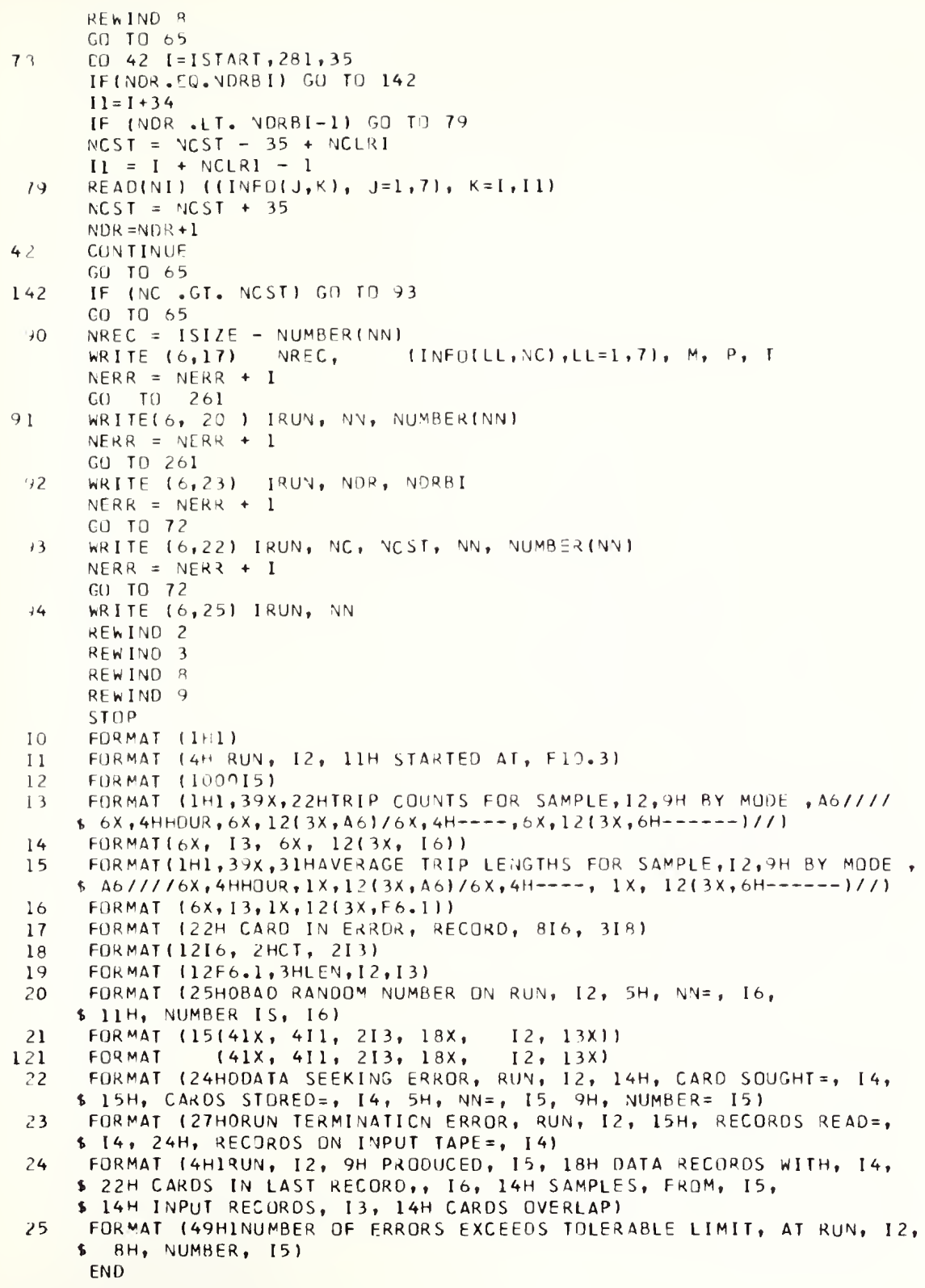


VIए A 
VITA

Gordon Arthur Shunk was born December 23, 1938, in Kankakee, Illinois. He attended elementary schools there and was graduated from Kankakee High School in June, 1956.

He attended DePauw University from September, 1956, until June, 1959, majoring in pre-engineering sciences and mathematics. The A.B. degree was awarded in June, 1961.

He transferred to Purdue University in June, 1959, and was awarded the B.S.C.E. degree in June, 1961, and the M.S.C.E. degree in June, 1962. From June, 1962, until January, 1964, he was employed as a Highway Engineer (Trainee) by the U. S. Bureau of Public Roads. He returned to Purdue in February, 1964, to work on the Ph.D. and has been employed as a Graduate Instructor in Research since that time.

He is a Student Member of the Institute of Traffic Engineers, an Associate Member of the American Society of Civil Engineers, and an Academic supporting member of the Highway Research Board. He is a member of Chi Epsilon and Tau Beta Pi and an Associate Member of the Society of the Sigma Xi.

He is married and has one son. 

